
$16 / 6$

b225 Carmeges 

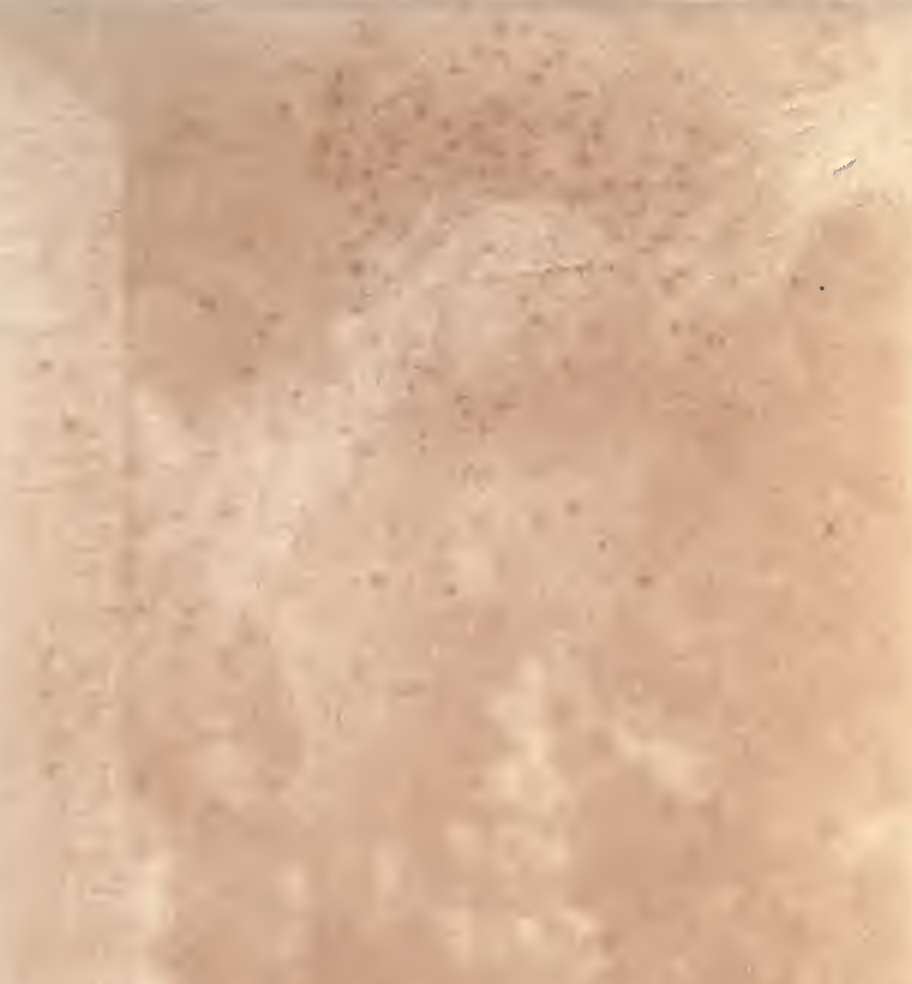
s

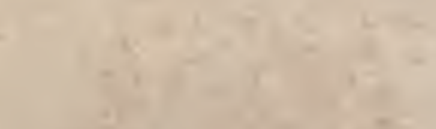

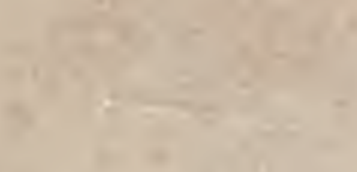

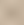

$-$

s

+

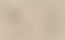

$=$

$+2$

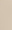


SCIENCE AND LIFE 
BY THE SAME AUTHOR

THE INTERPRETATION OF RADIUM

PROGRESSIVE SCIENCE SERIES 


\section{SCIENCE AND LIFE} ABERDEEN ADDRESSES

BY FREDERICK SODDY, M.A., F.R.S.

DR LEE'S PROFEBgOR OF INORGANIC AND PHYBICAL CHEMIBTRX

ONIVERSITY OY OXFORD; LATELX PROFRBSOR OF CHIMIBTRY UNIVERATT OF $\triangle B R R D E E N$

JOHN MURRAY, ALBEMARLE STREET, W. 
All rights reserved. 


\section{TO MY STUDENTS OF THE UNIVERSITY OF ABERDEEN}

THIS BOOK IS DEDICATED

IN GRATITUDE FOR THEIR LOYAL AND SYMPATHETIC APPRECIATION 


\section{P R E F A C E}

I IIAVE collected together this series of addresses and articles, written, for the most part, during my five years at the University of Aberdeen, in the hope that, in volume form, they may prove acceptable to the students of the university and those for whom, in the first place, they were written. But I am not without hope that, in these days of stress and change, they may be useful to a wider circle, anxious to explore to the foundations the causes of modern unrest, and to rectify for the future the causes which have led to failure in the past. I have, from the standpoint of an original investigator in physical science, attempted to show how fundamentally and beyond the possibility of escape our knowledge and control of the inanimate world underlies and determines the development of all the potentialities of life. Admittedly, the attempt is a very imperfect one, but scientific investigators too seldom endeavour at all to make known the bearing of their special fields of inquiry upon the general problems of life and belief.

Written at a time when millions of young men were being killed in consequence of the destinies of scientific nations being in the hands of people of archaic mental outlook, no mock deference has been paid to conventional habits of thought. The times seem to call for outspokenness, if one has anything to say, rather than persuasive propagandism and 
time-serving compromise. It may be recalled that scientific men have, for nearly a century, pointed out the dangers to the nation of the traditional school and university training, disastrous especially in that it embraces even those who are to be its rulers and statesmen.

Naturally, radioactivity and its conclusions as to the immanence and illimitableness of natural energy, still confused in orthodox religions with the Deity, enter largely into the subject-matter, and I have included two articles, giving some more connected account of these advances. The first, "The Evolution of Matter," is intended for the general reader, and the second, "The Conception of the Chemical Element as enlarged by the Study of Radioactive Change," for students of chemistry, who may desire to acquaint themselves further with these developments.

In a collection of separate and self-contained articles such as this, some repetition is unavoidable, but I have attempted to minimise it. I trust, in so far as I have not been successful, that it may be pardoned in view of the hitherto almost complete neglect by the intellectual world of the theme, for philosophies "of lighter and less solid wood."

I have included, as an appendix, some articles and reports bearing on certain definite charges which I have made, and which have remained unanswered, of the financial treatment of science by the Carnegie Trustees for the Universities of Scotland, and the University of Aberdeen. These are specific instances of what it would be possible to multiply no doubt indefinitely, and I include them, in the first place, to justify the complaint that something more than mere neglect of science by the British nation is involved, and that, in the educational institutions and government of this country, science has not received, nor is 
it likely in the future to receive, the ordinary honourable fair-play supposed to be characteristic of British standards. The dead past might well be left to bury its dead, if there were any sign of a different spirit prevailing in the future. But, with the present spirit still dominant, how can it be expected that modern men will bequeath their wealth to the universities here, as they habitually do in America? Nor is it much use Parliament voting large grants for the purpose of fostering scientific research, or Ministers taking from the taxes increased sums to promote scientific education, until the administration of them is taken out of the hands of those who have proved their unfitness for such a trust in the past.

My acknowledgments are due to the Chemical Society, the British Science Guild, and the editors and publishers of Science Progress, the Aberdeen University Review, and other publications for permission to reprint articles appearing in their pages.

FREDERICK SODdy.

ABERDEEN, September I9I9. 


\section{CONTENTS}

Science And Life

From an Article originally contributed to The Candid Quarterly Review, and republished in abbreviated and revised form in The Student Movement, Dec. I918-Feb. IgIg.

Physical Force-Man's Servant or his Master?

Address to the Aberdeen Branch of the Independent Labour Party, Nov. I915.

Chemistry and National Prosperity .

Remarks to the Aberdeen Chamber of Commerce, Annual Meeting, Feb. Igr6.

Science and the State - $\quad$ - 1 .

Address to the Aberdeen Branch of the Independent Labour Party, Oct. 19r6.

The Future of Science, and what Bars the IVAy .

Presidential Address to the Aberdeen University Scientific Association, Nov. Igr6.

The Evolution of Matter

Contributed to the Aberdeen University Review, Feb. I917.

The Conception of the Chemical Element as Enlarged by the Study of Radioactive Change Address to the Chemical Society, London, Dec. 1918 ; published in the Journal of the Chemical Society, Transactions, Jan. Igrg. 
Matter, Energy, Consciousness, and Spirit . . 149

Address to the Aberdeen University Christian Union, April IgIg.

To the New Launch! . . . . . 175

Contributed to the first number of The Crucible, May Igrg.

The Ideals of a Science School . . . I8

Farewell Address to the Aberdeen University Scientific Association, June rgrg.

\section{APPENDIX}

A. A Criticism of the Financial Operations of the Carnegie Trust for the Universities of SCOTLAND

Contributed to Science Progress, Jan. I9I7.

B. Report of a Committee of the British Science

Guild upon the Carnegie Trust and

ScIENTIFIC RESEARCH . . . . 218

Journal of the British Science Guild, Dec. I917.

C. Carnegie Trust for the Universities of Scotland Twelfth Annual Report of the Executive Committee of the British Science Guild, July Igr8. 


\section{SCIENCE AND LIFE ${ }^{1}$}

"Science is the great instrument of social change, all the greater because its object is not change but knowledge, and its silent appropriation of this dominant function, amid the din of political and religious strife, is the most vital of all the revolutions which have marked the development of modern civilisation."-A. J. BALFOUR, Decadence, 1908.

THE curiously limited outlook of the devotees of scientific inquiries, the strange contrast between the recluseness of the individual and the cumulative consequences to society of their work, has been the note struck by many modern commentators. The spirit of the mythical don, who thanked the Almighty at the close of a life-long tussle with a mathematical problem that its solution could never be of the least possible use to anyone, is still revered as the pure distilled essence of scientific endeavour. That this cloisteral attitude is essential to the highest and most practical discovery is patent from a casual examination of the history of science. But whether it is sane to leave entirely to the unscientific wisdom of the age the proper direction and utilisation for the many of the treasure so acquired, is a question to which the answer is equally patent from a casual examination of the history of the application of science. The immense acquisition to the wealth and resources of mankind which has been the result

1 This is a revised and abbreviated version of an article which appeared in The Candid Quarterly some years ago, and subsequently in The Student Movement, December 1918 to February 1919. 
of the past century of science, should have been the golden opportunity of statesmen and humanitarians and the raw material out of which the sum total of human happiness could have been augmented. Instead, it has but revealed a growing incapacity and failure on the part of the altruist to appreciate the nature and power of the new weapon that science has placed in his hands, and an ever-increasing rapacity and far-sightedness on the part of the egotist to secure it for his own ends.

For many a decade now, owing primarily and indisputably to the intellectual achievements of a comparative handful of men of communistic and cloisteral habit of thought, a steady shower of material benefits has been raining down upon humanity, and for these benefits men have fought in the traditional manner of the struggle when the fickle sunlight was the sole hazardous income of the world. The strong have fed and grown fat upon a larger and ever larger share of the manna. Initial slight differences of strength and sagacity have become so emphasised by the virile stream that the more successful are becoming monstrously so, and the unsuccessful less and less able to secure a full meal than before the shower began.

Already it savours of indelicacy and tactlessness to recall that the exploiters of all this wealth are not its creators; that the spirit of acquisitiveness which has ensured success to them, rather than to their immediate neighbours, is the antithesis of the spirit by which the wealth was won.

Amid all the sneers at the impracticability and visionary character of communist schemes, let it not be forgotten that science is a communism, neither theoretical nor on paper, but actual and in practice. The results of those who labour in the fields of knowledge for its own sake are published freely and 
pooled in the general stock for the benefit of all. Common ownership of all its acquisitions is the breath of its life. Secrecy or individualism of any kind would destroy its fertility.

\section{The Material Basis of Life.}

To the altruist, to whom wealth and human happiness are far from being synonyms, science is viewed with distrust. A phrase "like the growing materialism of the age" is a curious betrayal of a habit of thought which would be ludicrous if it were not fraught with disaster. The physical conditions of existence are more fundamental than the æsthetic, moral or intellectual. A child must be fed before it can be taught. A certain standard of living above that of animals is a preliminary condition for the development of any of the special qualities of human beings. Philosophies, codes, political systems and religions must follow the lead of science and range themselves in alliance with, rather than in defiance of, these inanimate fundamentals, or, like a machine designed in ignorance of the principles of mechanics, they constitute themselves a danger to the community. Of these elementary physical conditions, which absolutely control existence, and which take precedence over every other, mankind remained in total ignorance until they suddenly changed. Most fish probably remain utterly oblivious of the existence of water until rudely hauled into the upper air. In the essentially unchanging physical environment, in which all but the latest epoch of recorded history has been enacted, lies the probable explanation of the seeming paralysis which has overtaken the sources of constructive thought and action since science in the last century revolutionised the major physical condition of life. 
The results of a sudden acquisition of wealth without effort, or with a relative minimum of effort, are proverbial, and science, that has secured wealth beyond precedent and promises wealth beyond belief, has till now been too closely pursued by the proverbial results. But is the whole accumulated wisdom of the ages really sterile and impotent before this problem, of how to use wealth, of how to secure that a greater part of the sum-total of increased material resources shall be made to contribute to the sum-total of human happiness? For at present, it has not only shown itself powerless to bring about this result, but it is, an uncharitable observer might conclude, in league with the other side, and is active, so far as it is active at all, in ensuring that the improvement in material conditions shall increase the sum-total of human misery.

\section{The Application of Scientific Discovery.}

The statesman from whom the writer has ventured to borrow the quotation at the head of this article, showed a rare insight into the character of the world movement which has followed the application of scientific discovery, and was able to penetrate beneath the superficial consequences "appropriately associated with materialism and greed." Something "seriously to be ranked with religion and patriotism as an important force for raising men's lives above what is small, personal and self-centred," "a source not merely of material convenience but of spiritual elevation" was hinted at from a remote standpoint, over and beyond the nearer prospect of "smoky cities, polluted rivers and desecrated landscapes." But those who can take a nearer, narrower and less clouded view, feel as though they had "stared at the Pacific." For, from the point of vantage attained 
from the foremost outskirts of physical science, there lies in full view a realm till now untrodden by mortals even in their dreams - the promise of power to fulfil ambitions as yet latent, wealth and energy adequate to eliminate for ever the struggle for existence on its physical side, strength, at least in great measure, to make of life whatsoever we will. Even the probable route forward can be dimly made out, the way the pioneers will most likely pursue to enter the promised land. And then?

Judging from past experience, from the uses to which the enlarged opportunities and dominance already conferred by physical science have been put, is it so certain that man is ripe for such a myriadfold multiplication of his physical powers? Apart altogether from war, what would the unscientific wisdom of the age make of the golden opportunity more publicly beneficial than more millionaires and more slums? There arises the challenge: Is there a single practical branch of human thought or knowledge which has been left untouched, nay, more, which has not been altered to its very foundations, by the progress of science? The education of those to whom for the most part is entrusted the happiness and destiny of nations ceases where it should begin.

For a modern ruler the laws of the conservation and transformation of energy, whence the vivifying stream takes its source, the ways it wends its course in nature, and how, under wisdom and knowledge, it may be intertwined with human destiny, instead of careering headlong to the ocean, are a study at least as pregnant with consequences to life as any lesson taught by the long unscientific history of man. The essential public questions of the day find in such modern advances a suggestive and connected interpretation. 
Youth ought to breathe in science with its mother tongue, in addition to the ancient wisdom of those who lived directly on sunlight. A prolonged course of pettifogging crofting fits no man to administer vast possessions. With the exception of a few, to whom it is a hobby, public men in this country are as ignorant of the meaning of science to life as the man in the street is of the Greek alphabet.

It is not difficult to comprehend the precise condition which science has introduced into human affairs, and to which every feature peculiar to the present age can be more or less directly traced. It is the effective control and utilisation of inanimate sources of energy. The power of a man to do work -one man-power-is, in its purely physical sense, now an insignificant accomplishment, and could only again justify his existence if other sources of power failed. To increase and multiply one man-power is the object of all social systems from time immemorial.

The modern Ship of State moves with an unseen power. Old salts still trim the useless sails in true maritime fashion, and there is a talk on deck of hurricanes and doldrums, maelstroms and monsoons. But those below the deck, who provide the power, know where the ship would sail to, if sail it ever had to again. Curious persons in cloisteral seclusion are experimenting with new sources of energy, which, if ever harnessed, would make coal and oil as useless as oars and sails. If they fail in their quest, or are too late, so that coal and oil, everywhere sought for, are no longer found, and the only hope of men lay in their time-honoured traps to catch the sunlight, who doubts that galley-slaves and helots would reappear in the world once more? The history of man is dominated by, and reflects, the amount of available energy. The energy available for each individual man is his income, and the philosophy which can 
teach him to be content with penury should be capable of teaching him also the uses of wealth.

A single modern machine does the work of tens of thousands of labourers, releasing them from the benumbing and soul-destroying effect of unremittent physical labour. The very same movement which lightened the task of men, favoured women even more. The minimisation of individual brute strength in the affairs of life could hardly do otherwise.

\section{Its Effect on Education.}

Each year science increases by so many millions of horse-power its patient armies of inanimate slaves. The adoption of slave labour by Imperial Rome, we are taught, laid that mighty civilisation in the dust. Already the new slave of science has laid in ruins all the ineradicable doctrines derived from the history and experience of a time when the physical environment was unchanging. Those who pleaded just for one or two at least of the ancient seats of learning to be left untouched and unreformed amid the startling and dangerous innovations of science, as a sanctuary for what was noble and enduring in the thought of the past, may have perpetuated an anachronism, safe enough in a monastery, but infinitely more dangerous than innovation where it concerns the education of future generations of public men. If men so trained had been debarred from holding public positions in the State, or even if they had been regarded, so far as their training was serious, as specialists, instead of becoming the fashion and being preferred as the traditional type which all systems of general education should strive to produce, no possible objection could be taken. But it is absurd that the administration of a modern State should be left to men ignorant of science and of its 
human consequences. More serious consequences have attended the overweighting of education by dead and moribund habits of thought than would have attended an overweighting of education with science. So great is the discontinuity between the present and any previous period.

One may believe that the human aspect of learning, if it is the highest, is also the last aspect to be achieved, and if no adequate appreciation of the older humanities can be arrived at without long preparation in the grammar and etymology of ancient languages, so no adequate appreciation of the newer scientific humanities can be derived without a long discipline in the grammar and principles of science. In spite of all make-believe to the contrary, this is the age of science.

One may walk through any city, as the early Greek sculptor did in his day, absorbing unconsciously from its medley of sights and sounds the fleeting impressions which, in a trained mind, fuse together and congeal, epitomising for all time the animation of a moment. Science is not sculpturing from models. Si monumentum requiris, circumspice. But the workmen are building in steel and the designers are thinking in stone.

\section{The NeEd for Adaptation.}

Human nature, in general, is the result of an age-long adaptation to what has been hitherto, for any one country, an essentially unchanging physical environment. Emigration to other countries, as in the population of the Americas, produces corresponding marked changes of human nature, and the rapidity of these changes among the mixed population which finds its way into the United States is well known. The subjection of inanimate sources 
of energy resulted in a far vaster and more sudden change of physical environment than a mere geographical alteration, and its effect on human nature have been more immediate and universal than could be produced by any local migrations in themselves. The change is the more immediate and complete, as one generation succeeds another, among those upon whom the struggle for existence presses the more directly. It began at the bottom with the unskilled labourer. It is resisted the more strenuously, and for the time the more effectively, in accordance as an accumulation of wealth, interests or privileges serves to protect the resister from the natural consequences of being out of tune with his environment, or endear him to the conditions which are changing.

In such resistance is to be found the explanation of the disquieting fact that the vast social reconstruction everywhere in progress is volcanic rather than a normal healthy growth. There is scarcely a social change of any consequence which has not, like the right of combination of labour, taken its origin and assumed strength from below, and burst through the resistance offered to it from above. After having been denounced as anti-social, it is, in due course, welcomed and universally adopted by official and orthodox circles, so soon as the further progress of the movement has made it appear as the least of inevitable evils. Even the nationalisation of railways, land, and the sources of wealth, the conscription of capital, and all the rank heresies of a little while ago, are now receiving serious consideration. Perhaps most significant of all such ideas is that of the international co-operative labour movement against war.

This movement is a remarkable instance of how the forces compelling change find expression, in spite of the most innate traditions, such as patriotism 
and the martial spirit, which were once the essentials of survival, whatever they may be to-day. The progress of change spreading upwards throughout society leads to some strange paradoxes. Official constructive philosophy long since deteriorated in a soil utterly exhausted by a monotonous alternation of introspective and retrospective agriculture and the bearing of a monotonous succession of the same dwindling harvest. It alone remains sterile, whilst all around, in the most unexpected places, the fertilising influence of the new knowledge, won and being won by the perfection of the extrospective or experimental method, is producing a luxuriant, if tangled, growth.

\section{The Energy of Coal.}

So far as the mere multiplication of the physical capacity of the race is concerned, the shifting and transport of loads, the hurling of projectiles or the minimisation of animal strength, the social effects of science are obvious enough. But these are but special instances of a universal change, which the modern doctrine of energy enables us to envisage in its entirety. All life-processes demand for their continuation and maintenance a continuous supply of energy, which is derived from food. A modern maxim might be, "Look after the energy and the matter will look after itself." In metabolism, so far as matter is concerned, there is a closed cycle. Men feed on animals, and animals on plants. The plants feed on the carbon-dioxide and other products of the animal metabolism, reconverting them into food. The net result is nil, or nearly so, as far as the material changes are concerned. They cancel out. But the one essential physical factor that makes the process possible is the supply of energy as sunlight 
to the plant, which, unlike the animal, can utilise it in this form for its life's work.

Scientifically there is nothing peculiar about vital energy, or about one form of available energy rather than another. That is to say, if not yet, some time in the future, the synthesis of food from the material constituents and any form of available energy will probably become possible. Historically, and till quite recently, the energy of sunlight, apart from an insignificant source in the tides, was the sole income of energy available for the world, and the traditional source by which, through the intermediary of plant metabolism, both men and animals lived. Mankind still lives solely on the energy derived from the sun, but in addition to his former income, utilised as before through the pursuit of agriculture, he has secured the control of a handsome legacy of solar energy, laid by in former times. $\mathrm{He}$ is living on an immensely more lavish scale than any of his predecessors, not because he has had any great increase in salary in the proper sense, not even because he is, in the mass, somewhat more intelligent, but because he is squandering an inheritance. The plants which, alone of living forms, can utilise the energy of sunlight, were at work for man ages before the remotest likeness to his image had appeared upon the world, and, even then, were laying the foundations on which alone his present greatness rests. Quite extraordinary physiographical conditions must have prevailed, an alternate uplifting and depressing of the bed of the ocean, time and again, as one age succeeded another, when the luxuriant forests of the carboniferous era flourished in the sun, and then sank beneath the sea. In this fossilised vegetation, preserved as coal, sandwiched between alternate layers of shale, is conserved some tiny fraction of the solar energy so prodigally radiated 
throughout those bygone wastes of geological time. It is kindled, its store of energy bursts again into flame, and a civilisation, such as the world has never known, springs into being with the sunlight of a hundred million years ago augmenting its own.

The source of energy by which the modern world lives so profligately is no steady or perennial stream, such as that out of which our forefathers evolved their greatness. It is a stagnant pond, trapped from the main cosmical flow by a fortunate sequence of earth-movements, being drained at an ever-increasing rate and in an ever-increasing number of ways. "You have given me a store of energy," the modern Archimedes might say, "and steel" wherewith to apply it, and lo! I have moved the world."

\section{Water Power.}

In justice to science, however, it must be said that not all its conquests are effected by the expenditure of the capital sum of energy ; for there is a secondary, but considerable, source of energy available to the modern world, representing the better utilisation of the fixed income. Water power, or white fuel, as it is picturesquely called abroad, is a small part of the perennial supply of solar energy, conserved by purely physical processes, without the elaborate intervention of life at all, and the utilisation of which on every count, except the æsthetic, is a source of pure gain to the community. Energy itself is indestructible, and in itself is only valuable in its conversion from what may be called higher to lower forms. The natural transformations occur without loss of the absolute amount of energy. Rather what is lost is merely opportunity to direct those transformations to useful ends.

In nature this opportunity passes as a rule 
quickly. Of the immense amount of radiant energy received by the earth, only a very minute proportion is arrested in its transformation. Most finds its way unused into the great ocean of heat energy of nearly uniform temperature, and the attainment of this dead level marks the final goal of every stream of energy received by or set in motion in the world, whether it is utilised or not. The opportunity once passed can never be retrieved. The energy now being considered formerly so ran to waste. Now it, to a great extent, turns turbines linked to dynamos, feeds the fires of electric furnaces at temperatures rivalled only by the originating sun, links itself to matter in the form of compounds, which are used to fertilise the soil and facilitate the work of sunlight and the seed, producing food. The food nourishes an army of workers, and the energy of the falling waterdrops, arrested in their headlong passage to the sea, now pursues a long eventful journey, beyond even the ken of the cold calculations of science. Linked in intimacy with human destiny, it translates thought and intelligence into action, before the partnership is severed, and it merges itself at last into the general level it set out so bravely to reach, headlong and divinely useless at one bound. Science that has done this has moved the whole world nearer to the glow. Not at its door, surely, should be laid the consequences if the energy of the falling waterdrops has been drained to provide the machinery of destruction, rather than of life.

\section{The Source of Cosmical Energy.}

Until the twentieth century had entered its opening decade a thoughtful observer of the social consequences of science would have seen in the revolution cause for profound uneasiness. Here was no stable or enduring development, but rather the 
accelerating progress of the spendthrift to destruction, so soon as the inheritance had been squandered and the inevitable day of reckoning arrived. When coal and oil were exhausted, and the daily modicum of sunlight represented once again, as of yore, the whole precarious means of livelihood of the world, the new inanimate servant of science, like the slaves of the ancients, would prove a dangerous helpmate, and the mushroom civilisation it had engendered would dissolve like the historic empires of the past, this time submerging the world.

No one had guessed the truth, though geological records tell of a history, vastly longer than human, during which, without much change, certainly without any evidence of progressive exhaustion, the energy of the sun had been invigorating and quickening the world. The fixed stars overhead, shining without apparent change of splendour throughout the past ages so far back as human memory extends, speak of a continuous outpouring of energy which, making all allowance for the vast scale of cosmical events, possesses a character of permanence and endurance foreign to the processes and events which hitherto had come within the ken of science. No one had guessed the original source of the stream of energy which rejuvenates the universe, nor that it has its rise, not in the unfathomable immensities of space, but in the individual atoms of matter all around. In so far as it is dominated by the supply of available energy, the limits of the possible expansion and development of the race in the future have been virtually abolished by this discovery of the immanence of the physical sources of life and motion in the universe.

Painfully and with infinite slowness man has crawled to the elevation from which he can envisage his eventful past as a whole from one standpoint, as 
that of a struggle, still largely internecine rather than co-operative, for a miserably inadequate allowance of energy. He looks back across the gulf of time from the day of the nameless and forgotten savage, who first discovered the art of kindling a fire, to himself, his logical descendant, master of a world largely nourished by the energy of fuel, and humming with the music of inanimate machinery. He turns his thoughts downward into the earth and wonders how long the source of his new life will hold out. He looks up once more at the unchanging stars and realises, as one who before has been but blind, that the immeasurable interval that separates him from the hidden sources which bear the universe along, is no immeasurable interval of space, whatever it may be of future time. The main stream sweeps past his doors, and the great gulf that yawns between him and the consummation of his emancipation looks small enough compared with the gulf that yawns behind.

No better illustration could be chosen of the spirit of absolute detachment from practical affairs, in which the highest and most practical knowledge is won, than the familiar history of the march of events which, in the closing decade of the nineteenth century and the opening years of the twentieth, revealed the immanence and accessibility of cosmical energy. To spend a feverish life in the attempt to transmute base-metal into gold, or to discover the secret of perpetual motion, would be to tread a well-trodden highway leading nowhere. But to exhibit a divine curiosity in an abstruse phenomenon, such as the rays given out by fluorescent substances, and whether any of them, like the X-rays, are able to penetrate an opaque material, to follow nature rather than to lead, and to win a grain of knowledge for the communism of science, is to stumble upon secrets such as these unawares. 
So radium was discovered, and it has been remarked that the future race will date the coming in of its kingdom from this discovery, mainly due to a woman.

Through the wealth of new discovery that followed the recognition and investigation of natural radioactivity, we have but to pursue still the single connected thread which science has shot through the whole fabric of human history. Rays of a fundamentally new character are given out by radium, of various kinds and intense interest, and a thousand new phenomena make themselves manifest, but like galley slaves and fertilisers, waterfalls and food, they must here be brought into line from the single view point. Their energy is of the same category and obeys the same laws as the forms which before have nourished and embellished life. Not yet, at least, has science got outside the jurisdiction of that universal legislation, whatever may be its ultimate aspirations.

The energy evolved by radium spontaneously, however new and wonderful it may be, is yet measurable in current coin. In a single day it approaches in magnitude the energy evolved from a similar weight of any materials undergoing the most energetic chemical reactions known. In a year it evolves about 150 times as much energy as would be evolved in the complete combustion of the same weight of coal. Yet in the fifteen years that have elapsed since the discovery no measurable diminution of this rate of emission has been observed. If science is right, this emission will steadily decrease as the centuries roll by. But it is still possible to put a value on the total amount of energy a given weight of radium will furnish before the outflow comes to an end. It is about a third of a million times as great as would be evolved in the 
combustion of the same weight of coal, the source of energy on which the world, in so far as it is modern, subsists.

Whence arises such a stream still flowing in this world of ancient lineage, from a material extracted from minerals found in rocks, many of them coeval with the beginning of geological time? Tracked to earth, the clue to the great secret, for which a thousand telescopes might have s!vept the sky for ever and in vain, lay in a scrap of matter, dowered with something of the same inexhaustible radiance that hitherto has been the sole prerogative of the distant stars and sun.

The solution of these problems followed the proof that the energy of radioactive substances was evolved in new kinds of change, which are distinguished from those studied in chemistry in two ways. In the first place they are more fundamental, and concern a plane in the complexity of matter hitherto not penetrated. It is the unit of matter, indivisible in chemical changes, the atom of the radioactive element, which in radioactive changes subdivides or disintegrates. Secondly, per unit weight of matter changing, energy of the order of a million times greater than in any previously known change is given out.

Just as chemical changes, the disruption and formation of molecules and the rearrangement of the component atoms out of which they are built - such changes as the explosion of dynamite or gunpowder-occur with far greater corresponding changes of energy than physical changes, like the change of state in the vaporisation of water or condensation of steam, so with these new changes, which are concerned with the inner architecture of atoms. All material processes studied hitherto have been concerned solely with the external relationships of atoms. 
With the discovery of radioactivity the Rubicon was crossed, and physical science found itself in a new world, in the presence of giant-like primary manifestations of energy which proceed in absolute indifference to and completely unaffected by any of the pygmy second-order influences of the world external to themselves, the old world of chemistry and physics.

These radioactive disintegrations of the atom proceed in a long sequence of successive changes at characteristic rates. The primary parent-elements, uranium and thorium, each stand, as it were, at the head of a long genealogical table, comprising some fourteen members in the first, and twelve members in the second case, before the processes come to an end and the outflow of energy accompanying them ceases.

Each of the changes proceeds at definite rates which, so far as has been ascertained, are absolutely independent of every known consideration, and so it comes about that each of these successive products has a characteristic average period of life. Its atom remains in existence for a period of time which is, on the average, definite, and which varies among the various successive members between the extremes, estimated indirectly in a variety of ways, of a hundred-thousand-millionth of a second on the one hand and twenty thousand million years on the other. The two parent-elements are the longest lived, and preserve the strain of their less enduring children throughout the ages, over periods which exceed those covered even by the utmost estimates of the duration of geological time.

Radium is but one of the products of the uranium series, and its special interest is chiefly to be ascribed to the fact that the rate at which it changes, estimated as one-two thousand five hundredth part per 
annum, is so slow that over ordinary periods of time it is imperceptible, and yet so rapid that the amount of energy continuously evolved is, considering the excessively minute quantity of matter, truly astonishing. The other members of the series which change more rapidly possess a radioactivity which, though it is more intense, is more ephemeral. Moreover, the quantity of each member of the series, coexisting with its parent, is proportional to its period of life. For it is a balanced or equilibrium quantity, when the rate of formation equals the rate of change. The more quickly changing members never accumulate in ponderable quantity and, for them, it is impossible to prove, by the older methods of science, that they are, indeed, new elementary substances, possessing distinct chemical character, atomic weight and spectrum. For radium, though the proportion in which it exists in the richest uranium mineral is exceedingly minute, it is just possible to obtain enough to weigh and to prepare in a pure condition for chemical examination.

The most slowly changing members, on the other hand, are the parent-elements, uranium and thorium, which were well-studied by chemists for a century, so feeble is their radioactivity and so slow their rate of disintegration, without a suspicion that, in them, the oft-suspected process of the evolution of the elements was still in progress before their eyes.

There is a certain quality of permanence about experimental scientific discovery which is not always believed. An important addition to experimental knowledge, whether made in the time of Robert Boyle or yesterday, is never displaced. Points of view may change, theories interpreting and explaining experimental knowledge may have their periods of adolescence, maturity and decline, but the framework of the structure, the experimental fact round 
which ideas are arranged, is too well and truly laid to fear demolition. Even when, as in the present day, the foundations of science are shifted to an ever deeper and more fundamental plane the experimental basis of fact is unthreatened. The idea that the whole edifice of chemical science was tottering to its fall as the result of the discovery of the intra-atomic changes of the radio-elements, is one that has always been too absurd to call for reply. But for that science and its clear-cut conception of the chemical elements, the result of more than three centuries of continuous experimental labour, the facts of radioactivity might still have been as arresting and magnificent as any discoveries ever were. But without the older knowledge, exquisitely and finely wrought, for the newer knowledge to dovetail into and complete, the chief human significance of the new science and its power to interpret the physical side of the drama of life could scarcely have been so early perceived.

Radium, no longer a mystery, one of the chemical elements doing what more than a score are doing at their own characteristic rates, owes its peculiar position to the fact that it is changing neither too slowly nor too quickly in reference to the allotted span of threescore years and ten. Energy of the order of a million times that evolved in the combustion of the same weight of coal, instead of being, as in the case of radium, evolved in the average period of 2500 years, is in the case of uranium and thorium spread over a term of thousands of millions of years. The effects are small but enduring, and, almost imperceptible in themselves, come to maturity in due time in the cosmical calendar. Small as is the proportion of uranium and thorium in the rocks of the earth, the energy they evolve is estimated to be far more than the earth loses to outer space, 
if the surface composition of the rocks is maintained uniformly throughout the core. Unless this is not the case, or unless the energy they evolve is being utilised in unknown ways, the conclusion follows that the interior of the globe must be getting hotter instead of colder. The uncomfortable prediction of the ultimate destruction of the world by fire, is now at least as probable as the former fate pictured by science, that the world must be steadily cooling, and that it was only a matter of time before it became lifeless and dead.

The clock wound up in the beginning to run for a certain time, a universe provided at its creation with a certain store of available energy to dissipate and live by at an ever decreasing rate, until it arrived ultimately and inevitably at complete physical stagnation and death, is being displaced by a less arbitrary view as science advances and invades more and more the vast territory still beyond its ken. It is at least legitimate to conceive a universe of permanent régime, carrying in its smallest ultimate particles the seeds of its own regeneration. But the linking of the ends of the process together into such a closed cycle still involves the assumption of events that remain unknown and a reversal of the known continuous direction of energy transformations. Such a reversal may well occur under conditions still, and possibly for ever, beyond the power of experiment to reproduce in the laboratory.

The dream of the alchemist, the transmutation of the elements, so far from being a chimerical idea, or a process to be sought for possibly in the transcendental chemistry of glowing suns, is in continuous natural operation on the earth amongst the most complex sorts of atoms known to the chemist. All heavy elements, presumably, if they could be transmuted artificially into lighter ones, would evolve 
energy on the same scale as uranium, thorium and radium. Such transmutations are still beyond the power of man to effect, but he would be a bold prophet who would declare for how long a time this may remain true.

If the ancient legend of a philosopher's stone ever becomes reality, and if means are found for artificially transmuting the elements, or artificially increasing to a sufficient extent the natural rate of their disintegration, the transmutation of the material would be of little significance compared with the liberation of a source of energy immensely more abundant and powerful than any now available. As foretold of the philosopher's stone, transmutation would be, in a physical sense, the veritable elixir of life.

( The gulf of ignorance which alone divides us from the use and application of the new source of energy would have been bridged. Exhaustion of the coal-supply would no longer have any terrors, for fuel and fuel-fed machines would be superseded, as they in their turn have displaced animal labour. The Ship of Life would have drawn out for ever from the shallows and backwaters wherein it took its origin, and, fairly launched on the primal tide, the flood would bear it far. The story of the struggle for existence on a daily modicum of sunlight, the fevered existence of the moment on ever-increasing draughts from a dwindling store, the meaning of which was no sooner realised than it was in danger of exhaustion, would become as the nightmare of the past. Reality and myth would exchange places. For, in sober truth, if one attempted to forecast, from the experience of the past, the future of a world able to draw at will upon a virtually infinite supply of energy, one would be compelled to depict it simply as a veritable Garden of Eden. 
The Garden of Eden with its tree of knowledge of which Adam partook impiously, and was cast adrift to earn his bread by the sweat of his brow, lest he should discover and partake of the tree of life, and the whole biblical account of the fall of man, though very ancient as human records go, dates only from yesterday in the whole life of the race. Men have lived on this planet not for thousands but for millions of years past, and of all this length of time myth and history record but the latest moment. Did some earlier race of men actually tread the road we are treading to-day and achieve that emancipation from the physical struggle for existence which would assuredly result from the accomplishment of artificial transmutation? The idea may appear a fanciful one, but it may be reasonably commended to the notice of those who have made a special study of the ancient mythologies and the origins of human beliefs.

The exploiters of the wealth of the world are not its creators. If they were they might have a wider view than that it was created for the competitive acquisition of the most rapacious, unscrupulous and already too well-equipped. The actual state of the world at home and abroad in regard to industry, politics, social conditions and relationships is surely an indictment of, the rule of the possessive and acquisitive more powerful than any judge could frame.

The claim is so often made that brains and labour are only two of the three essentials of civilised existence, and that the third, if not the greatest of these, is capital, that one may well ask what is meant. If capital means wealth, that is, the accumulated resources of the world in knowledge and material achievements, the statement is true. If it means the ownership of wealth, without which brains, labour 
and knowledge are all unproductive, the statement is only too true. But if it means the individual system of ownership of wealth, and that under another system brains, labour and knowledge would be powerless to advance humanity, the statement is not true. From the point of view of the community, capital is not wealth but debt, the not owning by the community of the resources of the planet whereon it resides ; and no more effective and disastrous check to its productive power could well be invented.

More and more is society becoming indebted for the necessities of its continuance to a peculiar class brought into existence by the operation of a corrupt code of laws and government derived from a darker intellectual age. Highly skilled as are the advocates of this code in making black look white, they are scarcely equal to the task of masquerading the debts of the community as its wealth.

The multiplication rather than the competitive acquisition of the means of livelihood would be the paramount concern of any community worthy of the name, and, as the obvious preliminary thereto, the study and interpretation of the laws of nature, under which men thrive or starve, would be fostered and honoured above the amassing and expenditure of wealth, above even the profession of arms. The creative element, whether the discoverer and originator at the one end or the artificer and labourer at the other, may well ask how is the world the gainer for all their splendid thought and magnificent achievements. This element has never yet ruled the community, and according to the elements who have made such disastrous attempts to do so, it never will. But the same was said, by the same type of mind, about flying before men flew, and probably of every new and difficult step so far accomplished in the ascent of man. 


\section{PHYSICAL FORCE-MAN'S SERVANT OR HIS MASTER ? ${ }^{1}$}

THE words "physical force" in my title probably convey to you the correct notion of what is the main subject of my address without any further explanation. As a matter of fact, the term "force," in a strictly scientific sense, is slightly different from that in which it is popularly employed. The word in the title is to be taken in its popular meaning, which is not the passive force or pressure exerted, for example, by a column supporting a roof, but force actively at work, moving something against a resistance; or, if passive, like the force of a coiled spring, or of an explosive, waiting, as it were, the opportunity to become active and do work. In scientific language energy is the term now used to signify what once was, and still is, popularly called force. Energy is the power of doing work (kinetic energy), or anything which can be converted into work (potential energy). When a gun is fired, for example, the potential energy of the explosive is converted into the kinetic energy of the bullet, and this bullet possesses then the power of doing work, of moving itself against a resistance - the resistance of the air and the resistance of the target it strikes.

In ordinary language physical force is often referred to as "brute force," but science does not

${ }^{1}$ Address to the Independent Labour Party, Aberdeen, 17th November 1915 . 
now put much, if any, weight on the various origins of force, or, if you will allow me henceforth to use the proper word, the various origins of energy. The energy is the important thing, whether it is brute energy or not-the power of working and battling against resistance, either of a living animal or of a mass of dead matter in motion. This theory of energy, or doctrine of work-work in the strictly physical sense, not, for example, brain work or artistic work-is of vital importance in fields very remote from science. A living being is distinguished from a dead one because it is working every second of its life, and death is the stoppage of that work. But it is not only living things that work continuously. A running river, a waterfall, is doing the same. When we speak of this as a live world in distinction to the moon, which is often spoken of as a dead one, we mean not only that there is no life on the moon, but also no movement of anything, and no change of any kind.

Energy, in general, is due to motion. If the things moving are masses large enough to see, we speak of their mechanical energy. If the things moving are too small to see, even with the microscope-the molecules or smallest particles of matter that exist-we speak of their energy as heat energy. If the particles are still smaller, not matter at all, but electrons or particles of electricity, we speak of their energy as electrical encrgy. But everything that moves, or has in it the potentiality of movement, possesses energy, and if we trace this energy to its source we find that, in almost every case, it comes from the sun. Trains and ships bear their burdens across land and sea, living creatures run or swim or fly by virtue of energy that comes to us from the sun in the form of radiation, that is, light and heat. In the processes of agriculture this radiant energy is 
converted into the potential energy of food, and so is utilised by life. But the steam and oil engine also work by virtue of the energy of the sun, which, in bygone times, was stored up by great masses of vegetation, and is now preserved in coal and fuel. Potential energy, or energy on the leash, is not capable of being apprehended until it is converted into kinetic energy. Ignite coal and its potential energy - a form of chemical energy - turns, like that of a released spring, into kinetic, and the molecules of the burning coal are suddenly thrown into a state of intense chaotic motion, which we call heat. But vital energy or vital force, the energy of a man working or living, are not special and peculiar to life. They are one with the great flow of inanimate energy reaching us from the sun, which bears the whole world along.

Energy, someone may say, is a mere abstraction, a mere term, not a real thing. As you will. In this, as in many another respect, it is like another abstraction no one would deny reality to, and that abstraction is wealth. Wealth is the power of purchasing, as energy is the power of working. I cannot show you energy, only its effects. I cannot show you wealth, only its effects and its purely conventional symbol, money. Money is not wealth to a starving man in a deserted place. It is both a symbol and a measure of wealth earned, as work done is a measure of energy expended. Heat energy, mechanical energy, chemical energy, and so on, are different forms rather than different kinds of energy, just as coins, bank-notes, cheques, and so on, are forms of money. The bank-teller totals up a heterogeneous collection of coins, paper money, securities of various kinds and currencies, all as one sum of money, and then thinks of that sum, not of the sovereigns and shillings, notes and cheques he was 
handling the moment before. So the scientific man looks into the processes of nature, sunshine and fire, storm and lightning and tempest, the battling of the elements, the rushing tumult of man and his machinery, the majestic circling of the moon and planets; stranger still, the silent, sleeping powers of coal, explosives, food and fertilisers. $\mathrm{He}$ is no more lost among them than the bank-teller is among his miscellaneous collection of monies. He totals them all in terms of energy, the power of working. The enormous variety of activities they display bother him not at all.

Now, just as strict watch as the bank-teller keeps on the credit and debit sides of the accounts of all his customers, nature keeps over the energy accounts of all its manifold processes. There is no work done for which the energy required does not have to be supplied, just as no money can be withdrawn from a bank into which none has been paid. Money cannot be spent twice, more must be forthcoming, and so it is with energy. It can only be spent once, and, whether spent usefully or uselessly, whether doing enduring work or dissipated doing nothing permanent, once spent it cannot be recovered. Very easy indeed it is to waste energy. The performance of any work demands so much energy, but any amount more may be demanded if the worker is inefficient. Abstraction or not, energy is as real as wealth,-I am not sure that they are not two aspects of the same thing. The one drives the commercial and industrial activities of men, and the other the whole physical activities of the entire universe.

Human beings and beasts of burden were at first almost the sole sources of useful energy, the only available labourers to overtake the heavy work of the world. For countless ages the inanimate energy of nature, of wind, waterfall and fire, proved too 
difficult to harness and control. It is only a century since the new era of inanimate energy began, since science drilled the tumultuous rush of the swarms of molecules, too small to be seen, and out of their infinite variety of motions in all directions at onceout of heat-made the working motion of the steam engine. Animate energy, "brute force," became dwarfed indeed beside the working giant whose food was fuel. What is more, it had to recognise that it indeed was no divinity, no "vital spark" of origin divine animating a mass of clay. It was just energy, no more no less, ' to that bank-teller keeping count, and it made a very humble sum compared with the accounts of his inanimate customers.

At once there came about an enormous increase in the world's work, done no longer by living workers but by the inanimate labourers, water-power, coal and oil, which science had enslaved. So that to-day a single machine puts forth a continuous round of labour which an army of men could not keep going for an hour.

Steam engines, locomotives, electric trams, and petrol-driven motor cars have made some of the main aspects of inanimate energy very familiar. We all know that if we want such energy or power in any form we have to pay for it, whether we get it as a finished product, as the electrical energy laid on to consumers' houses and paid for by the unit, or in a partially-manufactured state as coal gas, or in its raw state as coal. In neither case do we care at all for the electricity or gas or coal we buy; we are buying energy, the power of doing so much work, the power of producing so much heat, light, and so on, as the case may be. We are all aware how largely this inanimate power has replaced animal labour. Whether at the docks or on ships or trains or cars, some animal-man, horse, mule or ox-has 
been emancipated and his place taken by his tireless competitor. But it will be less familiar to some of you that this energy can not only displace, it can replace animate energy, and as time goes on it will more and more replace it. Conceivably, some future race of men, instead of sitting down to dinner, will attach themselves to something akin to an electric lamp-socket and draw thence from the public mains the supply of pure physical energy required for the day's work without any necessity of absorbing at the same time the useless husks - the material wrappings in which this energy is done up-that constitute our present food.

Now, though less generally appreciated at its true human significance than other scientific developments of the nineteenth century, this is probably the most fundamental and important. The doctrine of organic evolution cut away some of our most cherished notions about ourselves on the biological side. Fallen man-a discredited creature-with eyes ever turned backwards into his alleged more glorious past, a feeble and ineffective imitator of bygone days, dressed up by myth and poetic fancy to appear divine, gave place to the truer and more robust conception of man ascending from the animal world, a creature of hope and promise, with eyes ever forward on the future, and with reason gradually growing and developing to the point of comprehending the terms on which he stands with universal nature. Simultaneous with this profound reversal of mental outlook came the realisation that the physical strength in which he gloried was, even less than his body, of divine origin, but was borrowed from the inanimate world and could be augmented therefrom without the agency of life at all. Never before in his long history had any fundamental factor of his existence so suddenly and completely changed. 
His physical necessities became a problem completely apprehended, a problem of energy, pure and simple. Life, the mystifier, scarcely complicated it. The pale, pursuing spectre which has dogged the ages and dragged them down is to be exorcised, not by mystical philosophy and religions, but by physics, chemistry and engineering.

But even on the purely philosophical side the gain is not inconsiderable. In constructing a machine which will run and perform continuous work, the scientific man has most nearly approached an imitation of the living body. Conversely, the living body has been often likened to a machine. If we regard merely the physical attributes of life and ignore the moral, æsthetic and spiritual aspects, then, undoubtedly, the body is a machine. Especially during sleep is the parallel exact. It is a machine set to run automatically whilst the engineer, the brain, has for the time being vacated the controlling platform. The pumping of the blood by the heart, the pumping of air by the lungs, the digestion of food, with their attendant sub-conscious regulations and adjustments, go on in the living body, both asleep and awake, in a definite round of themselves, much as a machine runs in its appointed cycles by virtue of its automatic valves and regulators. Awake and alert, it is a machine with the engineer at the helm, continually opening and closing non-automatic valves, making it vary in its actions, not over one or two, or possibly a dozen different combinations of motion, but over a practically infinite variety. But, whatever the complexities introduced by wakefulness, the sub-conscious regulation of the human machine does not cease for an instant. If we go further, beyond the physical realm of motion and forces, and trespass upon the intellectual activities of the brain, and the still finer moral, æsthetic and spiritual activities of the soul, 
then, in spite of these further complexities, the mechanical aspect of the body can still no more be ignored than can the prime mover of a loom producing the most wonderful and artistic textiles. For good or ill, that machine has as much or little a right to be considered the man as his soul or brain. The attempt to amputate the spiritual from the physical world paralyses both.

The mechanistic notion of life, the representation of the body as primarily and fundamentally a machine, is often bitterly and not very intelligently opposed. We are told that the machine-the scientist's imitation of life - is not merely a purely inanimate mechanism. In its cunning combination of valves and regulators it has a brain, part of the brain of its designer. The partial likeness is that of the machine to the man, of the limited imitation to the original ; not the other way about, which is true enough. But let us bear in mind one essential and undeniable fact. Machine or man, inanimate mechanism with the mechanical imitation of a brain, or brain controlling an animate mechanism, what of the power? The power to live, the power to do work, is not in the brain nor in the body, not in the valves nor the moving parts. The power, whether of life or of mechanism, is external. That is the real ground of the analogy.

Inanimate energy, which before ran to waste or lay in the ground unused, began to be guided by human intelligence and shaped for human ends. What this energy can do for good and evil the world is everywhere now the witness. Primitive man froze on the site of what are now coal mines, and starved within the sound of the waterfalls that now are working to provide our food. The energy was there, the knowledge to utilise it was not. So while we are leading cramped lives and fighting among ourselves, 
whether in peace or war, for a modicum of the means of existence, science tells us that, in the commonest materials that make up the framework of the world, there is energy of a magnitude of which we have no experience, and the means of livelihood upon a scale of which we have no standard. The energy is there. The knowledge that can utilise it is not-not yet.

If the nineteenth century is destined to be remembered in history on account of the establishment of the doctrine of energy, to the twentieth, young as it still is, belongs the credit of elevating and extending that doctrine to the extent that makes it of universal human interest. One simple question concerning the source of energy the nineteenth century quite failed to answer. Divorcing from the problem everything but its purely physical aspect, and putting it in its widest form, there remained unanswered the problem of its origin. How is it that the world is not yet grown old and "dead," though geologists dispute among themselves whether its history, in much the same condition as at present, can be traced back a hundred million or a thousand million years? Or, look up on a clear night at the same stars as those that greeted the gaze of the cavedweller and the mastodon when man was young. How can nature, the bank-teller, account for such a large expenditure of energy, over so prolonged a period, without long ago having become bankrupt? The sun and stars do not burn coal. Even if they did, Lord Kelvin computed that the combustion of a mass of coal the size of the sun would only suffice for 5000 years of the present rate of output of solar energy. Though, without any new source of energy, it was found by him to be possible to account for solar radiation over a period of some millions of years, the claims of the geologists for hundreds or thousands of millions could not be satisfied. What 
is the origin of the stream of energy pouring out into space from stars so numerous that every living person in the world might claim a separate one as his own? That is the problem that has stared us in the face since we began to understand the laws of energy, an academic problem, perhaps, until it is realised that it is necessary for us to be able to get our hands on the levers controlling the primary sources of energy, or, when our fuel supplies are exhausted, relapse into barbarism.

At the close of the nineteenth century an extraordinary series of discoveries in physics and chemistry put into our hands a scrap of a material called radium, which asked us precisely the same question as the stars, but at point-blank range. It is a new element discovered by $M$. and Mme. Curie in a uranium - containing mineral, pitchblende. It possesses the outstanding property of emitting energy, in relatively large amount, and in new and surprising forms, spontaneously and continuously. All we have learned of this new property, radioactivity, shows that this steady emission of energy is going on in the rocks, from which the radium is extracted, at precisely the same rate as from the radium after it has been extracted, and has been going on for hundreds of millions of years. The explanation follows from the discovery that these radioactive elements are undergoing slow changes into other elements, changes of precisely the same kind as the alchemist sought to effect when he strove in vain to transmute the base metals into gold. Modern chemistry is unable to achieve such changes, but they are now known to be going on slowly and spontaneously in the radioactive elements. We can at present only watch and follow them. We have not yet succeeded in interfering with them or quickening their rate. 
Hitherto in the chemical changes, from which the world derives its chief supplies of energy, such as the combustion of fuel, different elements, such as carbon and oxygen, combine together but do not suffer any intrinsic or fundamental alteration. The compound formed, carbon dioxide, can be decomposed by the chemist to give back again the original carbon and the oxygen, not entirely different elements. In other cases, the decomposition of certain compounds may give rise to the evolution of energy. Examples are to be found in all the modern high explosives, such as gun-cotton, nitroglycerine (dynamite), picric acid (lyddite), and trinitro toluene (T.N.T.). But in no case, except in the radioactive elements, has a veritable transmutation of one element into others been observed.

We have obtained evidence, in consequence of these new discoveries, that in the atoms of matter exists a store of energy beyond comparison greater than any over which we have obtained control. In the slow changes of the radioactive elements there is known to be an evolution of energy nearly a million times as great as has ever been obtained from a similar weight of matter before. The energy is there, but the knowledge of how to liberate it at will and apply it to useful ends is not -not yet.

The problem will be solved when we have learned how to transmute one kind of element into another at will, and not before. It may well take science many years, possibly even centuries, to learn how to do this, but already the quarry is in full view and, by numerous routes, investigators are starting off in hot pursuit. We need only recall the past history of the progress of science to be assured that, whether it takes years or centuries, artificial transmutation and the rendering available of a supply of energy as much 
beyond that of fuel as the latter is beyond brute energy will be eventually effected.

It is unlikely, but not impossible, that such a discovery might be made almost at once. A magnificent scientific achievement it would be, but, all the same, I trust it will not be made until it is clearly understood what is involved. Let us suppose that it became possible to extract the energy, which now oozes out, so to speak, from radioactive materials over a period of thousands of millions of years, in as short a time as we pleased. From a pound weight of such substances one would get about as much energy as would be obtained by burning I 50 tons of coal. How splendid! Or a pound weight could be made to do the work of 150 tons of dynamite. Ah! there's the rub. Imagine, if you can, what the present war would be like if such an explosive had actually been discovered instead of being still in the keeping of the future. Yet it is a discovery that conceivably might be made to-morrow, in time for its development and perfection for the use or destruction, let us say, of the next generation, and which, it is pretty certain, will be made by science sooner or later. Surely it will not need this last actual demonstration to convince the world that it is doomed, if it fools with the achievements of science as it has fooled too long in the past. Physical force, the slave of science, is it to be the master or the servant of man? The cold logic of science shows, without the possibility of escape, that this question if not faced now can have only one miserable end.

From time immemorial man has boasted and gloried in his physical prowess. $\mathrm{He}$ was a rude animal, whose turbulent experience has preserved, as a religion, this pride in force as the ultimate arbiter. Christianity for two thousand years has inculcated the opposite creed, but, while largely 
adopted by civilised peoples as the ostensible principle of their internal private relationships, it has never been adopted by any nation in its international relationships. The principle of force as ultimate arbiter in international quarrels remained unchallenged through the nineteenth century, though a strong, if politically impotent, revulsion against it grew in this country, through the development of a stronger public conscience, as it appeared to us, through satiety in conquest and physical deterioration, as our enemies preferred to believe.

But do not make the fatal mistake of supposing that what always has been, necessarily always will be. When man rose to the intellectual stature at which he could command the waterfall to do his will, kindle a fire and marshal the chaos of motion we call heat into the rhythmic working movement of a fuel-fed engine, irrigate the desert and make two grains of corn grow where one grew before, he broke with his past, for good or evil, once for all. The physical factors of life till the nineteenth century had been practically stereotyped. But now a new factor is at work in the world which alters its whole economy, and in light of which everything old, whether appertaining to peace or war, to the body, the brain or the soul, awaits its turn to be reexamined, and, if found wanting, discarded.

Science multiplied man's physical powers ten thousand-fold, and increased his capacity both of construction and destruction in like ratio. He spent the vast increase of wealth, which had accrued to him 'from the peaceful applications of science, in preparing, like his ancestors, for war. The war has come. As to its results, there is nothing in history that can give the slightest clue. The principle of force as the ultimate arbiter is now undergoing its re-examination. It has survived nineteen centuries 
of Christianity. Is it to be perpetuated or destroyed by science?

Some thought science had already made war impossible. As it has not, it may be concluded that no future development of science, however world-shattering, will of itself have that effect. Others thought that the sensitive and elaborate ramifications of international commerce and credit would effectually prevent war, or quench it quickly if it broke out, relying, as it seems, on a cobweb to stop the rush of a tiger. Everyone of us will carry to our graves some real knowledge of what modern war is and means. Future generations, let us hope at least, will know as little about it as we ourselves knew a couple of years ago. They will read about it in books, as we read, and it will mean as little in comparison to them as the Napoleonic Wars meant to us. It is our duty, therefore, to spend our lives and brains thinking this thing out for ourselves. It must not be left for our successors to relearn all over again.

We are faced with a new factor of unlimited possibilities of development. Science will not stand still, even though the foreshadowed release of interatomic energy be delayed for centuries. The increasing horrors and the certain ruin of war both to victor and vanquished will not stop it, though it must make it of necessity less frequent. The more deeply we ponder on this as a practical question we shall find, I think, that the first step is to narrow the issue and to ask whether, and if so how, wars, such as this war that is now being waged, can be prevented from ever occurring again. Then we come to grips with a practical problem. For consider the absolute stupidity and wantonness of the present war. We are fighting Germany as we would fight a homicidal maniac who has suddenly started to run 
amok, and we have to kill the maniac or he will kill us. There is no great question of irreconcilable principle involved, I mean in the sense that there was in the great American Civil War, or that was at issue when contending religions - as the Cross and the Crescent-came to death-grips. Before the war the Germans were our friends and equals. We intermarried without social stigma or disability. There are some nationalities - the Jews are an example - which do not mix with any other even after centuries of life together. There are others - the negro race of the United States offer an example-with whom, rather than mix, a nation will break every law, human and divine. Again there are others-the British Empire affords as good and as perplexing examples as any - against whom, for fear of being cheapened economically and socially, preventive measures are taken to forbid or hamper their free immigration into our territories.

These are a few examples of what for comparison I will describe as racial causes of war. I indicate them merely to show how very far from practical politics any attempt to banish war and the thought of war from the world at one step is likely for long to remain, unless we are content to solve the simpler problem first.

But the present war does not come within their category. Let us take Germany at her own valuation, as a virile and expanding people, denied a place in the sun, hemmed in on all sides by decadent and stagnant populations in possession of the fairest parts of the earth. Individually her people were peculiarly capable of fighting for their own hands according to the recognised, if lax, standards of private law and commercial morality, and so they had already peacefully penetrated far and wide into the 
less crowded countries of the earth. Everywhere they were treated as friends and equals. There were no restrictions as to their owning property or intermarrying with nationals in their adopted countries. The feelings of Germans towards neighbouring nations, and those whose hospitality they sought, would be better described as the ordinary one of national contempt rather than racial horror-the contempt which no nation, least of all ours, is free from in its estimate of others. She thought she could win, she knew what she wanted-I am not sure that we yet know-and as, since the FrancoPrussian War, she has always declared frankly was the German method, she struck when she was ready to strike, with no more thought or compunction than if her neighbours had not been human beings. It is commonly supposed that the completion of the Kiel Canal fixed the exact time. The war has already lasted long enough to show that she had to wait for something vastly more fundamental. A group of chemical processes-technically referred to as the fixation of atmospheric nitrogen-had to be perfected and put into practice in the especial form necessary for her war needs, before she had any chance of success, for on these new processes, cut off as she is from most outside supplies, she depends for the raw materials of explosives. It all seems to have been nationally thought out in cold blood to the dotting of the last $i$. Had it been successful they would have gloried in it, as some of the more sanguine still are glorying.

We expect, of course, professional soldiers to think along these lines and to act, under civil control, according to these tenets. But for an entire nation-once great in philosophy, literature and the arts, once possessing an empire vastly wider than the material possessions that can be seized and 
fought over by soldiers-for such a nation to have adopted militarism as the national soul and conscience, and to take its orders and ideas from soldiers, appears to us to-day, however it may be viewed by the historian, to have brought the world to a parting of the ways. Whether it is because of our more fortunate geographical position, or whether it is because we are an older nation than Germany, whatever fate the future holds for us individually and as a nation, we cannot accept that as the end. It means, simply, that man has risen in intellectual stature to the point at which he is in league rather than at war with mighty Nature, in order that nations may never be able to live mutually at peace again. It is not a war between irreconcilable principles. It is a war between the fundamental principle of all national co-existence and its contemptuous negation.

If we concern ourselves, when the time comes, merely with the relatively small task of making wars of this sort more difficult or impossible to recur, we can leave with a good conscience to our successors the wider and more complex task of dealing with the racial causes of internecine strife, wherein peoples of different colours and civilisations strive for mastery. No doctor talks at large about the termination of disease. He knows too well the almost infinite variety of disease. But where would you find a doctor who, knowing leprosy, let us say, to be incurable, not only discountenanced any attempt to cure it, but also would not hear of any attempt to cure, let us say, consumption. So it is with war. Its causes are as manifold and as ineradicated as the causes of disease. But there are many kinds of war, each requiring totally different consideration. If we are either unduly discouraged on the one hand, or unduly sanguine on the other, as the result 
of the present conflict, and tolerate vague platitudes about war and peace in the large, then, when peace comes to be settled, we shall have difficulty in escaping from the chains of the very militarism which, instinctively, millions of our people have sprung to arms to destroy. 


\section{CHEMISTRY AND NATIONAL PROSPERI'IY ${ }^{1}$}

I HAVE been asked by the Aberdeen Chamber of Commerce to say a few words on the importance of chemistry in the affairs of the nation, and the part that skilled chemists can play in furthering the general prosperity of the community.

The war has been already the means of removing some misconceptions and of the making of some discoveries. It has, for example, discovered the science of chemistry to a vast number of people, not excluding Cabinet ministers, who hitherto have associated it vaguely with the gilded mortar and pestle and mysterious flagons of brightly coloured fluids of the apothecary. Long ago a French savant described us as a country where the apothecaries call themselves chemists. Another discovery that is destined to be made is the difference between money and wealth.

The wealth of a country is in its matter and energy, - matter, the passive resister, that in the raw state will not do anything you want it to do ; and energy, both animate and inanimate, which is for ever trying to do what you do not want it to do, and needs to be controlled. So man found the world, and so, largely, till the beginning of last

${ }^{1}$ Address to the Annual Meeting of the Aberdeen Chamber of Commerce, 8th February 1916. 


\section{CHEMISTRY ANI NATIONAL PROSPERITY}

century he left it, moralising and philosophising eternally about himself, and leaving a vast legacy of these elegant accumulations for the "education" of his children. Ignorant of the most elementary facts outside himself, and of the simplest principles which control absolutely his life from the cradle to the grave, he was worse than that. He attempted, with considerable initial success, by means of a cunningly devised "educational" system to entail the conclusions of these preposterous self-examinations in perpetuity upon his children. We have first to break this entail, or so much of it, if any, as still survives after the conclusion of this disastrous war. I read in the columns of Nature the other day that the only officers in the British Army who receive a scientific training are those belonging to the Royal Artillery and the Royal Engineers who are attached to the regular army; that for cavalry and infantry officers practically no facilities exist; that the teaching of science at Sandhurst was abandoned many years ago, and has not yet been resumed; that at the present time boys who receive commissions immediately on leaving school are devoting their time to the dead languages, and enter the army without a scrap of scientific knowledge.

However, what I want here mainly to emphasise is that after the war, whatever be its outcome, science and its application can retrieve every disaster and make good even the present seemingly irreparable destruction. Science is neither the upbuilder nor the destroyer. It is the docile slave of its human masters. It will appear as the one or the other, according as the moral outlook of the latter is derived from a progressive and deepening sense of responsibility, awakened by the realisation of the true position which man occupies with regard to the external realities of nature, or an 
impossible compromise between this and the old mixed mythologies.

Let us glance at the change that has come over the world with regard to the relations of man to ènergy and matter. Instead of being between these two as between a steam-hammer and an anvil, he has climbed to the controlling gear and has his hand upon the valve. And the hand on this valve is the hand of the chemist and physicist and their executive officer, the engineer.

Power, before running to waste and making at best but an idle show, at the bidding of these three now works, battering raw materials into life-giving commodities; and so it is throughout the length and breadth of the busy world to-day. Science has its hand on the lever controlling the major physical factors of our existence.

Just as you see that a properly authenticated banker has the control of your money, see to the hand that has control of your wealth. If it be in the hands of an honest, well-trained and capable chemist, you will be surprised what unimagined wealth is slipping past your very doors to waste itself, as waterfalls used to do, though rarely so inoffensively and picturesquely. But science-the knowledge of . things outside of and independent of our own poor selves and our imaginings-though it has made the world wealthy, is no soulless materialism. Those who think so can know nothing of science, little indeed of wealth, less still of the want of it, and of all that the want of wealth has meant for humanity in its upward progress towards control. "They have but fed on the roses and lain on the lilies of life."

There is just this much sardonic justification for the sedulously fostered confusion between creative science and sordid materialism. In the old days the genius of the pure thinker and lover of wisdom for its 
own sake did not directly contribute to the immediate material prosperity of the community. In these days of experimental science it is this type which governs it. Starving, in the time-honoured manner, a great pioneer of religion, reason or art was cheap. But starve the same type of mind in science now and the community starves with him. It cannot possibly compete, either in war or peace, with any modern nation that treasures as its most fertile asset the original mind of the discoverer and inventor and the bold exploring spirit of the scientific investigator.

It is true that society may, like an old-established firm, carry on in dignified rottenness in the ways of a bygone generation and live for a while upon its established reputation, if its rivals and competitors are obliging enough to do the same. It is true that ruin may apparently be staved off by the growing power of money and the law to enslave the creators of wealth in the community. Huge individual fortunes may so be built up, but at an ultimate cost to the country altogether disproportionate to the private gain. No quicker road to general impoverishment could well be chosen than the treatment habitually accorded in this country to the poor discoverer and inventor, preyed upon by rascals of every description who flourish under the protective majesty of the law, and in the grip of a commercialism that deems it the highest wisdom not to pay for anything it can get by other means. A country that so mistakes the making of money for the creation of wealth is going to pay in its pocket as well as in its prestige. So is the whirligig of time fast bringing its revenges!

In conclusion, I would like to say a few words about chemists and the training of chemists. The chemist, if he is a genuine pioneer, is not usually a very worldly-wise person, and he suffers grievously in any sort of beggar-my-neighbour competition. 
He may be able to put on half a sheet of notepaper that which will keep in prosperity a whole class in the community for a generation. But, being a chemist and not a business man, at the end of that time he will be lucky if he is still outside the poorhouse, and still more lucky if he can still call any shred of his discoveries his own. $\mathrm{He}$ is no individualist. He knows that every step on the long road leading up to his discoveries, except the last little step he made himself, was laboriously taken by his predecessors and colleagues and presented to him as a free gift in the past.

This sort of chemist, the real discovering person, is a very rare bird, but a few of them would go a very long way. It is almost needless to say that this is not the sort of chemist that is specially catered for by university curricula. In fact, from the business point of view he is a thoroughly bad investment. He pays no more fees than his far more numerous class-mates, his training is preposterously expensive, if he is to know his subject and not merely to know about it, and, worse still, when he is hatched, no one, scarcely even his own professor, can really be quite sure whether he is a swan or a goose.

Obviously, with universities whose finances are managed by business men, the good staple lines of chemical students are far more attractive. You can turn them out in large numbers relatively cheaply; there is always a steady demand, their fees aggregate to a considerable sum and bear an appreciable proportion to the costs of their education. The firstyear medical students are the most numerous and uniform in their requirements in the Scottish universities. Then there are those who are going to be teachers, and take chemistry for a year as one of the science subjects they are allowed, in strict moderation, to take for an Arts degree. Lastly, there are the 
science students, who take chemistry as one of the three subjects required for the B.Sc. And of this last, relatively very small class, one-third, perhaps, intend to take up the study of chemistry seriously, and at the end of their training have made any real beginning at all towards the qualification of a trained chemist.

Speaking, not even purely as a chemist, and gauging the relative value to the nation of all this teaching, it is to my mind in the inverse ratio to that in which it would be regarded if numbers, or revenue earned to the university, were the criteria. You need the small army of professionally-trained students to keep the machine going. But a machine that just keeps itself going is not a prime mover. A university that does not provide training, the best it can afford, at whatever seemingly unremunerative expenditure, for those who are to be pioneers, who are to stand erect for the first time and know their way, where all before have been befogged, in whose solitary footsteps the small army can follow, such a university is to my mind oblivious to the more important and more repaying side of its dual function. 


\section{SCIENCE AND THE STATE ${ }^{1}$}

I wish to discuss with you to-night some of the relations between Science and the State. I want to show how, in the particular question we are considering, one is brought up instantly against the democratic idea as it is applied, falsely, as I think, to education, the idea of equal educational opportunities to all, not in the narrow sense to which later I wish to subscribe a hearty enough adherence, but in the practical sense in which it finds application in the schools and universities of this country.' I have to make what I know must appeal to many of you as a very bold, not to say provocative, statement at the outset, and it is simply this. Educate your millions, and bring to every boy and girl in this country the benefits of as sound and thorough an education as you can afford. The fact remains that, for sheer practical value to the community, and hard cash in the pockets of each member of it, there are a few, say one in every million, who are worth as much to the community as the rest of the million put together, and whom, if you miss or merge with the rest, the education of the million will avail you little indeed. I know, in these democratic days, it sounds like a restatement of the doctrine of a privileged class, living at the expense of the community. But be assured the statement is democratic enough in this,

${ }^{1}$ Address to the Independent Labour Party, Aberdeen, Ist October 1916. 
at least, that the few geniuses I have in mind are drawn from no exclusive hierarchy or caste, but appear in the cradles of the world as capriciously as the wind which bloweth where it listeth, and according to laws, if such there be, that hitherto have defied the search of the new-born science of eugenics.

My statement is novel only in one respect. The geniuses I have in mind are the creative geniuses of science, rather than those of literature or art. In this field, the statement is as commonplace as regards Shakespeare or a Michael Angelo. Its novelty, if it is novel, is that it applies to the practical values of the everyday world, the measure of which is money, as much as to æsthetical and ethical values, which cannot be measured in the current coin. I know I shall be told, though probably not by you, that these latter things are of more value than money, that a man may gain the whole world and lose his own soul, and so on. You, at least, will not be over-impressed by this talk about the dangers of materialism, which comes appropriately enough from those that neither toil nor spin. You will have sufficient acquaintance with the realities of the world in which you live to know that, for every soul slain by over-indulgence and luxury, thousands perish besotted by the lack of the bare necessities of a decent existence, and that the animalising influence of want, and a hopeless, unremitting battle for the primal needs of the body, must be faithfully dealt with before you can even begin to think of the higher spiritual and social aspirations of humanity, rather than of the few. Before the advent of science such universal aspirations were not capable of being satisfied.

So if I choose this ground-the ground of practical everyday life rather than that of the visionary and dreamer-it is not because it is the only aspect of 
science, but because it is the one of most general practical importance.

The elevating influences of the study of Nature, the sublime emotions awakened by the spectacle of the mists being slowly dissipated from the veiled countenance of Truth, are at least as potent as any encountered by man in his persistent and unwearing dissection of his own self. But, distinct from this, science is unique in pointing the way to the realisation of that necessary practical antecedent of all that makes life universally holy rather than animal. Neglect it, and the finer voices may call, but the ears that should hear will be dull.

There may be a tendency on the part of some of my audience to regard science as something particularly associated with the waging of war and to look upon scientific men as a class as under the suspicion of being in the pay of the great armament firms of the world, and as finding, in the universal race for armaments, the most profitable and natural outlet for their inventive and productive genius. Whether or not I am mistaken in that impression, at least it can hardly be gainsaid that this point of view is foremost in the minds of those most influential and vocal of the leaders of public opinion, to whom, for the most part, the war has discovered the importance and indispensability of science for the first time.

I wish to-night, if I can, to do something first to combat this false impression. It is true, of course, at the moment that scientific researches and inquiries are now very largely suspended, and that the energies of scientific men in this country have almost wholly been drawn into the vortex, in common with the rest of the energies of the nation. Scientific men here now, as much or more than any other class, are concerned with science no longer, but only with its 
profane application to the more efficient destruction of their fellow-men. But this which, at the moment, passes for science with the ignorant is an aspect which is the absolute opposite of its proper function. A fire-engine, the purpose of which is to quench a conflagration by pouring water on the flames, could even more effectively be used for an exactly opposite purpose by supplying it with petroleum instead of with water. Is the inventor of the fire-engine less a benefactor of the community on this account? If some lunatic used a fire-engine for this purpose, would you immure the inventor or the lunatic?

Those who in the early stages of the war were so ready to regard the initial supremacy in military science of the enemy as but one aspect of his moral degeneracy, have now realised that science is as indispensable to a good cause as to a bad one. Science is not responsible for the morals of its human employers. That is their affair. No one in his senses would recruit $\mathrm{C}_{3}$ policemen because the cause of the criminal is bad.

The newly awakened interest for science in this country is entirely due, not to any sudden love of truth, any desire to understand and walk familiarly through the labyrinth of Nature, any weariness with the old rule-of-thumb and hit-or-miss methods of our ancestors. It is due simply to the realisation of the fact that it is indispensable in war, and that without it we shall go down as completely as the Dervishes did at Omdurman and for precisely the same reason.

It was, I think, a German philosopher' who remarked-"Chemistry to one is a goddess, to another an excellent cow," and to this one might add, "to the third a handmaid of war."

So one can discuss the relation of science to the State from this triple point of view. Science as the representative of Mars has now been admitted to be 
indispensable. As the cow to be milked for marketable knowledge, it is beginning also to be realised that in times of peace, or rather the peaceful war of industrialism and commerce that is expected to follow the signing of the terms of peace, science is as important and indispensable as it is for open hostilities. Plenty there will be to advocate its claims under these heads.

But its third claim as the goddess, as indispensable for the enrichment of the life of the common people and the elevation of ideals, is the one with which I am to-day most nearly concerned; in the words of Huxley, "in the conviction which has grown up with my growth and strengthened with my strength, that there is no alleviation to the sufferings of mankind except veracity of thought and action, and the resolute facing of the world as it is when the garment of make-believe with which pious hands have hidden its uglier features has been stripped off."

I know some of you are great readers, and I can recommend to you, for this aspect of science, a book by Professor R. A. Gregory called Discovery, or the Spirit and Service of Science. Whilst as specially concerned with chemistry and what it has accomplished for the material well-being and uplifting of mankind, the recent Thomson lectures in Aberdeen by Professor Findlay, now issued under the title of Chemistry in the Service of Man, will probably be a revelation to those to whom the term chemistry has hitherto meant either an apothecary or an analyst.

I may quote one passage from the former:-

"Blessing and honour and glory and power are not the usual rewards of a life devoted to science. All the benefits of modern civilisation are due to the achievements of science or inventions based upon 
them; but neither the multitude nor its masters are familiar with the names of the men whose work has provided the comforts of the present day. If you seek fame and riches, enter not upon a scientific career; for they are easier won in politics or commerce or many other walks of life. If, however, you will be content with the satisfaction which faithful and unselfish work always brings, Nature offers you a rich field in which you can exercise your intellect."

Rather than being in league with militarism and armament firms, science is, in fact, the only really working socialism. Scientific men work too often without reward for the love of their science, and freely publish their discoveries for the good of the whole community. Though the contributor of the last mite of knowledge usually gets popular credit for the whole discovery, the advance of science as a whole is entirely bound up with this communism of its inheritance. The spirit of secrecy, and of individual ownership of knowledge, is absolutely antagonistic to the spirit of science.

It is a commonplace to the scientific man that the grandest discoveries that have been made and those at once most productive and fruitful in money-making applications, both to the legitimate arts of peace and the illegitimate purposes of war, have been made by men in the simple pursuit of truth for its own sake and without thought of any pecuniary reward, or even of practical applications. You cán trust the State, after the lesson it has had, to see that the application of science to war and to industry and manufacture receives more attention and encouragement than it did in the past. But pure scientific research and investigation, made with the simple desire to extend the bounds of knowledge, is the goose that lays these golden eggs, and there 
will be plenty of covetous hands itching for its life in the hope of immediate and instant gain.

What passes for science with most people is the application of new knowledge to useful purposes. The instinct of self-preservation and of pecuniary gain are powerful guarantees that these will not be neglected. But before you can apply knowledge you must discover it, and this primal discovery has been and must be almost entirely the work of the comparatively few, working without thought or expectation of gain for the love of truth and unhampered by any pecuniary or practical considerations.

We arrive at this paradox, the truth of which is established by the whole history of science, that though you may foster in a general way the discovery of new knowledge, as distinct from the application of these discoveries to utilitarian ends, you cannot command the discovery of any new knowledge in particular. The attitude of the man of science is not that of the technologist or engineer. $\mathrm{He}$ sets forth into an unknown land not to discover anything definite, anything of use to anyone, but to discover what there is in the unknown to be discovered, however apparently commonplace and unimportant it may seem. The grander the discovery, the more trivial and utterly useless it often appears at first sight. The commonest and most ordinary phenomena, to which the eyes of humanity have become so accustomed as to be hardly consciously aware of, frequently furnish the greatest amount of new knowledge.

In a new country, before the rush of gold-seekers, of lumbermen, or of farmers, must come the pioneer. He cannot command gold or timber or arable land, he finds simply what there is to be found. The new countries of the world are rapidly filling, and 
in a short time hardly one will remain to be explored or exploited. But there is a realm of inexhaustible extent, which actually grows larger with every step taken forward in its exploration. It is the realm of ignorance beyond the world of knowledge and completely surrounding it. As the known world expands, the boundaries between the known and the unknown lengthen, jumping-off places for the pioneer into the unknown become more and more numerous, and the pace of progress increases and ever must increase. This world of ignorance is the El Dorado of the future, limitless and inexhaustible so long as the spirit of divine curiosity to know haunts the earth.

To be the first human being to make a discovery of incalculable and, possibly, never-ending consequence to humanity, is in itself no mean reward for an investigator, without honour, glory and power being added. The million others, who never make discoveries, can never know the mental exaltation and satisfaction, far above the worth of rubies, that the discoverer in any walk of life experiences. Nevertheless, if science is to be of practical benefit to the million and the means of raising the universal standard of life, it is a simple business proposition to make sure that the scientific investigator is provided with the means necessary for the pursuit of his proper work. The harvest is great but the workers are few, and, hitherto, they have been recruited mainly from among those who have possessed, in addition to the requisite enthusiasm and knowledge, private means of support sufficing for their everyday needs. For in pure scientific research, as distinct from applied science, there is, apart from its costliness altogether, not even the means of earning a bare subsistence. 
A parallel to the normal attitude of the world towards science and its application, respectively, may be found in its attitude towards the musical performer and the musical composer. The musical world will go wild with enthusiasm over the perfect rendering of any of its favourite compositions, and will shower upon the skilled artists wealth and honour. But the man who created the music, an infinitely rarer kind of genius, probably had difficulty in obtaining a bare livelihood by his art, and would have just as much difficulty, if he lived now, as he would have had in past times.

Science in the capacity of the creator of knowledge is esteemed as little by the world as creative work in art, literature or music. Not that it is not appreciated in theory, but the appreciation so lags behind the accomplishment that the creator has ample time to die of starvation. Yet this is the science from which fundamentally all the benefits of modern civilisation are derived. This is the science that has made it possible for us to-day to afford to wage war on a thousand-fold more extravagant scale than ever before in history. This is the science that is to pay the bill if it can be paid without a general depression in the standard of living below the level of decency for the many, and which alone, after the unparalleled waste of the past two years, given fair play, can hope to keep the wolf from the door. If one judged from history solely, bad times must follow the present orgy as night follows day. The only question is whether science, which in the past century is estimated to have increased the wealth of the world a thousand-fold, will not also make each million of debt now incurred bear no more heavily than each thousand did upon our unsophisticated ancestors. 
It is low ground to plead for fair play to science. It is the ground of the hymn-

"O Lord, we know that all we give Will be a thousand times repaid."

I suppose most of my hearers, like myself, have outgrown many of their rooted convictions of two years ago many times. Great changes have come over all of us, and greater will come, perhaps, when the full tide of our manhood, who have sacrificed all they had and sunk their individual interests and aspirations in the general social weal, returns. The particular faith in me that has undergone eclipse at the moment is a faith in democracy, and if an aristocracy of intelligence were practical, I am afraid I should vote for it.

The one problem that it seems to me has not been solved by this democracy, if it is a democracy, is that of finding each man his proper life-work and then letting him do it; and, until it is solved, the complex organism that the modern State is, must remain a heterogeneous collection of individuals rather than a community. Perhaps it is that two of a trade seldom agree, but I have never been wildly enthusiastic of German science. I admire it, of course, as much as any, but what I mean is that I never have believed that, compared with that of the rest of the scientific world, it was at all pre-eminent. Germany is not a democracy, and I have no love for her political system. But it is indisputable that Germany uses her people to infinitely better advantage than we do, and that there is in the State a power of finding, for the infinitely complex and varied needs of a modern nation, the infinitely complex and varied individuals necessary each for their particular job. Here we delight in racing cart-horses and leaving Derby winners to haul coal. 
As regards the most important and fundamental things of life-such as, to mention only as illustrations, the number of people that can be supported in a given country in a given standard of comfort and affluence, the amount of food the country can grow or buy, whether it can outpour from its superabundance into the less fertile and more necessitous countries of the earth, or whether it remains a malaria-haunted or fever-stricken jungle, ruled by the mosquito-the 999,999 out of the million have no direct say whatever. It little matters whether they are an absolute monarchy like Russia, a republic like France or the United States, or, to come to this country, whether they are ruled by an aristocracy of blood, an aristocracy of wealth, or the loudest of cheap presses. These questions are settled otherwise in the laboratory by men, sometimes, as in the case of malaria and yellow fever, with the special problem to be solved before them, more often impelled by a divine curiosity and the desire to know and understand Nature for her own sake and the sake of truth, and without any care whether or not all the labour and thought they expend in the search will or will not be repaid in increased good to the community.

Now, willing enough as I am to subscribe to the doctrine that every one born into the world may be a potential Faraday, a potential Newton, or a potential Pasteur, I am absolutely certain that the 999,999 out of the million are in fact nothing of the kind and never could be, even if they had the laboratory resources of the whole world put at their disposal, and Faraday, Newton and Pasteur reincarnated to serve as their professors.

What applies in science applies everywhere. The creative element is not the only element, but it is the pace-maker of progress and civilisation. For 
one that leads a thousand can follow, and, when the path followed is the path of natural knowledge, each of these thousand can teach another thousand new means of livelihood.

You cannot starve into non-productiveness a poet, an artist, a parson, or any great thinker of the old type, nearly as easily as you can starve a scientific genius. Because they are more self-contained. To them the brain is both the raw material and the machine for finishing and producing it. But, to the devotees of the newer philosophy, the raw material is not in the brain but is to be sought for in external nature; and in handling this raw material, mastery over materials by scientific methods of experiment is, at least, of equal importance with mastery over the processes of thought. In other words, laboratories are required, and, though an artist without a studio, or an evangelist without a church, might conceivably find under the blue dome of heaven a substitute, a scientific man without a laboratory is in most branches a misnomer.

As science advances and most of the more accessible fields of knowledge have been gleaned of their harvest, the need for more and more powerful and elaborate appliances and more and more costly materials ever grows. Yet, if one-tenth of one per cent. of all the added wealth that scientific men have, without acknowledgment and without reward, earned for the community were repaid, it would suffice them, beyond their wildest dreams of avarice, for laboratories and maintenance.

Suppose, then, we have found capable scientific men, not necessarily any outstanding genius like Newton, not one in a million, but say we have picked out the best of every thousand in the community, the chances are that the thousand, which we have picked out of a million, will contain any potential 
Newton the age may have produced, and a number of thoroughly useful understudies as well.

Many people suppose thereby that the work is finished and all has been done that should be done. They have forgotten, however, the primary purpose it was all about. The problem which I stated that this democracy has not solved is the finding for each man his proper life-work and then letting him do it. We have assumed, in our discission of the relations between science and the State, that the men to advance science and the buildings in which they are to work have been found. It remains, therefore, only to let the scientific men alone to do their work. But this is precisely what is almost never done in this country. The candidates go through a long and severe course of training, selection and apprenticeship at apprentice's wages, fitting themselves for their life-work. They must show some evidence of the capacity of making original investigations and discoveries before they are put in charge of one or other of the laboratories of the country, and when they get there they teach.

Now the teaching and training of students for scientific professions and for scientific investigation is almost as vital and important to the welfare of the country as the making of scientific discoveries. But it is a totally different business to that of scientific investigation. Some try more or less successfully to do both, but, in Scotland at least, it is the teaching function of the university, rather than its equally important function as the natural home of scientific investigation, which has hitherto claimed an altogether disproportionate share. I cannot recall a single Research Professor in any university of the United Kingdom. In America, Johns Hopkins University, for example, entirely devotes itself to research. Here everything else comes first. Re- 
search is not treated as anyone's business in life, but as a thing to be pursued as a hobby in odd moments between the various and manifold duties of a professor and his staff, and in vacations.

But teaching research-that is again a serious business. It would be a thousand pities if some potential genius, for lack of research scholarships and fellowships, was lost to this country. Everyone must have at least a chance of proving their capacity for research. Most excellent. But what I want to know is why trouble if, as soon as that capacity is proved, the possessor is to be put in a position where it will never again be possible for him to devote himself to research as a business, but merely as a recreation in the interval of teaching! Before the war, at least, these research scholarships and fellowships were a veritable cul-de-sac to the many, through the general apathy and neglect of science by which this country is distinguished. There literally were not teaching posts, let alone research posts, open for more than a very few of the successful. Too many found themselves stranded without any opening whatever, whereas if they had eschewed research and devoted themselves to any ordinary profession, a very much lower scale of capacity would have ensured them an ample and expanding livelihood.

Extravagant comparisons have been appearing in the press lately between the Scottish and the English educational systems, in favour of the former. But if this is justifiable at all, it can only be with regard to one side of the question-the education of the general masses of the population, and that, admittedly, refers to a past generation rather than to-day. In regard to this equally important question of scientific research and investigation, Scotland is as far behind England as England is behind the rest of 
the world. In the newer uriversities of England, in Manchester, Leeds, Liverpool, London, and so on, there is at least an honest attempt being made to make them real homes of research. In Scotland, the country to which Mr Carnegie, in 1901, gave a million pounds for this very object, the money has been largely diverted from that purpose, and routine teaching is yearly absorbing a larger part of it.

To sum up, scientific research is capable of raising the general standard of life, without limit, by the solution it affords of the material and physical problems that prevent progress. But for it to do so, it must no longer be treated as a hobby or parttime occupation of the leisure hours of busy teachers, engaged in catering for the needs of the multitude in education, but as a serious business distinct altogether from teaching, perhaps the most serious and momentous of all the manifold activities of the State. For from it flows the knowledge of Nature, upon which every advance that governs the material prosperity of the nation depends, which the inventors, technologists, engineers and medical men apply to useful purposes, and which, through them, makes all the difference between unemployment and prosperity, disease and health, retrogression and progress, and lastly, which, in time of war, is as necessary to the defence of the realm as the courage of brave deeds and the endurance of stout hearts. In its highest and most fruitful forms scientific research needs that same overpowering and divine passion for truth, that horror of, and detestation for, even the shadow of a lie, which is the common necessary antecedent of all forms of creative work. But it needs laboratories and special homes for its successful prosecution, freedom from interruption and distraction, and a lifetime's devotion-all of these, always as it progresses, more and more. It is, if only for these reasons, more 
easy to stultify and prevent than any other form of creative work. In itself, it may make little or no general appeal to the aspirations and instincts of the community, whose material interests nevertheless are practically governed by it.

The problem of how this is to be achieved, as well as the satisfaction of the educational needs of the multitude, a totally different question, is the problem which, in my opinion, this democracy has not solved, and which it must solve if it is to justify its right to survive. 


\section{THE FU'TURE OF SCIENCE, AND WHAT BARS THE WAY ${ }^{1}$}

THE future of science is a fit subject for the consideration of the Aberdeen University Scientific Society in these days when everything is being cast into the crucible of war to be consumed or refined. I have added to the title, "and what bars the way," because I believe that active opposition has still to be overcome before science takes its rightful place in the Scottish universities. Indeed, one has only to contrast the growth and power of science in the outside world, not merely the world of things and facts, but equally the world of ideas, with the position it holds relatively to the so-called classical studies in the ancient universities, with the possible exception of Cambridge, or, again, to contrast these with the new universities that have sprung up in England and Wales, to realise that the older institutions have lost whatever capacity they may once have had for intellectual leadership, and toil painfully behind the times, a clog rather than a stimulus to the coming task of national reconstruction. The period of outspoken, honest opposition and hostility to science of a couple of generations ago on the part of those whose most ancient and cherished beliefs had been rudely overthrown by the growth of our knowledge of external nature, has given place to a far more

1 Presidential Address to the Aberdeen University Scientific Society, 3rd November 1916. 
insidious and deadly secret distrust and hostility to science, on the part of those left still with power and influence in the councils of the State. This second phase, meaner in motive than the first, derives its strength from a negative source, far stronger than any downright antagonism, from sheer mental inertia and the comforting belief of the masses that the world is big enough and lazy enough to swallow up science without really departing, by a hair's-breadth, from any of its former habits of thought, or relinquishing any of its old, inefficient, empirical methods. As one of the few clear decisions yet reached by the war, this second and infinitely more dangerous phase of hostility to science has, I believe, received its death-blow. Whether its end be lingering or sudden it is too soon to say.

The curricula of ancient universities accumulate rather than evolve. The new cult of science is sandwiched with a culture that came to maturity thousands of years ago. Nothing is ever abolished from the curriculum. If there were real freedom of choice, the survival of the fittest would operate. But the whole system of bursaries and regulations for degrees is to bolster up and perpetuate a museum of ancient learning, and the system of finance to divert to its support the resources needed for living subjects. What Sir Arthur Evans has characterised as the dull incuria of the parents to intellectual pursuits allows it. The result is that the ancient universities become, not by any means the quiet sanctuaries of ancient learning, which would be relatively harmless, but the active agents in perpetuating in power a type of man who is hopelessly out of tune with his environment, however rational he may have been in the Middle Ages. Then Latin was much what Esperanto is trying to become to-day, a universal written language, and as necessary 
to every student as a knowledge of technical French, German or Italian is to the student of to-day.

Most of those who otherwise would be attempting here to reconcile to their digestions the varied menu of the feast of learning are away attempting a more practical reconciliation on the battlefields of Europe. There all the discoveries and inventions of modern times, capable of being twisted by human ingenuity to the purpose of destruction, are being pitted against one another in the defence of those primal instincts of national honour and safety which we inherit from ancient man, and to the strength of which, it has been remarked with universal satisfaction, education has added if possible a more terrible pertinacity and devotion.

What will be the nature of the reconciliation? I am not thinking even vaguely of the terms of peace, the new map of Europe or future forms of government. We have reached a stage in the evolution of the world when something has to give.

That something has already given is fairly obvious. Every enthusiast deems his hour has now come. The war, we hear, is to produce a great spiritual revival, and the thoughts of men are to be turned from their practical and material concerns to higher things. Or, if we listen again, science is coming to its own to regulate all the affairs of a nation chastened by catastrophe to a fitting sense of its colossal folly. One cries that the go-as-you-please existence of the British Empire is at an end, and every citizen is to be trained to bear arms to defend his country and to carry into the avocations of peace the spirit of co-ordination and subordination to a common purpose learned in the barrack-room. While another cries, and the cry seems to lose its ring of confidence as the struggle lengthens, that this war is a war to end war for ever. 
Merely to enumerate a few of these antagonistic aspirations is to show that no decision has been reached as regards them, nor indeed can be till a decision is first reached on the field. It is merely as though the bottom had dropped out of the mill-race of human emotions and each jostling element in the turbulence, suddenly relieved from the antagonism and obstruction of its neighbours, had sprung forward crying victory. Yet, all are agreed that little in our daily lives will be the same as it was before the war. The universities of the future will certainly not be, as in the past, proud to be considered the last sanctuaries of lost causes. But there is one definite decision that has been reached, whatever be the issue of the conflict, which concerns us deeply, and that is that science, whether it be loved or hated, whatever else be relegated to a museum of antiquities, is absolutely essential and indispensable if the nation is to survive either in war or in peace. Magna est veritas et prevalet.

The reconciliation that will be arrived at on the battlefield will be a reconciliation of exhaustion. The reconciliation that will endure must be one between the old in thought and manner and the new in things, which can no longer co-exist. The humanist, the student of man, must admit into his world the science of the external universe, and modify his ideas accordingly. Instead of his being the central figure in a system of his own creation, man is being constrained to move in an orbit by a power external to himself. The battle between the old and the new has but lately been joined in earnest. But the incongruity of the battlefield - the most wonderful and terrible of scientific weapons, submarines, dreadnoughts, zeppelins and aeroplanes, each a mass of the most ingenious and beautifully constructed scientific machinery - grappling on behalf of political 
systems that are mouldering and codes of international ethics that are frankly savage-is but a symptom of the age. The antinomy between the old and the new is to be seen in its greatest perfection only in the ancient universities. As the child is father to the man, it is in the schools and universities of a country that the horoscope of its future is cast. They are the microcosm wherein is to be sought the discordant elements which have to be reconciled. But this is a reconciliation which must begin a generation or two before it can mature, and in this reconciliation the council-chamber is world-wide and the plenipotentiaries are university teachers and schoolmasters.

It is the growth of the power of things over ideas, of science over instincts, of external nature over human nature, that gives to the problem of war its only feature of novelty and therein its only hope of solution. Science now forges the thunderbolts that Jove is pleased to hurl. It has displaced Ceres the giver of harvest, Mercury the messenger of the gods, and well-nigh all the ancient deities, save Jove. Jove remains to cultivate the artistic temperament on the top of Olympus, dissipating on his loves and his hates, his fears and his jealousies, the resources of a world which he is powerless to replenish, and which has outgrown him.

The older subjects have one great advantage over science. In the course of their long history they have developed an unrivalled vocabulary of vituperation and contumely for poachers in their preserves who have sneaked in in disguise. Would that they might occasionally direct it against those amongst themselves who are for ever discussing science and scientific research, and are as intimate with either as I am with the Greek drama. Indeed, thanks to the compulsory Latin and Greek in our early education 
and to the absence of compulsory science in theirs, the comparison is unduly favourable. We are told that science is materialistic and concerned with the bread-and-butter side of life, whereas the humanistic studies elevate human character and inspire human ideals. Our criticism of these studies is that the elevation of human ideals and inspiration of human character has not progressed to keep pace with the growth of physical power put into the hands of men by science. They are ideals that cannot co-exist with science without wrecking the world. As for the bread-and-butter libel, our trouble is that scientific knowledge and capacity in this country has been valued so cheaply, whereas the road to prosperity and honour has lain along the well-beaten and timehonoured road. The smallest acquaintance with the history of scientific progress would disclose what is a commonplace to scientific men, that all the grandest discoveries which have been subsequently exploited for utilitarian ends and have brought in untold millions of wealth to the commerce and industries of the country, have been made uniformly by men, without reward and without even the thought or expectation of reward, labouring solely for pure love of Truth. We are warned with unconscious humour of the danger "of the divorce of science and the scientific spirit from literature and art, from morality and religion, and generally from the human element of education." But the scientific man is not especially deaf to the appeal which literature, music, painting and sculpture, the ethics of human conduct, morality and religion make to mankind in general, though he may be more conscious of their limitations than others. It is the ordinary man and his instructors, the statesman, the headmaster, the poet, divine and artist who, too often, through defects in their early education, are both blind and deaf to the spirit of 
science. Their present attention has been directed to its existence by the fear of annihilation, and their interest is mainly in its profanation to the purpose of destruction.

They inhabit a world a thousand times more wealthy than their predecessors did, but they do not understand why. They can wage war on a thousand times more lavish and destructive a scale, but it is not to them that the world can look for recuperation. Science, which has enlarged the heritage of man beyond reckoning, and which promises to enlarge it beyond the dreams of phantasy, is a sealed book to the majority, more than any other branch of human activity and endeavour at the present time. The opponents of science are already arguing for the retention of everything that is time-honoured and classical in our curricula alongside with what is essentially modern and of present-day significance. It is not so much that the subjects they represent have no present-day application as that, as they represent them, in complete isolation from the main development of scientific thought, their influence has become pernicious and a barrier to a properlybalanced co-ordination between the old and the new. Every argument they use against scientific specialisation untempered by humanistic influences applies with much greater aptness to their stereotyped humanism, uninstructed by knowledge of the external world, and incapable of adapting itself to a world of men which has changed in essential respects more in the past century than in the whole previous period of recorded history. If they are incapable of growth and development to keep pace with the growth of science, if enthralled with the contemplation of the world as it was they cannot envisage the world as it is, science would be the last to deny them a sanctuary in the ancient homes of learning, but 
science does deny them the right or the power to mould the destinies of the present or of the future. But a sanctuary in which to keep alive the memory of the glories of departed times is in fact the thing they dread most. They claim nothing less than that their decadent humanism shall continue to be in the future, as it has been in the past, the sole avenue to positions of lucre, honour, opportunity and influence in vast fields of State service-a claim that is preposterous, and from which the present holocaust became possible.

No man can serve two masters, and, if he is a man not specially endowed with moral courage or special enthusiasm and talents, he will be but human if he elects to serve that master with most power in the State to start him on a prosperous career. Science has hitherto had little or no power to do that. The Civil Service is but one specially notorious instance, but it must suffice. Eminent scientific men have recently decided to insist, as a practical step towards the accomplishment of what they have been advocating for seventy years, that capital importance be assigned to the natural sciences in the competitive examinations for the Home and Indian Civil Service. Hitherto these examinations have been regulated by the desire not to secure the best men, most suitably trained for their work, but rather to secure men from particularly favoured universities, especially from Oxford. Science is not of any capital importance, and a man professing a group of the natural sciences as his central subject could only be successful by a miracle. If you wish to laugh, you should read the imaginary interview between a candidate and the Civil Service Commissioners in Science Progress for July IgI6. Ridicule is the only weapon against such folly. 
Unfortunately, however, the times are too serious for ridicule. At the first prick of the lance of a scientific enemy, the indispensability of science to the nation, if it is to continue to exist, became for the first time universally recognised. Were she all that her worst and most ignorant detractors have alleged, wooed she must be in earnest now, if only for the defence of her superior sisters. Before that realisation, every sort of objection that cant has hitherto invented to bar the way must now go down. We shall be a stronger people in future in the competitions of peace, as well as in the actual struggle of war, in consequence, but this will be but a small gain indeed compared with what we shall become if science teaches the nation to recognise Truth apart from traditional belief. To those to whom science is associated only with the carnage of the battlefield or with the hubbub of the market-place such an aspiration will be unintelligible. Nevertheless, to-day, in the orgy of lying which has accompanied the war, scientific truth is the only aspect of truth that has not been cheapened and made nauseating, and which stands so far above all personal prejudice and passion as to be unshaken. Until a similar veracity of thought and action becomes universal, there can, in the words of Huxley, be no alleviation of the sufferings of mankind.

The cult of science is becoming daily, almost hourly, more difficult to gainsay, but, in the curricula of the ancient universities, a culture that reached its zenith before the birth of Christ still struggles to retain its complete ascendency in human affairs and over the human mind. It has been said of mathematical analysis that it is merely a mill. Nothing can be got out in the answer, which, wittingly or unwittingly, was not introduced in the 
enunciation. But the same is generally true even of the humanistic and scientific philosophies. The mind is merely the mill, and what comes out depends only on what you put in. This does not detract from the value of the process, assuming, of course, as in mathematical analysis, that the mind is capable of reasoning correctly, and does not introduce errors of its own. In every sphere the solution of a problem is a vastly important step forward from its enunciation, though errors usually arise from the latter rather than from the former.

The humanistic philosophy feeds its mill with man and it gets out man. Man is the raw material, the reasoning machine, and the sole judge of the product, whether it is true or false, noble or base. Thinking that he was appealing beyond himself to a higher external power, and often indeed claiming direct inspiration therefrom, he created deities in the image of himself, and endowed them with various aspects of his own nature. There was no break in the vicious circle of thought, no real appeal beyond his own instincts and intuitions, until men of science, in their study of the laws of external nature, became acquainted with a very different and totally impersonal aspect of Truth, and a very different ruler of the universe than that which hitherto had appealed to the uninstructed and self-centred imagination of man. Now, in so far as the realm of external nature interacts with, and in the most fundamental sense possible, absolutely controls humanity, the mistake of neglecting it is serious. Conclusions which may have appealed irresistibly to the jury of the human intellect for thousands of years may be false, and may indeed raise the question whether man in fact is not essentially insane. That would certainly be the verdict at the present moment, if any outside rational being surveyed the world, seeing nothing but the 
physical aspects of the present struggle. Hitherto, Nature destroyed merely such men as got in the way, by chance and without any design, vindictive or benevolent. But now, for the first time on such a universal scale, Nature is organised to the uttermost by man with the design of destroying man, and there can be no question of her powers of accomplishing the work to which she has been put. Philosophies that have come down to us from the day of the wooden horse of Troy are not capable of dealing with such a new fact.

In the experimental philosophy of science the raw material is not man, but the ascertained facts of external nature so far as these can be discovered and established. The mill is still the human mind, but the raw material is external to and independent of the mind. That this is so is evidenced by no dialectical argument, but by the state of the world to-day and the progress it has made in the last hundred years, since the new philosophy reached its general and consistent fruition. Errors are still possible, as the mind still enters into the conclusion. But the mind is not now trying to lead, to dream dreams or to see visions, but "to give up every preconceived notion and to follow humbly wherever and to whatsoever abysses Nature leads," as Huxley said. The consensus arrived at when a number of minds, so striving, reach by different roads the same result in their pursuit of natural knowledge, is unique. The Oriental mind, as the Japanese and Hindu students of science have shown, meet on common ground with the American and European mind in the pursuit of natural science. Science is the only aspect of Truth that is universal and independent of the barriers that divide East from West and people of one religion from those of another. The mind is no longer dealing with its own unverifiable impres- 
sions. Nature is in the witness-box and experiment is the interrogating counsel. Provided the counsel is skilful and Nature communicative, the jury honest, receptive and free from preconceived opinion, the decision is true not merely to the canons of human reasoning, but true also to external reality. The verdicts of the humanistic and scientific philosophies differ from one another, as the rule rather than the exception, as much as did the Pythagorean and Copernican solar systems, when external reality is involved, and, after all, how often is it not? Just so far as the raw material is not concerned with man at all, directly, and in direct ratio to the extent that it is not concerned with life at all, other than the purely mechanistic and physico-chemical aspect of the vital process, a new world opens out independent of and hardly dreamt of by the older philosophy.

$\mathrm{Mr}$ A. J. Balfour, in his Glasgow Gifford lectures, has done good service by pointing out how, time and again, in the science of the inanimate universe, among some of the more fundamental theories, that particular theory which, as the subsequent history of science has shown, is destined to survive, has appealed irresistibly, and in the teeth of apparent evidence to the contrary, to the human mind as correct, generations or centuries before anything like a rigid or even satisfying proof was forthcoming. It is to be hoped that this may do something to stimulate interest among scientific men in a subject which has been distasteful ever since Bishop Berkeley made the impressive discovery that if you do not put the world of external reality to begin with into the mental mill, you may go on turning it for ever without it coming out.

In certain spheres, which daily and hourly are enlarging themselves to embrace more and more of our daily life, and to be fraught with 
weighty consequences to man, in departments where hitherto the humanistic philosophies have been supreme, the old intuitions have melted away in the light of science like snow in the light of the sun. In these spheres the world is, as it were, emerging from beneath an accumulation of perennial snow, which descended lightly, graciously and imperceptibly enough, but is now compacted into unyielding fetters, melting, it is true, but how reluctantly! Granted there may be heights above the snow-line which the rays of the sun can only beautify and render the more dazzlingly white, granted there may be deep valleys penetrating down to the common level to which the direct rays of the sun can never find access, the kiss of science is on all the fields wherein men labour and earn their bread, and it is only a matter of time before the frozen grip of the past relaxes for ever. An exuberance as of the Alpine meadows in spring will alternate with the desolation wrought by the avalanche, as the new influence unbuttresses the old polities and brings them roaring down. As the geologist of to-day will show you the scars that the surface of the earth still bears from the time when the glacial epoch relaxed its grip, so the conflict now fairly joined between the old and the new will not end without leaving scars as enduring and effecting changes as great.

The suddenness of the change would in any case have created a condition of things dangerous to live through. But it has been rendered immeasurably more dangerous and incalculable in this country by the attempt that has been made to put the youth of the nation into cold storage, to foster a love for a régime that is ending, never to return, to sow in the cradles of the future a secret contempt for and distrust of science and its methods, ineradicable save by death and impotent 
save for evil. The great function of death is to rejuvenate the world perennially, and to keep it in tune with a changing environment. Our wise men have tried to defeat it by drilling the oncoming generations in the dead languages and humanistic philosophies and religions of their forefathers, and the transitional period ahead promises to be most uncomfortable in this country.

But it has now been borne in on the consciousness of the most reactionary that for the State to leave science to the tender mercies of its priests and humanists is to ask for extermination. Our boasted moral superiority over our enemies can only make us deserve victory. Science alone can achieve it on the battlefield, and safeguard it subsequently. We may pray for rain, but as a shrewd clergyman once remarked, "What is the use of praying for rain with the wind in the east?"

Hitherto the war has been represented as originating in mistaken ideas of Right, but it equally is due to mediæval ideas of Might. The professors of history and politics and the military publicists of Germany, who revived and made palatable the ancient doctrine of "Might is Right," intoxicated, no doubt, by the new weapons and inventions of science, regarded them from the childish standpoint of the savage. These old ideas cannot coexist with science. If they involved merely the destruction of those who held them it would be just, but they jeopardise the whole race.

If the task of altering the character of a nation's education is, like afforestation, slow in its fruition, when accomplished it resembles rather the processes of geology in its initiation. Chemistry emerged as a science from being the handmaid to medicine 250 years ago, but in the Scottish universities its recognition, as a separate subject of 
education, apart from medical education, belongs almost wholly to the present century. Time was when learning and religion were synonymous, and culture and scholarship were the exclusive pursuit of the religious orders, who alone could read. The emancipation of learning from religion occurred with the Renaissance, but the two are still confused in the education of the school. I visited this summer a small place in Aberdeenshire, too small to be deemed worthy of a post office, a telegraph or telephone, but boasting two schools, a Roman Catholic and a Protestant school. It reminded one of the lines from lolanthe-

"For every child that's born into this world alive Is either a little Liberal or a little Conservative."

Happy is the nation that has already settled such questions as this. It is idle to cry peace where there is no peace. Between the spirit of science which welcomes criticism and knows no finality in its beliefs, or authority to impose them, and the spirit of the old creeds which, to survive, must entwine themselves with the immature intelligences of children, in the name of and in the place of education, there can be nothing in common and no real reconciliation.

I now wish to consider one or two of the barriers to the proper growth and development of science in this university. On the educational side the traditions are all in favour of breadth or shallowness as against narrowness or depth, according to which point of view you take. My own view is that education, whether in the classics, mathematics or in science, must be deep before it can be broad. To a man who has plumbed the depths of a single subject the whole world takes on a new meaning. $\mathrm{He}$ sees causes at work where another sees only confused effects. His education is only beginning 
where that of a man, who has achieved breadth without depth, ends. $\mathrm{He}$ is curious, his relative ignorance of other subjects than his own, and their freshness to his mind, make him so, whereas the other is satiated with imperfectly appreciated subjects which he thinks he knows, and he becomes dull.

I do not express myself on this matter as strongly as I might, because I know that I am against a tradition which in the past has paid. If I express an opinion at all it is because I cannot see, in the more strenuous times of the future, any chance of its continuing to pay, either in Scotland or elsewhere. The day of the amateur-Jack-of-all-trades and master of none-whether in government and administration, teaching, industry or commerce, seems to be definitely terminating as each country becomes less and less a self-contained community and more and more open to the competition of the world. If specialists are not turned out we shall be dependent upon them for the foreigner. I have no great assurance, in spite of the present revulsion of feeling, that ten years hence will not see our industries dominated by foreign chemists again, not because of any defect in the British chemist, but because of the appalling ignorance on the part of his employer and his total inability, engendered by his training, to appreciate what is new, not as something to be added on and made to accommodate itself to the old, but as replacing and totally expunging it.

The bursary system is one of the most potent factors in preserving the education of so many of our students upon traditional lines. Intended as an encouragement to picked students to come to the university to cuntinue their studies and complete their preparation for life, it has become a bribe to them to continue studies which otherwise would attract only a few, and those mainly to whom the 
necessity of earning a living in the modern world is not paramount.

The linguistic and historical group of studies are a common part of all general education. It is not these subjects in themselves but the spirit in which they are taught that the cause lies for criticism. Many people must have felt the humiliation abroad of being conversed to in their own language by a foreigner who has never set foot in this country. I envy the lads in modern technical colleges who are given a grip of the calculus, as a tool rather than a philosophy, at the time when my own efforts were being dissipated on the most useless and uninteresting parts of mathematics. I often say that I could not without a serious preparation pass the entrance examination into any university in the kingdom. It is idle to pretend that these are in any sense tests of a decent general school education, as they should be. It is supposed to be general, but is too often so highly specialised that no one, whatever his education, could pass it ten years after leaving school or college, without specially studying for it. Once, in some spare time, I entertained the idea of sitting the London University Matriculation Examination until I found that the English demanded was not what an ordinary man would think was meant, but an obsolete form of it, dating from the time of Chaucer and earlier, a most excellent and repaying subject no doubt for those who require it, but as far removed as Latin and Greek are from being evidence of a general education.

If the school curriculum were entirely recast along modern lines and subjected by unprejudiced experts to a thorough investigation, as is being done in some of the institutions for educational research in America, in order to eliminate what is unnecessary and retrograde, the school period ought to suffice to give 
every child of the standard of intelligence admitting to the university so thorough and sufficient a general education that, at the university, the serious life-work could be entered upon at once. A modernised school curriculum, finally and completely liberated from the deadening influence of the Middle Ages, would bring a child up to the university with something of that enthusiasm and passion for knowledge for its own sake which, of yore, was the pride of Scotland's poor scholars. "Cultural" subjects would remain, throughout life, the natural recreation from professional or highly specialised studies. The chief charge against the old curricula is that they destroy in youth the enthusiasm and aspiration for learning, without which educational systems are but useless machinery without motive power.

In experimental science in Scotland the greatest need for reform exists. The association of the Honours M.A. with the B.Sc. so favours certain subjects, especially mathematics and applied mathematics, by giving two degrees for little more than the work of either, that it has been a powerful factor in the neglect of experimental science. It is nearly incredible, but, until very recently here, and possibly elsewhere still, those who took this combination and were for the most part going to be science schoolmasters, were turned out to teach chemistry in schools without, of necessity, ever having worked in a chemical laboratory. What sort of chemistry, I wonder, is it that they hand on to their pupils. The science of the mathematical arts man with M.A. (Hon.), B.Sc., is too often such as is calculated to bring science into disrepute.

But it is on the financial side that this university is most open to criticism in its treatment of science. An investigation of the published accounts for I913I4, the year prior to the war, explained much that 
hitherto had been a mystery to me and left me frankly astounded. I have formed the deliberate opinion that it is useless for benefactors, like Mr Carnegie, to give money for science and scientific research, because under the existing system it will be diverted. Chemistry here would have been actually better off under the system that was in vogue before 1889 . The wealth that has poured into the coffers of the university, either from the Carnegie benefaction or from State grants, passes it by. ${ }^{1}$ It supports itself practically by hard teaching, and the money it is stated in the published accounts to get, and which, if it did get, would enable something to be done on the research side, are mere book-keeping transactions. Either this must be rectified or, before science can take its proper place in Scotland, new universities for science and modern subjects must be founded.

But apart from the petty tricks and sophistries by which those who claim to guard the eternal verities against the encroach of modern heresies have secured to themselves the benefit of monies intended for scientific study and research, the general attitude of this country toward science, whether from duliness, ignorance or antipathy, is unworthy of it. Of all the great nations of the earth none have benefited more by scientific discovery, and none have repaid the debt in more beggarly fashion. To boast of what this country has done in science as compared with other nations would be to follow the bad example of Germany. To boast of what this country has done for science as compared with other great powers would be impossible. But it is legitimate patriotism to be very proud and satisfied that, in spite of the lack of adequate encouragement and support, this, country can claim no mean or subordinate share 
in scientific developments even up to the present day.

I have laid these matters before the Scientific Association, not in any spirit of destructive criticism, but because they affect fundamentally and vitally your careers. It is upon you, rather than upon me or upon science, that the penalty falls. 


\section{'THE EVOLU'TION OF MA'T'TER '}

The ultimate constitution of matter is a subject which has always exercised a powerful attraction upon the minds of men. Philosophical speculations of the essential unity of all matter and of the possibility of transforming the different kinds into one another have come down to us from the ancients. The modern science of Chemistry had its origin in the actual attempts at such transformation or transmutation made by the alchemists in the Middle Ages. These attempts centred around the transmutation of lead or other base metal into gold, and the alchemists believed that there existed, and spent their lives trying to discover, a "philosopher's stone" to which was ascribed the power to effect this transmutation in almost unlimited amount. The philosopher's stone was also credited with acting as a universal medicine, prolonging life and health indefinitely, or at least to periods rivalling those enjoyed by the Hebrew patriarchs of old. Whether these ideas were wholly the inventions of charlatans, or whether they were the distorted parrot-like repetition of the wisdom of a lost Atlantis, none can now say. But it may be remarked that sober modern science of to-day sees in the power to effect transmutation of the elements the power to prolong the physical welfare of the community for indefinite periods. Indeed, without some such discovery the phase of civilisation, ushered in by

1 Contributed to the Aberdeen University Review, February 1917. 
science, must from its very nature be but transitory. We are spending improvidently in a year the physical means of life that would have sufficed our ancestors for a century, and the exhaustion of the available supplies of energy, upon which the present era of the world relies, is already no longer a remotely distant prospect.

So long as the world was supposed to be six - days older than man, and man a creature of the last 6000 years, the idea that we were "the first that ever burst" into the silent sea of science was pardonable enough. Possibly we were not. Just as no one would feel qualified to write a history of this country from materials gleaned from the newspapers of the present century, so no one ought to be so bold as to attempt to write a history of the human race from such written records as now exist, the most ancient of which go back to a time when the race was quite inappreciably younger than it is to-day. Neither is there any very valid ground for the belief that the startling advance civilisation had made in the past hundred or so years is in any way the climax or natural culmination of the slow and by no means even continuous progress previously. It seems rather a sudden forward leap apparently unconnected with and certainly not culminating necessarily out of the periodic ebb and flow of human fortune of which history tells. It is the work of a mere handful of men. The mass probably are little more scientific to-day than they were two thousand years ago, and this being the case, the advance does not appear to be the inauguration of the millennium, nor, indeed, of any other prolonged period of stable régime. Nothing but the most sublime egoism, the unconscious constitutional disability of the natural man to conceive of a universe not revolving around himself, can make 
it appear improbable that what occurred so suddenly and mysteriously in the past few centuries of recorded history may not have occurred before, not once but perhaps many times during the vastly longer period of which no record has yet been interpreted. It is only right to consider the possibility that the command exercised over Nature in the twentieth century may have been attained, possibly exceeded, previously.

However that may be, however slender may be the justification for such a view, and still more however fanciful it may seem to seek that justification in the rigmarole of alchemical charlatans of the Middle Ages, the fact remains that science to-day would ascribe to the problem of the ultimate constitution of matter, and the practical achievement of the problem of the transmutation of the elements, an importance and significance that cannot but be flattering to the instincts of the human mind over which these problems have for so long exerted a most powerful fascination.

Twenty years ago not a single valid fact was known to science about transmutation. To-day we may watch it going on, in the case of certain elements, spontaneously before our eyes, as it seems to have been going on, all unsuspected, from the beginning of time.

But till I 896 the universal experience of physical and chemical science was that the atoms of the chemical elements are the ultimate constituents out of which matter is built up and, in all processes then known and in every kind of change that matter undergoes, these remain unchanged and unchangeable. What did Clerk Maxwell say? The words of his British Association address at Bradford in 1873 have often been quoted, but they are so true, not only of the knowledge of his day, 
but are still true of all processes known before the fateful year I896, that they may be recalled again :

"Natural causes, as we know, are at work which tend to modify, if they do not at length destroy, all the arrangements and dimensions of the earth and the whole solar system. But though in the course of ages catastrophes have occurred and may yet occur in the heavens, though ancient systems may be dissolved and new systems evolved out of their ruirs, the molecules ${ }^{1}$ out of which these systems are built - the foundation stones of the material universe-remain unbroken and unworn."

Modern chemistry has at hand incomparably more powerful methods of experiment than were known to the alchemist. But the foundation stones of the material universe still remained unbroken and unworn.

After having been attacked without success by the alchemist with fanatical fervour and devotion, after having eluded the utmost efforts of the chemist to change them, until at last he had accepted his defeat as the firm basis on which to build his science, the eighty or so elements, that had been discovered and recognised, possessed a reputation for permanence and unchangeability that was unique in the whole universe of reality. Thus far and no further into the analysis of matter experiment had penetrated. Beyond there was nothing but speculation and imagination-plenty of both, but not of much value in science, apart from experimental knowledge, and least of all, perhaps, in favour with the "sceptical chemist." He knew the elements as a shepherd is supposed to know his flock, their properties, the

1 Clerk Maxwell was a physicist. If he had been a modern chemist he would have used the word atoms where he uses molecules. 
compounds they form in such wealth and variety, their spectra, and the relative weights of their atoms, down to the merest minutiæ and with an accuracy unsurpassed in quantitative science.

He discovered the most curious family resemblances between them, some being so similar in their whole character and so regular even in their differences that no discipline of the imagination could entirely suppress the private question, "What are they ?" even though the memory of those early heresies about transmutation and the unity of matter made it bad form to romance about them. Lastly, he made, when he put out the elements in the order of the relative weights of their atoms-beginning with hydrogen, the lightest atom, and ending with uranium, the heaviest-a sweeping generalisation about them known as the Periodic Law. Essentially this is that nearly the whole of the properties of the elements are periodically recurring functions of their atomic weights. The tenth element in the list has a close family resemblance to the second, the eleventh to the third, the twelfth to the fourth, and so on to the seventeenth which is like the ninth. The eighteenth is like the second and tenth, the nineteenth like the third and eleventh. Hydrogen, the first element, stands alone and has no analogues. After the twenty-second element, titanium, a change in the nature of the periodicity occurs, which becomes more complex. Another very abrupt change occurs at the fifty-sixth element, barium, when the rare-earth elements commence. These, the next thirteen or fourteen elements, all resemble one another with extreme closeness, in direct contradiction to what occurs with the elements both before and after them in the list. At the seventy-third element, tantalum, the law departed from at the fifty-sixth element is reverted to again 
as if it had never been interrupted, and goes on till the last element, uranium, is reached. This was a veritable cryptogram challenging interpretation, and although far from deciphered the first step in the finding of the key has now been taken. The Periodic Law is Nature as it is, not as we would have it, or as we would have made it, if the making of it had been ours. There are some curious minor exceptions even in its very arbitrary regularities. At first, also, gaps had to be left for missing elements to satisfy the scheme, and so the existence of elements not yet discovered, and even their very properties, were predicted, and in the majority of cases these predictions have been verified by the subsequent discovery of the missing members.

With regard to the very simplest constituents, into which the material universe has been resolved, there is thus a veritable tangle of complex relationships in contrast to that craving for simplicity, symmetry, and order which the mind is always attempting to satisfy in its interpretations of the external world.

In 1896 one of the elements, uranium, the last on the list, was discovered by Becquerel in Paris to possess a new property. It was described as radioactive to signify that it was continually and spontaneously emitting a new kind of radiation, analogous in its chief characteristics to the X-rays of Röntgen, discovered the year previously. M. and Mme. Curie then showed that thorium, the element next to uranium in atomic weight, possessed a similar property, but, with the doubtful exception of two others, potassium and rubidium, none of the other elements then known show the least evidence of radioactivity. Going back to the natural minerals in which uranium occurs, such as pitchblende, M. and Mme. Curie discovered therein several intensely 
radioactive new elements in almost infinitesimal quantity, the best known of which is radium. The radium is present in pitchblende in very minute quantity, not more than one part in five or ten millions of the mineral at most. Small as the quantity was, they succeeded in isolating the compounds of radium in the pure state, and ultimately accumulated enough, not only for a detailed investigation of its extraordinary radioactivity, but also of its chemical character, spectrum, and atomic weight. They found its atomic weight to be 226 , which is next to that of uranium, 238, and thorium, 234. This and its chemical character put it into a position in the periodic table in the family of the alkaline-earth elements, comprising calcium, 40, strontium, 85 , and barium, 137. In its whole character it has the closest resemblance to the latter element, and can only be separated from it by prolonged and tedious fractionation processes. Chemically it was normal in every respect, and its chemical character could have been predicted from the Periodic Law before its discovery. But in addition to its chemical character it had a whole new set of surprising radioactive properties in a very intense degree.

These discoveries naturally aroused the very greatest scientific interest. The very existence of radium, a substance capable of giving off spontaneously powerful new radiations which can be transformed into light and heat, and, indeed, not only capable of doing this, but, so far as we know, incapable of not doing it, ran counter to every principle of physical science. For whence comes the energy that is being given out in the process? So soon as pure radium compounds became available, the amount of this energy was measured and it was found to be sufficient to heat a quantity of water equal to the weight of the radium from the freezing- 
point to the boiling-point every three-quarters of an hour. In the combustion of fuel, from which the world draws by far the greater part of the energy it needs, the heat evolved is sufficient to raise a weight of water some 80 to 100 times the weight of fuel from the freezing-point to the boiling-point. Hence radium, weight for weight, gives out as much heat as the best fuel every three days, and in the fifteen years that have elapsed since it was first isolated, a quantity of energy nearly two thousand times as much as is obtainable from fuel has been given out by the radium, and the supply as yet shows no sign of exhaustion.

Before, however, these questions could be asked in this definite quantitative form they had been answered, from a detailed investigation of the radioactivity of the element thorium. Professor, now Sir Ernest, Rutherford, at M'Gill University, Montreal, and now at Manchester University, was one of the leading and most active physicists in the investigation of the new property, and, when the writer joined him in Montreal in I901, had made a large number of very startling and fundamental discoveries, and had developed the refined methods of investigation and measurement which, more than anything else, contributed to the rapid solution of the problem. The apparently steady and continuous outpouring of the radiations from thorium was found to be a most complex process, in which new substances were being continually produced. These new substances are endowed with a temporary or transient radioactivity, which in the course of time decays away and disappears. Simple methods of chemical analysis sufficed to remove from thorium altogether infinitesimal quantities of substances, to which, however, by far the greater part of the radioactivity was due. After removal the activity of these sub- 
stances steadily and continuously decayed. But the thorium from which they had been removed and which was thereby rendered nearly non-radioactive, gradually recovered its original activity again. Investigation proved that the thorium was in fact continually growing a fresh crop of these radioactive constituents. As fast as it was purified from them by a chemical process, more began to form. The quantities of material involved in these processes are so minute that they are far beyond the limit of detection by the balance or the spectroscope. Indeed, it is estimated that geological epochs of time would have to elapse in the case of thorium before a weighable quantity of the new materials was formed. Nevertheless the characteristic radioactivity they produce enables them to be followed and dealt with as easily, or perhaps more easily, than ordinary substances in weighable amount. Moreover, in certain cases the radioactive products are gasescalled the radioactive emanations-and in these cases no chemical separation is needed, as they diffuse away by themselves from the radioactive substance into the surrounding air and are the cause of many striking phenomena.

The doctrine of the unchangeableness of the chemical elements is no fixed article of belief in the chemists' creed, but is simply the expression of the facts known before the discovery of radioactivity, that in all material changes known the chemical elements do not essentially change. When a chemical element or one of its compounds is purified, it remains pure unless it is again mixed with other substances. The discovery that the radioactive substances are continually producing from themselves entirely different chemical elements overthrew the doctrine of the unchangeableness of the elements so far as those that are radioactive are concerned. Since 
these new changes cannot yet be artificially produced or imitated, the doctrine of the unchangeability of the elements remains in this limited sense still true.

Sir Ernest Rutherford and the writer were forced to the conclusion that the element thorium, and ultimately all the radio-elements, are in the process of slow spontaneous change. Their radioactivity is due in large measure to minute quantities of impurities, of totally different chemical character from themselves, that can be readily and completely removed by simple purification processes. But, once removed, the substances so purified do not remain pure. At a perfectly definite rate they regrow or produce the radioactive impurities, and these can be again separated as often as desired. Once separated, the radioactivity of the products dies away or decays, and the apparently steady continuous emission of rays from the parent substance is due to an equilibrium, in which new radioactive products are formed as fast as the radioactivity of those already produced disappears. Very rapidly a complete and satisfactory theory of the whole phenomena was developed, and fourteen years of further development of the science has not necessitated any modification. The atoms of the radio-elements are not permanently stable. After a term of existence which may be long or short, according to the nature of the atom in question, and which for the individual atoms of the same radio-element may have any actual value, but is for the average of all the atoms of any one kind a perfectly definite period, known as the period of average life, the atom explodes. 'Fragments are expelled from it at hitherto unknown velocities constituting the rays, of which more anon. What is left is the new atom of a new element, totally different from the parent. The radio-elements are in course of spontaneous transmutation into other elements, 
and the process proceeds through a long succession of more or less unstable intermediate elements, until the final stable product is reached. In this process energy is evolved of the order of a million times greater than the energy ever liberated in ordinary chemical changes, in which the groups of atoms, or the molecules, change, but not the constituent atoms themselves. The energy evolved by an ounce of radium, in the course of its life, equals that evolved from the burning of ten tons of coal. The period of average life in this case is about 2500 years, which means that $\frac{1}{2500}$ th part of any quantity of radium changes per annum.

The rate at which the various radioactive products change varies very widely. It may be slow or rapid, a matter of seconds or even billionths of a second on the one hand, or of years or centuries or æons on the other. It was reasonable to interpret what Mme. Curie had done for pitchblende in exactly the same way as had been done for thorium, merely extending the time scale. The radium, polonium, actinium and the other new intensely active radio-elements she discovered in such infinitesimal amount in pitchblende were in all probability the products of the change of the parent element uranium. The view carries with it the corollary that, if you separated uranium from radium and everything else completely and left it to itself, in the course of years or centuries a new crop of radium would be gradually formed. The case of radium is specially interesting as it has been established that it is an ordinary element resembling barium, with definite spectrum, atomic weight, chemical properties and position in the Periodic Table. It was one of very many startling predictions of a similar character made as soon as the new point of view was attained. But it has been the last to receive confirmation and the difficulties have been 
great. Were radium the first direct product, the growth of radium in uranium, initially purified completely from it, could be observed in the course of an hour, so excessively delicate are the radioactive tests for this new element. Experiments were started in 1903 in London, continued on a very much larger and more thorough scale in Glasgow, with the aid of $\mathrm{Mr}$ T. D. Mackenzie. Yet in I9I4 the expected confirmation was still not clearly forthcoming. Long before that time it was known that radium was not the direct product of uranium, and that another new radio-element, ionium, intervened in the series. The uranium changes into radium, via ionium, and this ionium is an exceedingly slowly changing element in comparison even with radium, not more than about $\frac{1}{100,000}$ th part changing every year. This retards enormously the initial rate of growth of radium and makes it proceed at first not linearly with the lapse of time, but according to the square of the lapse of time. That is, the growth after ten years would be I00 times, and after roo years 10,000 times, that in the initial year from purification. The oft-tested preparations of uranium were transplanted to Aberdeen in safety, and tests since carried out, in conjunction with Miss Ada Hitchins, last year satisfactorily established a growth of radium beyond all doubt in the largest preparation, and showed that the rate was proceeding as nearly as can yet be seen according to the square of the time. The growth of radium was not large. In three years it amounted to $\frac{1}{150,000,000,000,000}$ th of the quantity of uranium experimented upon, and in six years to just four times this quantity. The experiments gave, moreover, indirectly a maximum estimate of the rate of change of ionium as at most $\frac{1}{100,000}$ th part per year. This estimate has now been confirmed and made more definite by some very fine direct work on ionium 
itself at the Radium Institute of Vienna a few months ago, which gives the rate of change as $\frac{1}{145,000}$ th part per year. This is more than fifty times slower than the rate of change of radium itself, which has long been established to be about $\frac{1}{2500}$ th part per year. On the other hand the original uranium is estimated with fair probability to be changing 50,000 times more slowly than ionium, or not much more than $\frac{1}{10,000,000,000}$ th part changing per annum. In the course of $1,000,000,000$ years-a period beyond what even the geologists claim as the total age of the earthhardly more than Io per cent. of a given quantity of uranium would change-through ionium, radium and so on-into other elements. Yet, as has been mentioned, so delicate are our methods, that had radium been the first direct product of the change, an hour's observation on a kilogram of purified uranium would have sufficed to have established the growth beyond all doubt. As it is, the problem took thirteen years. Uranium and thorium are the only two primary radio-elements in the process of change. All the other radio-elements known, and they number thirty-three, are produced from one or other of them in the course of their long sequence of changes.

But what of the rays themselves, the expulsion of which first drew attention to the phenomenon, and which have furnished the necessary experimental means for the study of the whole problem? Like the X-rays, they do not reccgnise the optical properties, transparency and opacity, nor, to a great extent, the chemical nature of the matter in their path. They plough through everything, affected primarily only by the density of the absorbing medium, or by the actual mass of the material in their way. Physicists recognise three distinct types of rays-the $a$-, the $\beta$ - and the $\gamma$-rays, the first stcpped completely by a sheet of notepaper, but by 
far the most energetic and important of all, the second capable of penetrating perhaps $\frac{1}{8}$ th of an inch of glass or aluminium without being totally stopped, and the third reduced to half their original intensity by about $\frac{1}{2}$ inch of lead, though not absolutely completely stopped even by 20 inches. The $\gamma$-rays are far the most penetrating rays known and are really $\mathrm{X}$-rays, but far more penetrating than any that can be artificially produced. They are light waves of wave-length thousands of times shorter than those of visible light, and are probably a secondary phenomenon accompanying the expulsion of the $\beta$-rays. The $\beta$-rays, or $\beta$-particles, are electrons-the atoms of negative electricity divorced from matter, recognised as such by Sir J. J. Thomson in 1897 , but previously well-known in the phenomena of the Crookes' tube. They travel at a speed varying from a third up to nearly the velocity of light itself, which is very much greater than any that can be produced artificially. The $\alpha$-rays, or $\alpha$-particles, are atoms of matter, carrying two atomic charges of positive electricity-just twice the charge of positive electricity that the $\beta$-particles carry of negative electricity-and travelling with a velocity varying from $\frac{1}{20}$ th to $\frac{1}{15}$ th that of light, about a hundred times faster than matter had ever been known to travel previously. Their mass is several thousand times as great as that of the $\beta$-particle, and in spite of their feeble penetrative power, and, at first sight, less showy qualities, over 90 per cent. of the energy evolved in the change of an atom is emitted in the form of these $\alpha$-particles. Much of Rutherford's finest work has been in connection with these $\alpha$-particles.

The early measurements of the mass of the atom constituting the $a$-particle left a choice as to its nature, whether it was an atom of helium or of hydrogen, but strong indirect evidence of a very 
remarkable character favoured helium. Thus helium, though it forms no compounds, is found in minerals containing uranium and thorium, only in the minerals containing uranium and thorium, and always in them. Might not this helium be the $a$-particles fired off from the uranium and thorium in the mineral, and, unable to escape from the glassy minerals, accumulating in the material over long periods of geological time, until its presence was obvious and striking even to the relatively rough tests of chemistry and the spectroscope? Naturally, if one could only get enough radium the point might be tested directly, for the spectroscopic test for helium is very sensitive, a bubble of the gas, $\frac{1}{1000}$ th of a cubic millimetre in volume, that is, $\frac{1}{1000}$ th part of a large pin's head, being sufficient to give the characteristic spectrum. This was in 1903, at the time when pure radium compounds were being put on the market for the first time by the enterprise of the German technical chemist, Dr Giesel. The first thing done with it in the late Sir William Ramsay's laboratory in London was to see whether helium was being generated by it continuously, as should be the case if the $a$-particles were really positively charged atoms of helium. A few milligrams of radium only was available, but it proved sufficient, and the growth of helium from radium was established by the spectroscope by the aid of the beautiful methods of manipulation of gases, devised by Sir William in the course of his investigations on the rare gases of the atmosphere. Later, the writer established the continuous production of helium from uranium and thorium, though here, from a ton of either element in a year, the quantity of helium produced is only $\frac{1}{500}$ th of a milligram by weight-a quantity unweighable on the most sensitive chemical balance-or I I cubic millimetres by volume. Helium has also been detected as a 
product of polonium, actinium and other of the new radio-elements.

Gradually the tangled and complex succession of changes being undergone by uranium and thorium have been straightened out, and it is probable that the work is now complete. Some of the changes require millions of years, some are over in a billionth of a second or less. The atom of uranium expels $7 \alpha$ - and $5 \beta$-particles, in twelve successive changes, one particle per atom at each change. The atom of thorium expels $6 \alpha$ - and $3 \beta$-particles. The $\beta$-particles are atoms of electricity rather than of matter, and their expulsion affects the mass of the parent atom to only a negligible extent. But the $\alpha$-particles are atoms of helium and the expulsion of each particle must lower the atomic mass of the parent atom by 4 units.

So long as the process of disintegration of the atom is proceeding, the rays emitted and the energy they possess afford the necessary evidence for their experimental study. But when it is all over, how are we to proceed? The final product into which uranium or thorium turns, if it is the final product, by hypothesis emits no rays. The quantity produced from any manageable quantity of uranium or thorium in a lifetime is too small to detect chemically. How can we find out even what it is?

There is the method that already had indicated helium as the element constituting the $\alpha$-particle. In the natural radioactive minerals one would expect to find the end products of the radioactive changes in greater or less relative abundance, according as the mineral is geologically ancient or modern. This evidence for long indicated the element lead as the final product of the changes of uranium. To-day we know that the radioactive minerals are in reality geological clocks, and they record more accurately 
than in any other way the age of the stratum in which they occur. In a uranium mineral, for example, each I per cent. of lead in terms of the quantity of uranium signifies the lapse of a period of $80,000,000$ years. Errors of course are possible, if lead should have been an original constituent of the mineral, but these are minimised by taking a large number of different minerals. On the other hand every cubic centimetre by volume of helium per gram of uranium in a uranium mineral signifies $9,000,000$ years, and-as here helium, being a gas that forms no compounds, cannot have been initially present, and as, moreover, some will have escaped - the age of the mineral by this method is a minimum, whereas the age by the lead content may be too high. The carboniferous rocks tested by this new method appear to have an age of some $350,000,000$ and the oldest Archean rocks of over I, 500,000,000 years.

The actual production of lead has not yet been proved directly in the same way as the production of helium has, though, but for the war, in all probability this would now have been accomplished. But even without the actual direct proof of this kind there is practically no room for doubt on the point. Indeed by a very important development, about which a few words may be said in conclusion, we know that not only uranium but also thorium both produce the element lead as the final product, and though the lead from uranium is absolutely identical chemically and spectroscopically with the lead from uranium, yet they are different. Stranger still, the lead which chemists are familiar with as one of the elements is probably a mixture of both kinds.

We have seen that the expulsion of an $\alpha$-particle ought to lower the atomic weight of the element expelling it by 4 units, 4 being the atomic weight of helium. In its transformation into radium, uranium 
expels $3 \alpha$-particles. The atomic weight of uranium is 238 , and that found by Mme. Curie for radium is 226. So far so good. Radium in its further changes expels $5 \alpha$-particles, and the atomic weight of the end product should be therefore 206. The atomic weight of thorium is 232 , and, as it expels $6 a$-particles in all, that of the end product of thorium should be 208. The atomic weight of ordinary lead is $207 \cdot 2$. The atomic weight of bismuth is 208 , but the writer was unable to find in a special examination of over 20 kilograms of a certain thorium mineral even a trace of bismuth, though there was 0.3 per cent. of lead. This definitely rules bismuth out.

In the early months of I9I3 a fundamental step forward was taken into our knowledge of the nature of matter which started from the discovery of the simple complete law of elementary evolution as we have come to know it in radioactive change, which is largely due to two of the writer's old students, A. S. Russell and A. Fleck. The expulsion of the $\alpha$-particle, or the $\beta$-particle, from an atom leaves a new atom with properties different from the parent, but different in a very definite and striking way. If the particle expelled is the $a$-particle, the element after this expulsion invariably changes its whole chemical character and passes from the place it occupies in the Periodic Table to a new place, next but one to it in the direction of diminishing atomic weight. If the expelled particle is a $\beta$-particle the change of place is invariably into the next place in the opposite direction. After three changes in any order, one $\alpha$ - and two $\beta_{-,},-$a very common sequence in the series, - the element returns to the place it first occupied. Its atomic weight is less than it was by 4 units, but in its whole chemical nature and even in its spectrum, it is not merely like its original 
parent. It is chemically identical with it. Elements which so occupy the same place in the Periodic Table and are absolutely identical in all their chemical properties are called isotopes. The recognition of such isotopes is fundamentally new, and cuts more deeply into old-established ideas of the nature of matter than even the surprising discoveries of the genesis of one element out of another.

The present theory of atomic structure is due to Rutherford, and is based on experiments on the course followed by an $\alpha$-particle when it ploughs its way through the atoms of matter. These experiments have shown that the atom consists of a central nucleus, possessing all but a negligible part of the atomic mass but occupying only an exceedingly minute fraction of the atomic volume. The nucleus contains a preponderance of positive charges and is surrounded by an equivalent number of separate negative electrons, revolving in a system around it. This theory lent itself at once to the interpretation of the new developments here referred to, and both together, along with very important work by the late H. G. J. Moseley on the wave-lengths of the X-ray spectra of the elements, have furnished the key to the deciphering of the Periodic Law. It is melancholy to record that Moseley fell at Suvla Bay, aged only twenty-eight.

Prior knowledge of the atoms of matter has been superficial in the literal sense-confined entirely to the outermost shell of the atom. We have now penetrated to the interior and find, first, an inner shell, wherein X-rays take their origin, and, secondly, still further to the nucleus, the sanctum sanctorum of the atom, revealed only by radioactivity and alone concerned in this phenomenon. The same outer and inner shells-that is, the same kind of atom to the older knowledge-may contain demonstrably 
different nuclei. Matter is of indefinitely more kinds than the chemist and his Periodic Law have disclosed.

The places in the Periodic Table represent integral nett charges of electricity in the constitution of the nucleus. The expulsion of the $\alpha$-particle with its double charge of positive electricity shifts the element in the Periodic Table by two places in one direction and the expulsion of the $\beta$-particle, with its single charge of negative electricity, shifts it one place in the other direction. Nature does not deal in fractions of an atom of electricity any more than with fractions of an atom of matter. As we pass from hydrogen, at the beginning, to uranium, at the end, of the elements, we pass 92 places in the Periodic Table, each element differing from the one preceding it by a unit charge or "atom" of positive electricity in its nucleus. Hydrogen has one such and uranium 92 such unit positive charges. The number expressing the element's place in the Periodic Table is called the atomic number. It is the nett number of charges in the atomic nucleus, i.e. the difference between the separate positive and negative charges. Before the discovery of the radio-elements the following represented the last 14 places of the Periodic Table :-

\begin{tabular}{|c|c|c|c|c|c|c|c|c|c|c|c|c|c|}
\hline 79 & 80 & $8 \mathbf{I}$ & 82 & 83 & 84 & 85 & 86 & 87 & 88 & 89 & 90 & 9I & 92 \\
\hline 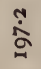 & $\begin{array}{l}0 \\
\text { ¿ } \\
\text { ¿ }\end{array}$ & 哯 & $\stackrel{\text { مे }}{\stackrel{N}{0}}$ & 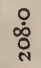 & & & & & & & స్ స్ & & $\stackrel{N}{\stackrel{N}{N}}$ \\
\hline 뭉 & 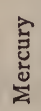 & 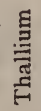 & త్త్త & 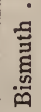 & & & & & & & 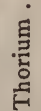 & & 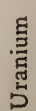 \\
\hline
\end{tabular}


The figures in the upper line are the atomic numbers, the figures after each element the atomic weights, both in terms of that of hydrogen as unity. Radium, when discovered, fell naturally into the vacant place No. 88 , and polonium and actinium are now known to occupy Nos. 84 and 89 . The three radioactive emanations of Rutherford, products of radium, actinium and thorium respectively, are chemically analogous to Ramsay's inert family of atmospheric gases, and occupy the place No. 86. No. 9I is known to be occupied by a product of uranium, having a period of average life of only $\mathrm{I}_{3}^{2}$ minutes, called Brevium. The numbers 85 and 87 in the above figure now alone remain vacant.

Thus radioactivity has peopled all but two of these vacant places, but it has done more. It has crowded into ten of the above places, between Nos. $8 \mathrm{I}$ and 92, no less than 39 distinct elements, and all of the elements occupying any one place-isotopes as they are called-are invariably identical in their whole chemical character. Ionium is isotopic with thorium, mesothorium I. with radium, and so on. To the chemist and the spectroscopist they would be taken as one. Not so, however, to the newer methods of radioactivity.

When the whole sequences of changes of uranium and thorium are set forth in the Periodic Table according to the $\alpha$ - and $\beta$-change rules mentioned, it is found that all the final products occupy the place, No. 82, occupied by lead. The atomic weight of the end product of uranium should be 206 and that for thorium 208, whereas the atomic weight of common lead is $207 \cdot 2$. This suggests that common lead is a mixture of isotopes rather than a single homogeneous element. The view rapidly received complete vindication. For the atomic weight of lead derived from minerals rich 
in thorium has been found to be higher than that of common lead, whereas the atomic weight of lead derived from minerals rich in uranium is lower. The values in fact vary from 206.0 to 207.7 .

The densities of the varieties of the lead, the writer recently found, differ in exactly the same way as the atomic weights, showing that the volume of the atom is the same though the weights are different, as was to be expected from general theoretical considerations. The difference is only small. "Thorium" lead is about $\frac{1}{4}$ per cent. heavier than common lead. Prof. Richards, of Harvard, has since found "uranium" lead to be $\frac{1}{2}$ per cent. lighter than common lead. But if such a difference occurred with gold, a bank-teller would be liable to be out by one sovereign, or two, in every 400 , if he weighed the coins instead of counting them.

Gold was the goal of alchemy, and it is interesting to ask whether the new discoveries have thrown any light on the alchemical problem of how to make gold from lead or mercury. The answer may be given at once. Gold is followed in the Periodic Table by mercury, thallium, lead, and bismuth, occupying successive places without gaps, as the figure shows. To get gold from mercury, expel from the atom of mercury one $\beta$-particle, which will make thallium, then one $\alpha$-particle, which will turn the thallium into gold. Or, to get gold from lead, expel from the atom of lead one $\alpha$-particle, which will turn it into mercury, and proceed as before.

It is interesting to note that, in the case of both the thorium and uranium disintegration series, at a certain stage, the expulsion of an $\alpha$-particle instead of a $\beta$-particle would have resulted in gold being produced, for in each case the place occupied by thallium is entered in the course of the changes. 
Unfortunately it is not yet possible to supplement these simple recipes for the artificial production of gold with the necessary instructions as to how an atom is to be caused to expel an $\alpha$ - or a $\beta$-particle at will, unless Nature has decreed that it should do so of itself, in which case nothing known will prevent it. But, if man ever achieves this further control over Nature, it is quite certain that the last thing he would want to do would be to turn lead or mercury into gold-for the sake of gold. The energy that would be liberated, if the control of these sub-atomic processes were as possible as is the control of ordinary chemical changes, such as combustion, would far exceed in importance and value the gold. Rather it would pay to transmute gold into silver or some base metal.

War, unless in the meantime man had found a better use-for the gifts of science, would not be the lingering agony it is to-day. Any selected section of the world, or the whole of it if necessary, could be depopulated with a swiftness and dispatch that would leave nothing to be desired.

Indeed in the whole tragic history of the past few years nothing has been perhaps more illuminating than the attitude of the world and its rulers to science. The intellectual aspect of the discoveries here briefly enumerated-the discovery of radioactivity, the realisation that it was due to a natural transmutation of the elements, the laborious tracing out, step by step, of the complicated sequence of changes, the discovery of the law connecting these changes with the Periodic Table, the first real understanding as to what constitutes the difference between one element and another, the vista that opens out should man ever exercise over these higher order of natural energy the control he has so effectively assumed over the lower - interesting 
perhaps, but what is the use of it all? There is a rumour, puffed judiciously in the press, that radium is a cure for cancer, and immediately there is a change. Stock exchanges get up radium, wild-cat mining schemes are floated, the public are invited to get rich quickly, and every quack and charlatan, with his radium ointment, radium pills, and radium waters, refurbishes his familiar propaganda. The charitable and benevolent, to whom the cry of suffering and the dying ever make its irresistible appeal, raise the funds to buy the radium. The genuine scientific investigator can no longer afford to, and goes without.

Again the scene changes and the country is spending nearly $£$ roo every second on the war. Radium, like every other gift of science, is pressed into the service of the war, as it is convenient for illuminating the dials of watches and scientific instruments at night, and the State, which before as regards anything productive or creative did not exist, must now afford anything for the purpose of destruction. Men, materials, and capital must be conscripted and organised to the last point for the purposes of occasional international strife.

But there is a struggle which is world-wide and never-ending, the struggle against external nature for control and mastery. The millions take no part in it, are hardly aware that it goes on, and would be surprised if they were told that their future fate and prosperity depended upon it rather more intimately than upon the issue of the doughty conflicts of the parliamentarians some of them send up to Westminster. Neither, again, would the mere alteration in the character of their education, making it scientific rather than classical, alone bring them salvation. For this struggle is by duel rather than by armies, and the issue of the duel the millions accept as blindly 
and dumbly as a decree of Providence. Enormous tracts of the British Empire are uninhabitable by white men by reason of malaria and yellow fever. It is the will of Allah. A solitary duellist ${ }^{1}$ against the unknown and not understood confronted Nature. A single intelligence in the teeth of official apathy and neglect sought the "million murdering cause," and found it. In India alone more than a million people died yearly from malaria before its cause and remedy were ascertained. The Panama Canal owes its successful construction to the work of this solitary individual in Bangalore, diligently followed up by others. Praise be to Allah!

The future of the British Empire is at the moment in the hands of five million stalwart men, with an organised nation of workers and vast accumulations of wealth and resources and every possible scientific discovery and invention behind to back them up. If the nation thinks, when peace returns, that the struggle against Nature, which after all is of more abiding and permanent interest to its destiny, large as the present contest looms to-day, can be best carried on in the old way by a handful of isolated individuals as a sort of hobby in their spare time, out of their own means, and in the intervals of more urgent professional duties, the nation is mad.

[The war being now over, it is not out of place to add that an even greater danger than neglect awaits the scientific investigator, the danger that he along with every other creative element in the community will be remorselessly shackled and exploited to bolster up the present discredited social system. There is abundant evidence since the war that science rules the world, and he who would aspire to rule it must first rule science. The prospect of creative science under the heel of government depart-

1 Sir Ronald Ross. 
ments ruled by lawyers, politicians, financiers and administrators of the modern official type is a prospect as appalling as the handing over of civilisation to the Hun. But in the modern world the community somehow must contrive to rule through its creative elements, rather than to allow the non-creative elements to rule the creative. Everything comes back to the unsolved problem of how to purify and strengthen the moral and ethical standards of the official classes, which have been so sadly perverted by their peculiar system of education, in order to make them conform more nearly to the standards of conduct and honesty entertained by the majority of ordinary respectable and benevolent people.] 


\section{THE CONCEP'TION OF THE CHEMICAL ELEMEN'T AS ENLARGED BY THE S'TUDY OF RADIOAC'TIVE CHANGE ${ }^{1}$}

THE Council of the Chemical Society have honoured me with the invitation to deliver one of three lectures bearing on the ultimate constitution of matter, and I accepted the invitation in my desire to show how greatly I appreciated it rather than with any prospect of being enabled, when the time came, to say anything on the subject which has not already been said before. The problem of the ultimate constitution' of matter belongs to another world than that through which for the past four years we have been living, and although hostilities have at length ceased, and we may look forward to an opportunity of resuming in the future the thread of our philosophical investigations, philosophy herself is not so easily to be resumed. Novel in one sense as are the ideas introduced into the concepts of physics and chemistry by the study of radioactivity, four years' interruption has made them appear rather as a remote historical accomplishment than as a contemporaneous development. Although no longer new, however, the more as the subject matures does it become apparent that these advances are of fundamental and increasing importance to the chemist.

One would perhaps have expected that on the

1 A Lecture delivered before the London Chemical Society on 19th December 1918. 
first and most fundamental conclusion arrived at in the study of radioactive change that the change is of a transmutational character, involving the spontaneous disintegration of the radio-element into others, it would have been the chemists who would have been most deeply interested, and who would have weighed the evidence and pronounced a decision. Yet judgment on the view, which was put forward more than fifteen years ago, on evidence, in my opinion, even then deserving of serious consideration, although accepted and universally adopted by the workers in the subject and by physicists, has gone by default so far as the majority of chemists are concerned. From the first, much of the most important evidence has been of a singularly simple and convincing chemical character.

\section{The Transmutational Character of Radio- active Change.}

If a chemist were to purify an element, say lead from silver, and found, on re-examining the lead at a later date, that silver was still present, and, again and again repeating the process, found always that silver, initially absent, reappeared, would he not be forced to conclude that lead was changing into silver and that silver was being produced by lead? It is because of the absence of evidence of this kind that the doctrine of the unchangeability of the elements has grown up. One positive example of the kind in question and that doctrine would be at an end. The conclusion to which, in 1902, Sir Ernest Rutherford and I were forced with regard to the element thorium was based on evidence of this direct and simple nature. By simple purification, by chemical and physical means, constituents responsible for the greater part of the radioactivity of 
thorium can be separated, and as often as they are separated they are regenerated at a perfectly definite and regular rate. One of these constituents, the emanation, is gaseous, and it can be separated from the thorium by no more elaborate means than by a puff of air. Certainly the actual quantity of thorium emanation is infinitesimal, but this did not hinder its complete chemical characterisation, for it was found to pass unabsorbed through every reagent tried, one or other of which would have absorbed every known gas with the exception of the gases of the argon family. The conclusion that the thorium emanation was a gas of the argon family produced by thorium, later extended to the similar gaseous products of radium and actinium, was a purely experimental conclusion reached before any theory whatever as to the nature of radioactivity had been advanced.

Another constituent responsible for part of the radioactivity we called thorium- $X$. It is left in the filtrate when a solution of thorium is precipitated with ammonia, although not when the thorium is precipitated by other reagents, such as sodium carbonate or phosphate. After this removal, however, thorium- $X$ re-forms in the thorium. Moreover, it is thorium- $X$, not thorium, that produces the emanation. The latter in turn produces the nonvolatile active deposit, in which the successive products, called thorium- $A,-B,-C$, and $-D$, are now recognised. The false interpretation of a similar phenomenon in the case of radium, before the radium emanation had been recognised, led to the view that inactive matter could be rendered temporarily radioactive by "induction," through contact with or association with radioactive matter. In the case of thorium, the discovery of the chemical character of the thorium emanation rendered the nature of the phenomenon clear almost from the first. 


\section{CONCEPTION OF THE CHEMICAL ELEMENT}

This, taken in conjunction with the atomic character of radioactivity, recognised by $\mathrm{Mme}$. Curie from the start, and with the fact that the law of radioactive change proved to be the same as the law of unimolecular reaction, made the conclusion that the radio-elements were undergoing a series of successive changes, in which new elements are produced, of chemical and physical character totally distinct from those of the parent element, the only one capable of explaining the facts.

Novel and unexpected as it was to find transmutation spontaneously in progress among the radioelements, the phenomena this explanation explained were equally novel and transcended what to a generation ago would have appeared to be the limits of the physically possible.

It is to pay chemistry a poor compliment to represent this conclusion as in any way contrary to the established foundations of chemistry. If it had not been for the correct conception of the nature of chemical change, the clear distinction between atoms and molecules, and the conclusion that in all changes in matter hitherto studied the element and the atom of the element remain essentially unchanged, which we owe to the founders of chemistry, the character of radioactivity would not have been arrived at so quickly. On the other hand, if radioactivity had not been almost instantly recognised as a case of spontaneous transmutation, then, if you will, there would have been something radically wrong with chemistry and the training it affords in the elucidation of the metamorphoses of matter.

With regard, however, to the various claims that have been made since, that transmutational changes can be artificially effected by the aid of the electric discharge in gases or the rays from radium, I have always regarded the evidence in this field as capable 
of simple alternative explanation. Different investigators have obtained entirely opposite results, and there is not that consensus of evidence one finds among those who have investigated radioactive change.

In another direction there has been a tendency to underrate the unique and unparalleled phenomenon of radioactive change, and to connect what is entirely and solely a development of the new experimental science of radioactivity with the somewhat older isolation of the electron and the electronic hypotheses of the constitution of matter to which that discovery has given rise. For example, Sir J. J. Thomson in his Romanes Lecture, I9I4, says: "Since the electron can be got from all the chemical elements we may conclude that electrons are a constituent of all the atoms. We have thus made the first step towards a knowledge of the structure of the atom and towards the goal towards which since the time of Prout many chemists have been striving, the proof that the atoms of the chemical elements are all built up of simpler atoms-primordial atoms, as they have been called." The removal of electrons from matter occurs in physical, chemical, and radioactive changes alike, exampled, respectively, by the electrification of a glass rod by friction, the ionisation of an electrolyte by solution, and by the $\beta$-ray change of radioactive substances. It is only in the latter case, however, that the electron can be regarded as a primordial constituent and the change as transmutational. Even to-day it is in radioactive phenomena, and in these alone, that the limits reached long ago in the chemical analysis of matter have been overstepped and the Rubicon, which a century ago Prout vaulted over so lightly in imagination, has actually been crossed by science. 
First and Second, Phases of Development.

Looking backward to the first recognition of the character of radioactive change in 1902 , it is possible to distinguish broadly two phases. The first phase, concerned mainly with the disentanglement of the long and complicated series of successive changes, commencing with the two primary radio-elements uranium and thorium, and including ultimately all the known radio-elements, added little to the conceptions of chemistry beyond the disturbing fact that the radio-elements, although in every other respect analogous to the ordinary elements, are in process of continuous transmutation. But in the second and more recent phase of radioactive change,-the study of the chemical character of the successive products and the law connecting this with the type of ray expelled in the change, the discovery of elements with different radioactive but identical chemical character, the recognition of these as isotopes, or elements occupying the same place in the periodic table, and the interpretation of the significance of the periodic law,-conceptions are arrived at which are not merely novel, but upsetting. In this phase, an aspect of the ultimate constitution of matter has been revealed that, although well within the scope of the conceptions of elements and atoms which we owe to the nineteenth century, nevertheless has totally escaped recognition. I am not much concerned with definitions, but I think the Chemical Society might safely offer a prize of a million pounds to any one of its members who will shortly and satisfactorily define the element and the atom for the benefit of and within the understanding of a first-year student of chemistry at the present time. 


\section{Chief Features of Radioactive Change.}

The features that distinguish radioactive change from chemical change, and which have made it possible in a few short years to reduce to some degree of finality and completeness the intensely complicated series of successive changes suffered by the elements uranium and thorium in the course of their disintegration, are chiefly two. In the first place, the whole phenomena are inevitable, incapable of being changed or deviated from their allotted course by any means whatever, independent of temperature, concentration, or the accumulation of products of reaction, the presence of catalysts, irreversible and capable of being accurately and quantitatively followed without alteration or disturbance of the changing system. The mathematical theory, although for many successive changes it becomes cumbrous and unwieldy to a degree, involves only the solution of one differential equation by a device quite within the compass of anyone possessing a knowledge of the bare elements of the calculus to employ. The second feature is in the magnitude of the energy evolved, which, weight for weight of matter changing, surpasses that evolved in the most exothermic chemical changes known, from one hundred thousand to a million times. Manifested in the form of rays, by their fluorescent, photographic, or ionising power capable of being put into evidence in almost inconceivably minute amount, changes are capable of being followed, and by the electroscope accurately measured, which would conceivably require to continue for millions of years before they could be experimentally detected by chemical or even by spectroscopic methods. The disintegration of the single atom is ascertainable, for example, in the spinthariscope of Sir William Crookes, where each 
of the scintillations separately visible is due to the impact of a single $\alpha$-particle on the zinc sulphide screen. On the same principle, methods have been developed and are in regular use for counting the number of atoms disintegrating per minute, whereas to the spectroscope at least $3 \cdot 10^{13}$ atoms as a minimum must be present, 25,000 times as many atoms as there are human beings alive in the world, before any element can be so detected. By the most curious compensation, almost of the nature of a providential dispensation which some may have found difficult to believe, the quantity of matter of itself is not of importance in investigating radioactive change. The methods depend on the rate of emission of energy, and this is proportional to the quantity of the changing element multiplied by its rate of change. In the disintegration series, the various members accumulate in quantities inversely proportional to the rates of change, and so it comes about that all changes within the series are equally within the scope of the method whether, as in the case of the parent elements, they involve periods surpassing the most liberal estimates of the duration of geological time or, as in the case of the $C^{\prime}$ members, are estimated to run their course in a time so short that light itself can travel but a very few millimetres, before the next change overtakes the changing atom.

The condition of radioactive equilibrium in which the quantities of the successive products assume the above stationary ratio is of .course entirely different from chemical equilibrium, and is the condition in which for each member of the series except the first as much is produced as changes further in the unit of time.

The foregoing applies so long as the changes continue. When they are finished and it is a question of ascertaining the ultimate products, the 
task may be likened to that of searching for a meteor which a moment before lit up the heavens and now has vanished into the night.

\section{The Ultimate Products.}

It is a matter for surprise that in all radioactive changes so far studied there appear to be only two ultimate products, helium and lead, the former constituting the $\alpha$-particles and the latter being produced both by uranium and thorium, withal, as we now know, not the same lead in the two cases. There are sufficient experimental reasons for doubting whether the disintegration of an atom into more nearly equal parts would be within range of detection by any of the known methods. A heavy atom like oxygen, for example, if expelled as a radiant particle, might not attain sufficient velocity to ionise gases, or, even if it did, the range over which the ionisation would extend, as we know from the ionisation produced by the recoil atoms, would be extremely small. It must be a matter for comment, however, that hydrogen never appears in these changes, as, if it were produced, it would almost certainly be as easy to ascertain as helium. It has always seemed to me a possibility that some genetic connection may exist, after all, between thorium and uranium, although I have never been able to frame even a possible mode of so connecting these two elements. With a difference of atomic weight of six units, it is impossible to pass from one to the other by addition or expulsion of helium atoms alone.

Both with regard to helium and lead, the composition of radioactive minerals gave the first clue to the identity of the ultimate products. After the discovery of radioactivity and the elucidation of its nature, the fact that helium was found only 
in minerals containing uranium and thorium assumed a totally new interpretation, borne out by the spectroscopic proof of the production of helium from radium by Sir William Ramsay and myself, and later from actinium, polonium, and even from uranium and thorium, all at the rates to be expected from radioactive data. The identification of the $\alpha$-particle with helium, after the weight of the $a$-particle had been shown by new physical methods to be four times that of the hydrogen atom, was accomplished by enclosing the radium emanation in a glass tube thin-walled enough to allow the $\alpha$-particle to go through, but perfectly impervious to the passage of gas. In these circumstances, helium in spectroscopically detectable quantity was proved by Rutherford to make its appearance outside the tube.

Such confirmations by the spectroscope, welcome and gratifying as they are, are nevertheless in a sense subsidiary to the main problem, namely, the task of unravelling the complicated series of changes into its individual steps, and the characterisation by their radioactivity of the several intermediate members of the series, such as by the determination of their periods and the physical constants of the radiation $\alpha-, \beta$-, or $\gamma$-, to which they give rise. The determination of their chemical character, although equally important, was only later fully accomplished.

\section{The Radiations.}

In the successive radioactive changes, $a$ - or $\beta$-particles are expelled, one $\alpha$-particle per atom disintegrating for each change, although for the $\beta$-particles our knowledge is less exact. In some cases, certainly, although these are exceptional, $\beta$-particles seem to be expelled along with $\alpha$-particles. 
The $\alpha$-particle is an atom of helium charged with two atomic charges of positive electricity, or, as we should now say, is the helium nucleus, deprived of the two electrons which are combined with it in the helium atom. The $\beta$-particle is the negative electron, and when expelled with sufficiently high velocity is accompanied with $\boldsymbol{\gamma}$-rays. The latter are $X$-rays of exceedingly short wave-length, varying from I. 3 to O. I Ångström units. ${ }^{1}$ A connection exists between the speed of the change and the speed of the particles expelled, and the more rapid the change the faster in general and the more penetrating are the attendant $\alpha$-or $\beta$-particles. In the case of the $a$-particle, an empirical logarithmic relation, known as the Geiger-Nuttall relation, enables us to calculate approximately the period of the changing element from the velocity or range of the $a$-particle, and vice versa, and by this means periods too long or too short to be directly measurable have been estimated. In the case of the $\beta$-rays, no definite quantitative law has yet been made out, but it is clear that a similar relationship must exist. One of the important corollaries is that changes much slower than the slowest known, namely, those of uranium and thorium, would probably not be detectable, as, even were $\alpha$ - or $\beta$-particles expelled, they would be of too low velocity probably to ionise gases or show fluorescent or photographic actions. Indeed, for mesothorium- $I$ and actinium this appears to be the case. No detectable radiation is expelled, although the products conform to what would occur

${ }^{1}$ The shortest wave-length so far resolved by the crystal reflection method is $0.072 \AA$. in the spectrum of the $\gamma$-rays of radium- $C$. Ishino and Rutherford have recently concluded, however, that the main $\gamma$-radiation of radium- $C$ must have a wavelength lying between 0.02 and $0.007 \AA$. (Phil. Mag., 1917, [vi.] 33, $129 ; 34,153)$. 


\section{CONCEPTION OF THE CHEMICAL ELEMENT}

in $\beta$-ray changes. The period of both substances is long, and it is probable that the $\beta$-particle is expelled, but is undetectable by ionisation methods. For the slowest $\beta$-ray change, that of radium- $D$, with a period of twenty-four years, the $\beta$-radiation is of such low velocity as to be only capable of detection by special care, and is far less penetrating than average $\alpha$-rays. These facts serve to show that changes may be going on in the non-radioactive elements which at present are beyond experimental means of detection.

\section{Period of Average Life.}

The law of radioactive change, which is the same for all cases, is that of unimolecular reaction, the rate of change, or quantity changing in unit of time, being a fraction, designated by $\lambda$ and known as the radioactive constant, of the amount present. The value of $\lambda$, although vastly different for different radio-elements, is an absolute constant, so far as is known, for any one element, independent of every consideration whatever. The period of average life is the reciprocal of this constant, but the actual life of any one atom may assume any value. This is an experimental fact very difficult to account for. For example, it is quite easy to compare the value of $\lambda$ for a collection of atoms ( $\mathrm{I}$ ) only just produced and not in existence a short interval before, and (2) that have remained undistinguished from an originally very much greater number, and each of which has been in existence many times the period of average life. In both cases the value of $\lambda$ is the same. This fact excludes from consideration as a conceivable cause of disintegration any gradual progressive alteration in the atom during its period of existence, as, for example, was at one time suggested, a gradual 
radiation of internal energy by the electrons in their orbits within the atom. So far, we must admit, the cause of atomic disintegration remains unknown, although Lindemann (Phil. Mag., 1915, [vi.], 30, 560) has attempted, with some success, to frame a theory to account for it.

\section{Branch Series.}

The development of the various radioactive sequences revealed that sometimes the series branches, and that in the change of one radioelement sometimes two products result, in general, in different amounts. Thus the uranium series at one point branches into the radium and actinium series, in proportion 92 to 8 out of 100 atoms disintegrating. Again, in the case of radium- $C$ and thorium- $C$ a similar branching occurs, and here in one branch an $\alpha$-ray change is followed by a $\beta$-ray change, and in the other branch the sequence is reversed. These cases are sufficiently explained if it be supposed that two simple radioactive changes are in progress in the same substance simultaneously, and that each obeys the law of simple change as though the other did not occur. The distribution of the original substance into the two products is then proportional to the relative rates of the two changes. If $\lambda_{1}$ and $\lambda_{2}$ are the radioactive constants of the two changes, the proportion between the two products is as $\lambda_{1}$ to $\lambda_{2}$, and the constant of the double change as a whole, $\lambda_{1}+\lambda_{2}$. For thorium- $C$, the ratio is as 65 to 35 , but for radium- $C 99.97$ to 0.03 . The first is relatively easy, but the second extremely difficult to follow experimentally. It is, for example, impossible to follow further what occurs to the minor branch owing to the minuteness of the quantity of material, and although this has to be represented as 


\section{CONCEPTION OF THE CHEMICAL ELEMENT}

not further changing, we have only negative evidence to go on. This branching is very important as showing how from one element two products or more in very different quantity may result, and may be the explanation of the excessive rarity of certain of the elements in nature.

\section{History of the Analysis of Matter.}

The second, and in many respects even more revolutionary phase in the development of the study of radioactive change arose out of the chemical characterisation of the successive products, but some historical comment on the various influences which have gone to shape the current conception of the chemical element may be of interest before dealing with this development.

The analysis of matter into different chemical elements was at first concerned with known materials obtainable in abundance. The question, then, was not as to the existence or otherwise of certain elements, but whether certain thoroughly well-known substances were elements or compounds. Boyle's original celebrated definition was a purely practical one. That was to be regarded as elementary which could not by any means be separated into different substances. Almost at once, however, there crept into the interpretation of this conception two fallacies, or two aspects of the same fallacy, implicit in all the later characterisations of the elements, right up to the present time, namely, first, that chemical analysis was necessarily the most fundamental and searching kind of material analysis, known or to be discovered, and, secondly, that chemical compounds were necessarily more difficult to resolve than simple mixtures. Any means soon came to mean any chemical means, and the element, in consequence, 
the chemical element. So was taken the first step which ultimately was to make the term chemical element, as it is at present understood, denote a definite but highly complex chemical conception, incapable of being defined or even understood without long years of training in the science, and totally different in every single respect from what a plain man or a beginner in the subject might reasonably suppose the term element ought to connote. The elementary and even the homogeneous character has departed from the conception of the chemical element, but the conception remains, and, whatever we choose to call it, will remain. The criterion of the chemical element soon came to be, in fact, the possession of a unique chemical character, distinguishing it and sufficing for its separation from all other elements. To this Dalton added a new criterion, the magnitude of the weight of the atom of the element, and each element unique in chemical character (as it happened) proved also to possess a unique atomic weight.

The discovery of the periodic law introduced the idea of families of chemically analogous elements, the members of which recurred after regular intervals when the elements were arranged in order of atomic weight. With the exception of hydrogen, every element became one of a group all totally distinct, but with obvious similarities. Boyle's practical definition of the element as that which could not be further resolved, more and more, as the century advanced, fell into desuetude. It became replaced by a theoretical conception, to which subsequently I propose to apply the term "heterotope," meaning the occupant of a separate place in the periodic table of elements. With this place came to be associated the unique chemical character, unique atomic weight, and later unique spectrum. On the claims of a 
substance to the title of element, as in settling disputes as to what multiple of the equivalent was to be adopted as the atomic weight, the periodic law became the court of appeal. Did a claimant to the title of element fit into a vacant place in the family of related elements? If it did, not only was there no doubt as to its atomic weight, but it certainly could scarcely be an ordinary compound or mixture. Whatever the elements were, it was clear that they were all of a class, the limits of chemical analysis, and, if complex, then all probably of the same kind of complexity.

Incidentally, also, the periodic law showed that although there was a connection between atomic weight and chemical character, there were exceptions, like tellurium and iodine, where the atomic weights appeared to have been reversed. This made it perfectly plain that it was merely a chance that no two elements happened to possess the same atomic weight. Dalton, as we shall come to describe, discovered in the atomic weight not merely a new atomic property, but a new class of atomic property which, until the present century, remained the only one of the kind known, and is concerned with a different region of the atom from that to which physical and chemical character, position in the periodic table, spectrum, and other identifying characteristics are to be referred.

The discovery of spectrum analysis led to the recognition of many new elements, cæsium and rubidium, thallium, indium, helium, and gallium all being so recognised before anything at all was known as to their other properties. In each case unique spectrum was later found to correspond with unique chemical character-except for the argon gases, all characterised by absence of chemical character-and unique atomic weight. 
Again, the first-fruits of the discovery of radioactivity were the recognition of the new elements polonium, radium, and actinium by their unique radioactive character in the first place. Then, in the case of radium, its claim to the title of element was confirmed, first by its exhibiting a unique spectrum, then by its possession of unique chemical character and atomic weight and by its occupying a vacant place in the periodic table. The emanations, next, as occupying a place in the family of argon gases, were easily characterised, and for the radium emanation unique spectrum was proved. Its origin from radium by loss of one $a$-particle gives the atomic weight as 222, which agrees with determinations of its density and rate of diffusion. The chemical characters of polonium and of actinium are different from those of the elements they most closely resemble. Polonium, or radium- $F$, by its close chemical analogy to both bismuth and tellurium, was characterised as an element of the sulphur family occupying the vacant place contiguous to bismuth. Actinium, by its resemblance in chemical character to the rare earths, and especially to lanthanum, although capable of being concentrated fractionally from that element, was reasonably supposed to occupy the vacant place in Group III, between radium and thorium. As will later appear evident, both these elements in due course may be expected to show unique spectra.

Further progress in the elucidation of the chemical character of successive products then underwent an abrupt and, at first, very puzzling change of direction. As member after member in the series was distinguished and characterised by its unique radioactive character, by its disintegration in definite and characteristic ways at definite and characteristic rates, no further chemically new elements were discovered. Unique radioactive character does not 
always, as it did with radium, imply unique chemical and spectroscopic character. The new members resembled known elements in chemical character so closeiy that they could not be separated from them by chemical analysis, although sharply differentiated from them by the radioactive properties. Radiolead, or radium- $D$, cannot be separated from the lead which, being a product of uranium, accompanies it always in uranium minerals. Ionium, the direct parent of radium, cannot be separated from thorium ; but the most instructive case, historically, which shows well how the new method of radioactive analysis serves to distinguish different elements, where chemical analysis fails, was the case of radiothorium.

\section{Chemically Non-separable Elements.}

Ramsay and Hahn, in the course of working up a large quantity of thorianite for radium, observed in fractionating the radium from the barium in the usual way that the activity of the material concentrated at both ends of the fractionation. The activity accumulating in the more soluble fractions was due to a new product, which they termed radiothorium. It produces thorium- $X$, the thorium emanation, etc., in successive changes. Naturally enough, they thought they had separated radiothorium by chemical processes from thorium, but they had not, for that, as we know, is quite impossible. Then Hahn found along with the other end fraction, containing the radium, a further new product, mesothorium, which is intermediate between thorium and radiothorium. The radiothorium they had separated from thorianite was not that present in the mineral when they started, but that which had re-formed from the mesothorium after it had been separated from the thorium in the mineral. Could any more elegant extension, not 
merely of knowledge, but of the means of obtaining knowledge, be imagined? Two different elements, thorium and radiothorium, which on account of their chemical resemblance could not be individually recognised, and in the original interpretation of the thorium disintegration series were taken as one, became individually knowable, because the latter is the product of the former through the intermediary of a third member, mesothorium, possessing chemical properties totally unlike either. Radioactive change thus became the means of a new analysis of matter, for which there is no counterpart outside the radioelements.

In turn, mesothorium suffered analysis into two successive products, mesothorium-I and -2 , the first distinguished by long period of life and a rayless disintegration into the second, which has a short life and gives powerful $\beta$ - and $\gamma$-radiation in its change into radiothorium.

I then found that mesothorium-I was chemically non-separable from radium, a discovery also made by Marckwald at the same time, and in I9I I I pointed out that in an $a$-ray change, such as ionium into radium, radium into emanation, thorium into mesothorium-I, and other cases, the expulsion of the $a$-particle causes the radio-element to shift its place in the periodic table by two places in the direction of diminishing mass and diminishing valency, whereas in successive changes in which $a$-particles are not expelled, it frequently reverts to its former position, as, for example, radiothorium from mesothorium and lead from radiolead.

To those actually engaged in the task of trying to separate the successive products of radioactive change by chemical analysis, it soon became clear that the chemical resemblances disclosed between certain of the members was such as to amount to 
chemical identity. The most obstinate cases of similarity previously known, among the rare earths, for example, cannot be compared with them. In all cases, radioactive methods afford the most delicate means for detecting the least alteration in the concentration of the constituents, and the most prolonged and careful attempts fail to produce a detectable separation.

At my request, Fleck undertook in my laboratory a systematic chemical examination of all the members of the series still imperfectly characterised, from the point of view of first finding which known element they most resembled and then finding whether or not they could be separated from that element. His researches were the means of finally unmasking the extreme simplicity and profound theoretical significance of the process of radioactive change. All the members of the series so far chemically uncharacterised he found to be chemically non-separable from one or other of the known elements, mesothorium-2 from actinium, radium- $A$ from polonium, the three $B$-members and radium- $D$ from lead, the three $C$-members and radium- $E$ from bismuth, actinium- $D$ and thorium- $D$ from thallium.

Radioactive Change and the Periodic Law.

In February, 1913, K. Fajans in Germany, from electrochemical evidence, and in this country A. S. Russell and I, independently, from Fleck's work, pointed out the complete generalisation which connects chemical character and radioactive change. In addition to the shift of two places in the periodic table caused by the expulsion of the $\alpha$-particle, it was now clear that the expulsion of the $\beta$-particle caused a shift of one place in the opposite direction. Since the $\alpha$-particle carries two atomic charges of positive 
electricity and the $\beta$-particle one atomic charge of negative electricity, the successive places in the periodic table must thus correspond with unit difference of charge in the atomic structure, a conclusion reached later for the whole periodic table, as far as aluminium, as the result of Moseley's investigations on the frequency of Barkla's characteristic $X$-radiations of the elements.

The non-separable elements, with identical chemical character, on this scheme were found all to occupy the same place in the periodic table, and on this account I named them isotopes. Conversely, the different elements recognised by chemical analysis should be termed "heterotopes," that is, substances occupying separate places in the periodic table, but themselves mixtures, actually proved or potential, of different isotopes, not necessarily homogeneous as regards atomic weight and radioactive character, but homogeneous as regards chemical and spectroscopic character, and also physical character, so far as that is not directly dependent on atomic mass.

\section{SPECTRA OF Isotopes.}

As regards the spectrum, the first indication that chemically non-separable elements probably possessed identical spectra arose out of the failure of Russell and Rossi and of Exner and Haschek in I9I 2 to detect any lines other than those of thorium in the spectrum of ionium-thorium preparations that might reasonably be supposed to contain an appreciable, if not considerable, percentage of ionium. The work of Hönigschmid on the atomic weight of ionium-thorium preparations has fully confirmed this view. The isotopes of lead of different atomic weight separated from uranium and thorium minerals have been found to possess 


\section{CONCEPTION OF THE CHEMICAL ELEMENT}

identical spectra. For this element, lead, Rutherford and Andrade have shown that the secondary $\gamma$-radiation excited by the impact of $\beta$-rays on a block of ordinary lead gave by crystal reflection two lines identical in wave-length with the two strongest lines in the $\gamma$-ray spectrum of radium- $B$, an isotope of lead, as Fleck showed, of atomic weight 214. This is of importance as indicating that $X$-rays and $\gamma$-rays, although no doubt originating in a deeper region of the atom than the ordinary light spectrum, do not originate in the deepest region of all to which the weight of an atom and its radioactive properties are to be referred.

\section{Description of the Figure.}

The generalisation, brought up to date, is set forth in detail in the Tables on p. I 34 and is illustrated by the accompanying figure, which is to be read at an angle of $45^{\circ}$, making the lines of atomic weight horizontal and the division between the successive places in the periodic table vertical. Starting from uranium and thorium, the series run in an alternating course across the table and extend over the last twelve places as far as the element thallium. At this point, it is interesting to note that the expulsion of an $\alpha$-instead of a $\beta$-particle would have resulted in the production of an isotope of gold, and so literally have realised the goal of the alchemist. As it happens, a $\beta$-particle is expelled and lead results, so far as the changes have yet been traced, in all cases as the final product.

It has been necessary, in order to separate the series from one another, to displace the actinium series to the right and the radium series to the left of the centre of the places, but this displacement within the single place is not intended to express 
any physical significance; but for the fact that many members would be superimposed, they would all be represented in the centre of the places. The periods of average life, which are always I.443 times the periods of half-change, are shown for each member above or below its symbol, a ? indicating that the period is estimated indirectly from the Geiger-Nuttall relation.

The figures at the head of each place represent the atomic numbers or number of the place in the periodic table, starting with hydrogen as unity, helium as 2, lithium as 3 , and so on. Moseley found that the square-root of the frequency of the characteristic $X$-radiation of an element was, for the $K$-series of radiations, proportional to integers less by one than the atomic numbers. Strictly speaking, there is no means of determining the absolute value of the atomic number, but the starting point having been fixed for any one element, the others can then be found in terms of it. Moseley assumed the atomic number of aluminium as $\mathbf{r} 3$, as it is the thirteenth known element in the list starting with hydrogen as unity. It is unlikely that any new elements will be discovered between hydrogen and aluminium, although if they were it would be necessary to alter the whole of the subsequent atomic numbers to correspond. For $X$-radiations of the other series, the square-roots of the frequencies are not proportional to integers even, although the differences are nearly integral for successive elements in the periodic table. The actual numbers in the figure, 92 for uranium, for example, are derived from the assumption that the atomic number of aluminium is 13 , but it is well to remember that, although relatively to one another based on experimental evidence, the absolute value is to some extent arbitrary. 


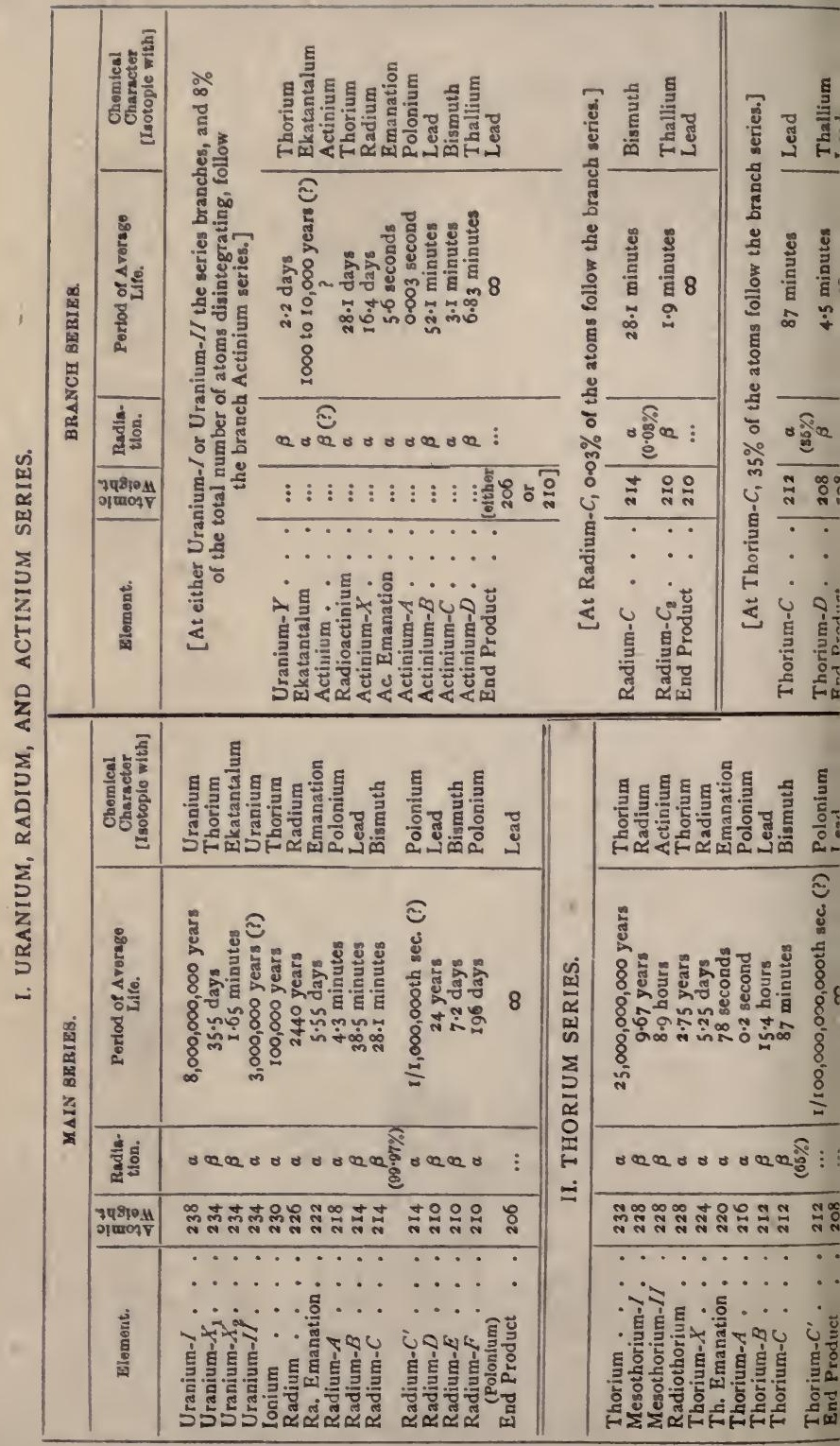



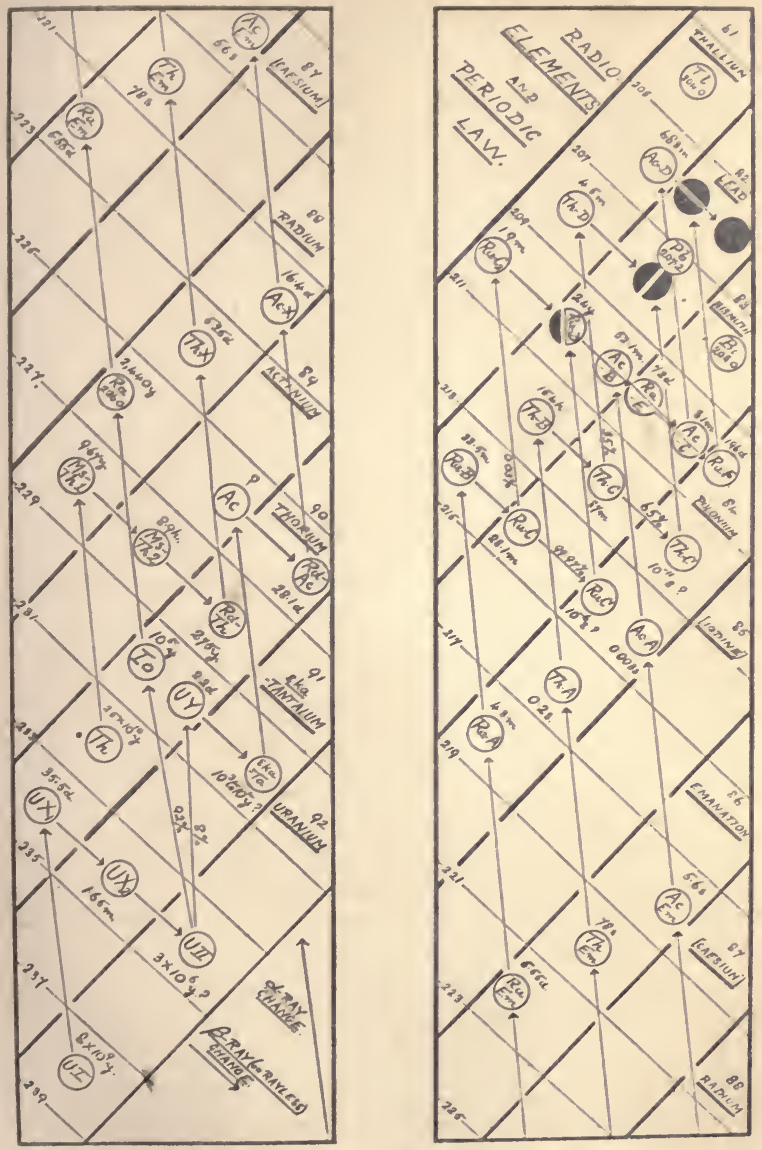

Sequence of Changes of Uranium (U) and Thorium (Th) into various Isotopes of Lead $(\mathrm{Pb})$.

[ Face page 134. 



\section{The Chemical Character of the Radio- ELEMENTS.}

The simple connection between the sequence of radioactive changes and the chemical character of the products has effected an enormous simplification, not only in the theory, but also in the practice of radio-chemistry. The series extends over twelve places, two, namely those in the families of the halogens and the alkali metals, being entirely skipped. In the ten occupied places are forty-three distinct types of matter, but only ten chemical elements. Seven of these ten, thallium, lead, bismuth, emanation, radium, thorium, and uranium, can now in every respect be considered, both chemically and spectroscopically, thoroughly well known. These seven places accommodate all but nine of the known radio-elements, and these nine, the isotopes of polonium, actinium, and ekatantalum respectively, are the only members the chemistry and physics of which cannot be referred to well-known elements obtainable in sufficient quantity for ordinary chemical and spectroscopic examination.

Of these three, polonium, although the element of which at present the chemistry is best known, is likely to remain the most difficult to bring into line with the others, for, although a vast amount of exact information has been obtained as to its reactions, it would seem to remain hopeless ever to obtain it in anything but infinitesimal amount owing to its relatively very short period.

The chemistry of actinium has been enormously simplified by the discovery that mesothorium-2 is isotopic with it, for the latter may be used as an indicator to show in what way the actinium distributes itself after any chemical treatment. Owing 
to its relatively small quantity as a branch product and to the fact that, itself, it gives no rays, the characteristic radioactivity of its products only making their appearance slowly after it has been separated, actinium has always been a difficult element to extract from the mineral and very easy to lose in chemical operations. There is now, however, another reason which will assist in the study of this element.

\section{The Origin of Actinium. Ekatantalum.}

The generalisation has now led to the elucidation of its origin and the discovery of its direct parent. From its constant association with uranium minerals, and the relative activity therein of its products in comparison with the activity of those of radium, it was considered to be a branch product of the uranium series, only 8 per cent. of the atoms of uranium disintegrating passing through the actinium series and 92 per cent. through the radium series. Its definite location in the periodic table, by virtue of its isotopism with mesothorium-2, made it clear that its parent must either be in the radium or the ekatantalum place, the former if it is produced in a $\beta$-ray change and the latter if it is produced in an $\alpha$-ray change.

The ekatantalum place was vacant when the generalisation was first made, but it was necessary to suppose that uranium- $X$, like mesothorium, comprised two successive products, uranium- $X_{1}$ and uranium- $X_{2}$, both giving $\beta$-rays, and the latter occupying the vacant place in question. This prediction was confirmed within a few weeks of its being made by the discovery by Fajans and Göhring of uranium- $X_{2}$, or brevium, a new member responsible for the more penetrating $\beta$-radiation given by uranium- $X$, 
and having a period of only $\mathrm{I} \cdot 65$ minutes. The possibility that actinium was produced in a $\beta$-ray change from an isotope of radium was experimentally disproved, and there remained only the second alternative, which was rendered the more probable by the existence of a member, uranium- $Y$, discovered by Antonoff, isotopic with uranium- $X_{1}$, and simultaneously produced with it from uranium in relative quantity such as is to be expected, if it were the first member of the actinium series. Uranium- $Y$, like uranium- $X_{1}$, gives soft $\beta$-rays, and hence its unknown product must be the isotope of uranium- $X_{2}$, and might also well prove to be the unknown direct parent of actinium in an $\alpha$-ray change of long period.

During the year the missing element has been found in two independent investigations (Soddy and Cranston, Proc. Roy. Soc., 1918, [A], 94, 384; O. Hahn and L. Meitner, Physikal. Zeitsch., 1918, 19, 208). The problem as it presented itself to us was so to treat a uranium mineral as to separate an element, if present, which possessed the chemical character of the known but hopelessly short-lived uranium- $X_{2}$, using the latter as an indicator in trying possible methods beforehand. The method adopted, distillation at an incipient red heat in a current of carbon tetrachloride vapour and air, was found to be very effective in volatilising uranium- $X_{2}$ from uranium- $X_{1}$, and when applied to pitchblende it was found to give a product in which none of the known pre-emanation members of the disintegration series were present. Thus was obtained a preparation from which actinium was at first absent, but which, with the lapse of time, continuously generated actinium, as characterised beyond the possibility of doubt by means of its active deposit.

It should be mentioned that the exact point at 


\section{CONCEPTION OF 'THE CHEMICAL ELEMENT}

which the uranium series branches has not yet been definitely ascertained, as there is a choice of alternatives, at present experimentally indistinguishable. Uranium- $Y$ may be either the product of uranium- $I$ or of uranium- $I I$, and the latter alternative, which is that shown in the figure, is taken for the present as likely to be on the whole the more probable. The point can only be settled by the determination of the atomic weight of ekatantalum or actinium.

Independently, Hahn and Meitner obtained the parent of actinium from the insoluble siliceous residues left after the treatment of pitchblende with nitric acid by adding tantalum, and then separating it and purifying it by chemical treatment. They showed that it gave $\alpha$-rays of range $3.314 \mathrm{~cm}$. of air at N.T.P., and, from this range, estimate its period to be from $10^{3}$ to $2 \cdot 10^{4}$ years. There should therefore be sufficient of the element in uranium minerals to enable the spectrum, atomic weight, and chemical character of the pure substance to be determined in the same way as for radium. Its separation on a large scale will enable actinium itself to be grown in a pure state, analogously to the preparation of radiothorium from mesothorium, and so should allow the spectrum at least of actinium to be found.

With regard to the period of actinium, there is at present a real conflict of evidence, and so it is impossible to say whether our knowledge of actinium is ever likely to become as complete as that of radium, or to remain, like that of polonium, confined to what can be learned from infinitesimal quantities. Cranston and I, on certain assumptions, concluded from indirect evidence that the period of actinium was 5000 years, but Hahn and Meitner, on the other hand, state that they have obtained evidence confirming Mme. Curie's provisional estimate of the period as about thirty years, from the direct obser- 
vation of the decay of the radiations of a sealed actinium preparation.

\section{Atomic Weight of Isotopes.}

It is clear that the periodic law connects, not primarily chemical character and atomic weight, but chemical character and atomic charge or atomic number, which alters its value by integers, not continuously, producing the step-by-step changes in chemical character which is at the basis of the analysis of matter into the chemical elements, or heterotopes. This atomic number is, however, the algebraic sum of positive and negative charges, so that the loss of the $\alpha$-particle with its two positive charges and of two negative electrons as $\beta$-particles leaves its value unchanged and produces an isotope of the element having an atomic weight four units less than the original. Unique chemical character and unique spectrum reaction is no proof of homogeneity, and so we arrive at the conclusion that the chemical elements, so far considered homogeneous, may be mixtures of isotopes, possessing different atomic structure and stability, revealed when they undergo radioactive change, and in some cases also different atomic weight. This, although within the scope of the Daltonian analysis of matter to detect, nevertheless, until radioactive investigations revealed this possibility, remained overlooked. In two cases, that of the isotopes of lead on the one hand, and of ionium and thorium on the other, this difference of atomic weight in elements spectroscopically and chemically identical has now been established by direct determinations.

The figure (facing p. I 34) shows that, so far as these changes have been followed, they all terminate in the place occupied by lead, and, if this is the real, as dis- 


\section{CONCEPTION OF THE CHEMICAL ELEMENT}

tinguished from the apparent end in all cases, all the ultimate products are isotopes of lead with atomic weight between 210 and 206. The product of radium- $C_{2}$, in the branch claiming only 0.03 per cent. of the whole ultimate product of radium, with atomic weight 2 ro, may be left out of account as being negligible, and also the product of the actinium branch for which the atomic weight is still uncertain; but the main products, namely, that of uranium with atomic weight 206 , and both the thorium products in the two branches, with atomic weight 208 , are different in different directions from that of common lead with atomic weight $207 \cdot 2$.

The conclusion that the ultimate product of thorium, as well as of uranium, was lead, was quite new and opposed to the opinion of those who had made a special study of the $\mathrm{Pb} / \mathrm{U}$ and $\mathrm{Pb} / \mathrm{Th}$ ratios of radioactive minerals of various geological periods.

I found, however, that the atomic weight of the lead separated from Ceylon thorite was 207.7, and Hönigschmid confirmed this with a specimen of my material and obtained the figure 207.77 . Just recently, from a specimen of lead separated from a Norwegian thorite by Fajans and his co-workers, he has found the value 207.90 (Zeitsch. Elektrochem., I9I8, 24, I63). Whereas the same investigator, and also T. W. Richards and others, have found values for the atomic weight of lead separated from uranium minerals all lower than that of common lead, and in two cases from carefully selected minerals between 206.0 and 206. I. I found my thorite lead was denser than common lead in the same proportion as its atomic weight was greater, and the densities of the various specimens of uranium lead have been found by Richards to be less than that of common lead, the atomic volume for all varieties being constant. The spectra of these various isotopes have been repeatedly 
examined, but hitherto no differences whatever have been established. ${ }^{1}$

The atomic weight of a mixture of ionium and thorium was found by Hönigschmid to be $23 \mathrm{I} \cdot 5 \mathrm{I}$ as compared with $232 \cdot 12$ for thorium, the spectra being identical and impurities absent in both specimens. The calculated value for the atomic weight of ionium is 230 , and the evidence, so far as it yet goes, is in accord with the view that, in the mixture examined, about 30 per cent. was ionium and 70 per cent. thorium. By a simple comparison of the emanating power of the mixture with that of the pure thorium preparacion under similar conditions, the proportion of ionium to thorium could be readily determined directly, since ionium does not give an emanation, and this unknown eliminated, but this has still to be done.

\section{The Different Varieties of Isotopes and HETEROTOPES.}

When isotopes, such as those just considered, possess different atomic weights, it is to be expected, although this has not yet been practically accomplished, that a separation by physical means, such as prolonged fractional diffusion, ought to be possible. Chlorine and other elements, the atomic weights of which depart largely from an integral value, seem to deserve a further physical analysis by this method. Sir J. J. Thomson's positive-ray method of gas analysis ought to be able to detect such isotopes of different atomic weight without separation, and at

1 Harkins and Aronberg (Proc. Nat. Acad. Sci., 1917, 3, 710), for ordinary lead and uranio-lead of atomic weight 206.34, examining the strongest line, 4058 , in the sixth order of spectrum obtained by a 10-inch grating, observed a constant difference of $0.0043 \AA$., but are themselves disposed to await further results before drawing any conclusions. This has now been confirmed ( $c f$. T. R. Merton, Nature, and October 1919). 


\section{CONCEPTION OF THE CHEMICAL ELEMENT}

one time it seemed that neon had been so resolved, but this has not yet been confirmed. ${ }^{1}$ It would be interesting also if the rotation of the salts of some optically active acid with different varieties of lead, separated from uranium and from thorium minerals, were examined. A difference is to be expected, although it is likely to be small, and possibly may be too minute to be detectable. Recent experiments at Harvard have shown that the refractive index of a crystal of lead nitrate is independent of the atomic weight of the contained lead, but the solubility, as is to be expected, is different, the molar solubility of different varieties being the same.

Isotopes need not, however, have different atomic weights. One of the clearest cases is in the two endproducts of thorium, but, if the scheme is correct as regards the branching point of the actinium series, ionium and uranium- $Y$, actinium- $A$ and radium- $C^{\prime}$, actinium- $C$ and radium- $E$, actinium- $B$ and radium- $D$, and the actinium and uranium isotopes of lead, are other cases. These result by branchings of the series, and, since in the respective branches the amount of energy evolved in the successive changes is different, the internal energy of the various pairs must be different, although for them atomic weight as well as spectroscopic and chemical character are all identical. I recently suggested in the case of the two end-products of thorium that possibly only one of these survives in geological time, namely, that produced in the smaller quantity, and that the other continues to break up in changes as yet undetected (Royal Institution Lecture, I8th May 1917; Nature, $1917,99,414$ and 433). This would account for the relative poverty of thorium minerals in lead, which was the original basis for the conclusion that lead

${ }_{1} \mathrm{Mr}$ Aston tells me this work is still being actively prosecuted at the Cavendish Laboratory. 
was not the ultimate product of thorium. The point still remains experimentally untested. Isobaric isotopes of the character in question can only at present be distinguished if they are unstable and break up further, but they must be taken into account in any theoretical conception we form of the ultimate structure of matter. The accomplishment of artificial transmutation would reveal them if they existed, and the discovery of any new property, like radioactivity, concerned with the nucleus of the atom rather than its external shell, might also be the means of revealing differences of this character.

On the other hand, the production of isobaric heterotopes is the ordinary consequence of $\beta$-ray changes, single or successive. Such heterotopes, possessing different chemical and spectroscopic character but the same atomic weight, have been recently termed isobares by A. W. Stewart (Phil. Mag., 1918, [vi.], 36, 326), who, following Fleck's work on the chemical resemblance, not amounting to non-separability, between quadrivalent uranium and thorium, has drawn a parallel between them and elements existing in more than one state of valency, as, for example, ferrous and ferric iron.

The extent to which the study of radioactive change has enlarged the conception of the chemical element may be summarised by the statement that now we have to take into account in our analysis of matter, not only the heterobaric heterotopes before recognised, but also heterobaric and isobaric isotopes and isobaric heterotopes or isobares.

\section{The Nuclear Atom.}

I have attempted to present the most important facts of radioactive change without introducing any theory or hypothesis at all as to the structure of the 


\section{CONCEPTION OF THE CHEMICAL ELEMEN'T}

atom. I think it important to keep the two matters distinct. Our knowledge of electricity, which in its modern phase may be considered to start from the relatively recent discovery of the electron, is still far too imperfect to enable any complete theory of atomic structure to be formulated. My task would be incomplete, however, if I did not refer briefly to the nuclear atom of Sir Ernest Rutherford, which may be regarded as the logical descendant of the earlier electronic atom of Sir J. J. Thomson. The weakness of the latter was that it took account essentially only of the negative electrons, and its attempt to ascribe the whole mass of the atom to these nearly massless particles involved the supposition that a single atom may contain hundreds of thousands of electrons. The actual number is now known to be rather less, as an average, than half the numerical value of the atomic weight. Although unsatisfactory in accounting for the mass of the atom on an electronic basis, it was much more in line with present views in accounting for chemical character and the arrangement of elements in the periodic table. The root idea that the successive elements in the table are distinguished by the increment of one electron in the outermost electronic ring, followed, as period succeeds period, by the completion of this ring and the formation of a new external one, so that members of the same chemical family have similar external ring systems, is still the most probable view yet advanced. In conjunction with the conception of the nucleus and the gradual unravelling of the various series of characteristic $X$-radiations, both experimentally and by mathematical analysis, it bids fair soon to give a definite concrete picture of the structure of all the different elements (compare L. Vegard, Phil. Mag., 191 8, [vi.], 35, 293). 
As regards the deepest region of atomic structure, wherein radioactive phenomena originate, the nuclear atom is the only one proposed that has any direct experimental foundation. It is based on the deflections suffered by the $a$-particle in its passage through the atoms of matter, on the one hand, as Bragg showed many years ago, on the exceedingly slight deviation of the overwhelming majority of the $a$-particles, and, on the other, on the subsequently discovered large deviations suffered by a minute proportion. The nuclear atom is a miniature solar system, like most model atoms, the negative electrons occupying the atomic volume by their orbits around a relatively excessively minute central sun or nucleus, wherein the atomic mass is concentrated, and consisting of an integral number of atomic positive charges equal to the atomic number of the element, and the number of electrons in the outer shell. An $\alpha$-particle is the nucleus of the helium atom, and, unless it passes very near the nucleus of the atom through which it penetrates, its path is practically undeflected. The few that chance to pass close to the exceedingly small but massive central nucleus are swung out of their path like a comet at perihelion, save that the forces at work are regarded as repulsive rather than attractive.

It appears from radioactive change that atomic disintegration occurs always in the central nucleus, both $\alpha$ - and $\beta$-particles originating therein. The atomic number of the element is its nett nuclear charge, the difference between the positive and negative charges entering into its constitution. Of all properties, mass and radioactivity alone depend on the nucleus; the physical and chemical character and the spectrum of an element originate in the outer shell. The character of the outer shell is fixed by the nett charge, not at all by the mass or internal 
constitution of the nucleus, and the integral variation of this charge from I to 92 gives the successive places of the periodic table. Expulsion of two $\beta$ and one $a$-particle in any order gives an isotope of the original element with atomic weight four units less. Isobaric isotopes resulting in branch changes differ only in the internal structure and stability of the nucleus. The atomic mass is the only nuclear property known before the discovery of radioactivity, and, except as regards this, the whole of physics and chemistry up to the close of the nineteenth century had not penetrated beyond the outer electronic shell of the atom. Even now, mass and radioactivity remain the sole nuclear properties known.

\section{Conclusion.}

Nemesis, swift and complete, has indeed overtaken the most conservative conception in the most conservative of sciences. The first phase robbed the chemical element of its time-honoured title to be considered the ultimate unchanging constituent of matter; but since its changes were spontaneous and beyond the power of science to imitate or influence to the slightest degree, the original conception of Boyle, the practical definition of the element as the limit to which the analysis of matter had been pushed, was left essentially almost unchanged.

The century that began with Dalton and ended with the discoveries of Becquerel and the Curies took the existing practical conception of the chemical element and theorised it almost out of recognition. The element was first atomised, and then the atom was made the central conception of the theory of the ultimate constitution of matter, on which modern chemistry has been reared, and from which its marvellous achievements, both practical and theoretical, have mainly sprung. The atom and the 
element became synonyms, related as the singular to the plural, and implicit throughout this century was the assumption that all the atoms of any one element are identical with one another in every respect. The only exception is in Sir William Crookes's conception of "meta-elements" as applied to the rare earths. Here the idea was rather that of a gradual and continuous difference among the different atoms of the same element, the properties of the latter being the mean of those of its individual atoms. Modern developments have tended definitely away from rather than towards this view.

The second phase in the development of radioactive change has now negatived each and every one of the conceptions of last century that associated the chemical element with the atom. The atoms of the same chemical element are only chemically alike. Unique chemical and spectroscopic character is the criterion, not of a single kind of atom, but rather of a single type of external atomic shell. Different chemical elements may have the same atomic mass, the same chemical element may have different atomic masses, and, most upsetting of all, the atoms of the same element may be of the same mass and yet be an unresolvable mixture of fundamentally distinct things. Present-day identity may conceal differences for the future of paramount importance when transmutation is practically realised. Then it may be found that the same element, homogeneous in every other respect, may change in definite proportion into two elements as different as lead and gold. The goal that inspires the search for the homogeneous constituents of matter is now known to be, like infinity, approachable rather than attainable. The word homogeneity can in future only be applied, qualified by reference to the experimental methods available for testing it. 


\section{CONCEPTION OF THE CHEMICAL ELEMENT}

All this, of course, does not in the least affect or minimise the practical importance of the conception of the chemical elements as understood before these discoveries. Every chemist knows the conception has had and will continue to have a real significance as representing the limit of the spectroscopic and chemical analysis of matter which remains, although it now is known to convey something very different from the original and natural conception of the chemical elements as the $l m n$ 's of the material alphabet. 


\section{MA'TTER, ENERGY, CONSCIOUSNESS}

\section{AND SPIRI'T ${ }^{1}$}

THE feeling is gradually awakening in the consciousness of the community, that the discoveries and advances made by science in the past century are not such as they have been accustomed to be represented by people to whom they are a sealed book, as important to money-making and trade, for waging war and overtaking the heavy drudgery of the world, but in an altogether different category from humane studies. The scientific materialist in seeking to understand the external physical universe, and the relation in which men stand thereto, has invaded territories which formerly the humanist and theologian had to themselves, and made discoveries which are essential to the understanding of modern life and its problems. If it were necessary to make choice between the old and the new in its relation to the world of to-day, rather than in relation to some remote childhood of the world, the knowledge gained in the last hundred years surely is the part of the whole of knowledge which could least be spared. It is just this part which men who have to govern modern peoples, administer the affairs of present-day empires, and instruct and educate the youth of the world, usually know least about. That science has something to say apart from its

1 Lecture to the Aberdeen University Christian Union, Marischal College, 25th April rorg. 
application to the material and utilitarian interests of men, that its revelation is both clear and inspiring, "a source not merely of material convenience but of spiritual elevation," as Mr Arthur Balfour has said, is, however, now being more generally understood.

Science has wrecked beyond repair certain dogmas and beliefs generally current prior to the development of the doctrine of evolution on the biological side. That doctrine has completely reversed the traditional outlook of men and turned their highest interest from the contemplation of the past to the problems of the future. But physical science, the science, in the first instance, of the inanimate world, contemporaneously with these great developments of biology, has contributed in its doctrine of energy an advance of direct and living human interest certainly not less, and possibly even of greater fundamental importance than the conception of evolution. It, therefore, is almost a duty of the scientific man, however little he may desire or feel himself competent for the task, to attempt to rebuild as well as destroy, and to state, so far as he can, what is his view of the matters in which hitherto the priest and the philosopher have, with insufficient knowledge of external nature, been left to themselves. Such a synthesis has been hitherto attempted, if at all, from the standpoint of biological science, with which, I need scarcely say, I am totally unfitted to deal. In approaching it from the purely physical standpoint, one has the very great advantage that one starts from a basis which now may be considered beyond controversy or cavil, and which even the phenomena of life cannot complicate or make obscure. On the other hand, the corresponding disadvantage is that one starts farther off from and has a greater distance to go 
to reach the domain that has to be brought into reconciliation with external nature. The biologist dealing with life from the scientific standpoint has the more central position. The ultimate problems of matter and energy, on the one hand, and consciousness and spirit, on the other, lie equally outside his true domain, and are apt to appear, perhaps, equally inaccessible and mysterious. The physicist from his more extreme standpoint, completely outside of the realm of life, may not be able to see very far, but what he can see is seen with all the certainty and definiteness that distinguish and characterise the explanation of the phenomena with which he deals. Do not draw the hasty conclusion that, because the clarity and unanimity reached in the study of inanimate nature have not been approached in the study of life, they have therefore no application whatever to the higher aspects of life. On the contrary, I hope to show that, as regards what it is impossible to believe at least, they effect a not inconsiderable simplification, and so pave the way at least for a more definite and truer human philosophy to replace the old.

\section{ImMORTALITy OR THE CONSERvation OF Personality.}

Life, so far as our direct experience is concerned, is lived in an intimate relation with the external physical universe, and the breaking of that connection is death. Almost before men could count or reason correctly about the simplest phenomena, they have contended that life transcends the breaking of the bond between it and the external world and persists after it has departed from this world. The attitude of mind is very familiar in science, as in other fields. Amid a world of appearance and 
change, science seeks the fundamental and abiding realities, and the test it applies is the test of "conservation." Whatever is conserved unchanged during all possible changes is regarded as real. We speak of the conservation of matter, because though, to casual observation, matter is anything but conserved,-for example, fuel is "consumed" by fire, and the acorn grows into the oak,-yet the appearances are false, and the total amount of matter remains constant in these as in all other changes.

Nor is it necessary that what is conserved should be material and tangible. We speak of the conservation of energy, meaning that in the variegated interplay of matter, motion and force, whatever happens, however complicated the mechanism or however violent and catastrophic the events, something is unchanged and remains the same before and after, and that something is termed energy. It is a complex conception capable of being illustrated in simple cases by reference to actual phenomena, but to be accurately defined needs to be expressed as a mathematical relation between the matter, forces and motions involved. But nothing, not even money, has a more real existence.

In modern science, matter and energy are the unchangeable realities that can neither be created nor destroyed. If they appear they must come from somewhere, and if they disappear they must go somewhere. So whatever extraordinary events may occur, behind the changing appearances there is a definite basis of unalterable reality in the physical world.

The doctrine of the immortality of the spirit or conservation of personality may be regarded as the inverse form of the scientific argument above. The real part of a man is not his bodily organism, which is continually wasting away and being as continually 
renewed, nor the physical energy at its command, which is derived entirely from the inanimate world, but is the personality resident in the body and in control of it. There is no other interpretation of the difference between a man alive one moment and dead the next, which, in spite of the great advances in the interpretation of the mechanism of life made by biology, altogether eludes apprehension in terms of the other fundamental conceptions to which our inquiries into ourselves and our environment have led.

In science we regard that which is indestructible as having real existence. In philosophy and religion that which has a real existence has been from time immemorial regarded as immortal, and it seems to be truly in accordance with the laws of thought, which in science has led to some of the grandest and most fruitful generalisations, to find the idea of personal immortality running like a thread through religious beliefs, even down to the most primitive. I make no pretence to using, in their correct technical philosophical meaning, such terms as consciousness, personality and spirit. All I am concerned, for my argument, to state is that in passing from the phenomena of the inanimate world to those of life in general we have to admit at least one fundamental conception which cannot be connected with the conceptions of the inanimate world, and which it now seems most unlikely ever will be.

I have already warned you that from physical premises it is not possible or easy to proceed very far, and I make no pretence of discussing whether the personality, conscience and soul of a man is or is not, without any entirely new fundamental conception, capable of being regarded as the further development of the simple consciousness, or awareness, of its existence as a separate creature, possessed by the 
lowly organism. I accept the, to my mind, complete break of continuity between the animate and inanimate worlds, as being all that is really demanded by our present knowledge. If I am told that unless I make another such break between man and the animals, I weaken the argument I have suggested in accounting for the origin of the belief in the immortality of the soul, by including therein all living creatures, however humble, it is only necessary to say that the general doctrine of evolution of man from the lower animals seems to point unmistakably in this direction.

\section{Science and Religion.}

It is a nice question whether it is easier for the religious man to connect his system of thought with that of science, or for a scientific man to find the due relationship between his conclusions and the common current outlook upon ethical and spiritual, if not specifically theological, beliefs. I would have thought that just as it is easier for a coachman to learn to drive a motor-car than for a chauffeur to learn to handle horses, so it ought to be easier for those whose concern has always been with human personality rather than its mechanism to master the essential principles that have led to the mechanistic philosophy of science. But that is probably mere personal bias. The two studies belong to different worlds, as the poles apart, so far as they concern humanity, but men can afford to neglect neither. It is the priests, not religion, it is difficult for scientific men to live with, and science cannot coexist with priest-craft. The scientific man seeks truth as a continually developing revelation, and he changes his outlook on the world according as it unfolds itself before his eyes. The priest teaches 
that in some remote period of the world God Himself revealed Truth once and for all time, and his profession is to guard it against all comers. I do not believe that the soul any more than the mind can stagnate. It must grow or decay. Christianity cannot be crystallised into a creed binding for all time and, least of all, into a creed dating back to the century that preceded the relapse of Europe into intellectual barbarism. The world changes and has changed in the last hundred years out of all recognition, not on account of anything contained in the Mosaic or Christian revelations, but on account of the new revelations of science. Though these have come about by a process the reverse of supernatural, by laborious experiment and measurement, by slow accumulation of knowledge and honest and unbiassed weighing of the evidence, they constitute an essential part of the whole truth, be our religious convictions what they may.

There is another important difference between what is understood by truth in the realms of science and religion respectively. A truth that claims to be a divine revelation must necessarily be supposed to be the absolute or ultimate truth, which, by common consent, is unattainable by any of the methods of human inquiry. What a scientific man conceives to be the truth is, in reality, something quite distinct. $\mathrm{He}$ is not concerned, and, indeed, it is hardly too much to say that he is not even greatly interested, in ultimate, absolute and unattainable truth. He frames a hypothesis and tests it in every possible way. So long as every known or to be discovered fact is in accord with the hypothesis, and no other hypothesis is in accord with them, it is all he seeks to know. If, in the external universe, every event and phenomenon occurs in the precise and often predicable way it would occur if the hypothesis 
were true, that hypothesis is regarded as the truth, until something occurs which proves it to be in error. There is sometimes loose talk-even among scientific men attempting to generalise concerning other subjects than those in which they have won their position-that the scientific hypotheses of one age become the laughing stock of the next, but such talkers are often the laughing stock of their own age to those best qualified to form an opinion. As a matter of fact, there is a steady and increasingly rapid advance being made into the foundations of knowledge, which is impressive in no way more than in the continuous evidence it affords that these foundations have been well and truly laid.

The methods of science in winning knowledge are of course its own. No one desires to suppose that they are the only methods by which Truth is to be sought or found. But when it comes to the modes of imparting knowledge already won, to educating the growing citizen to a knowledge of himself and his environment, we find differences as great.

In matters of science we do not start a child upon fundamentals. We do not say that in all the varied happenings of the universe the sum of half the product of the mass into the square of the velocity and of the product of the distance into the force remains constant. We do not start with the conception of energy and from it deduce mechanical, thermal, electrical and chemical phenomena. The conception of energy belongs to the generalised philosophy of physical science and is the end result of generations of scientific thinkers. But the priests, of sections at least of the Christian religion, get hold of the child and confront it with all the end products of the philosophy of the childhood of the world, God and the soul, heaven and hell, angels, spirits, and the mysteries of the Trinity, almost before it can walk. 
Philosophies, whether scientific or humane, are the end and not the beginning of wisdom. They are the epitomised expressions of the understanding of the age in which they originated, and, in themselves, or at any other age, they are as little intelligible as shorthand would be to one who has not learnt longhand. They are in no sense the stepping-stones from which a totally immature or uneducated mind can leap to the inheritance of the ages. It leaps rather into chaos and absurdity. Especially when there occurs, as did occur with the triumph of barbarism at the close of the fourth century, an almost total break of intellectual continuity between the age they served and that to which they survive, they are apt to convey meanings as remote from the original as the conception of energy is from that of the Deity.

\section{Man as THE LinK.}

Science and religion could afford to ignore one another entirely, if sought entirely for their own sake and if the ordinary man was not the link between them. A Hindu mystic or a monk in one of the ascetic orders of the Roman Catholic Church, who has withdrawn himself from the world and practised starvation, celibacy and general mortification of the body, aspires to reach a spiritual plane from which the world, either in its mechanical or its vital aspect, can be left behind and forgotten as a distraction and a curse. Far be it from me to libel a calling I do not profess to understand. My criticism merely is concerned with the value to humanity of the results attained. For whatever pinnacle of pure contemplative philosophy that may thus ultimately be reached, little that is communicable or of general value to the life or thought of the world seems to have been the result. 
His scientific analogue is, no doubt, equally selfish. He too must utterly immerse himself in his own plane of thought, and must investigate the mechanism of nature without giving consideration even to the existence of any other plane, or to whether his work be of good or evil import, valuable or useless to humanity. But such a man, unconsciously no doubt at first, but, as is now well understood, infallibly, has taken the one and only real method of discovery in science, and his work in other hands has been such as to change the mode of living and mental outlook of his kind.

But the interest of the average man will lie and must continue to rest in a just appreciation of the relations of these several worlds, the spiritual and the mechanical, to his own life. Not so much antagonistic as out of all direct connection, the one with the other, they do meet on common ground-in him. His is the unfortunate body from which, during life, neither the aspiring soul can altogether soar, nor the wheels of scientific materialism can be unmeshed. $\mathrm{He}$ has to make his peace with both, as he is the sufferer if his soul gets caught in the gear.

Neither the spiritual nor mechanical worlds contain him. First and foremost, neither spirit nor machine, he is an animal, born as animals are born, his normal healthy life largely occupied with the affairs of sex, with parents, mate and offspring and the domestic hearth, in later phases with the social, communal and national life.

Thus we have three distinct worlds, linked each to each, as the links of a chain, the middle link only being in direct relationship to the whole. The cold, soulless mechanism of the cosmos invades the living organism, and the principles of energy and matter which we encounter in the inanimate world govern man no less than mechanism. All that we can learn 
by science of the purely physico-chemical processes or mechanism of the living body has been learned in those deep foundations of knowledge appertaining to the simplest state of things, wherein phenomena and events are unobscured by the intervention of life. Mechanics, the science of moving masses of matter, has been extended to include masses that are not individually capable of being apprehended, to the individual molecules and atoms of which matter is built, the mechanics of which constitute chemistry and physics.

\section{The Scientific Control of the Mechanical WORLD.}

Naturally it is with this world that I am most concerned, for it is from here that any contribution that physical science can make to the common stock of philosophy must come, and, indeed, the clarification of thought that has resulted from the occupation and interpretation of the mechanical world, whether of cosmical systems or of the body of a man, is unique. For from this world mystery in any real sense has been banished.

I have to make this more clear. Our knowledge of matter and energy is not complete and in many respects is far from complete. But in this field we can move with an assurance, and a power of predicting events before they occur, which is true of no other realm of study. It is true also that Absolute or Ultimate Truth here, as elsewhere, may be for ever unattainable, that the fundamentals of to-daymatter electricity, the ether and energy-may in the fulness of time be displaced by still more fundamental conceptions. But do not believe that future advances in this field are going to invalidate and overthrow the conclusions already reached, so far as they concern life. We have lived long enough in this world to 
have acquired the sense of direction, though whole territories may await exploration. Though the road to the absolute truth stretches, as always, into a distance that may be approached but for ever recedes, we know the direction that the road takes. This is the crux of the whole matter. Its direction is definitely away from and not towards the mysteries of life and spirit. The path hewn by knowledge through ignorance points two ways in the direction of the absolute unattainable truth. Man has always tended to confound these two classes of the ultimately unknowable. Heaven is at once the abode of the constellations, which obey the laws of mechanics with undeviating precision, and where events and consequences are predicted before they occur to the fraction of a second, and also the abode of God, and the heavenly host of disembodied spirits. Magnetism is in a different world from the "animal magnetism" of Mesmer, and the wireless telegraphy that transmits messages through space affords no justification for believing, or otherwise, in telepathy. I have been struck with one curious point in the interest aroused by the recent advances in physics in the minds of the general public. I believe it is largely due to the underlying, if unexpressed, belief that, in thus laying bare the deeper secrets of external nature, we are approaching the nearer to the solution of the problems of life and the soul. One's scientific sense of direction tells that the further one advances towards the ultimate insoluble problems of physics, the more completely one leaves behind the phenomenon of life and all its mysteries. The advance in this direction has been from life and not towards it, and the clouded horizons towards which we move, whatever they may contain of wonder and revelation, are likely to afford little of moment to the real mystery of life. 
The measure of the exactness and extent of our knowledge of the inanimate universe is shown by our powers of controlling it and guiding it to serve our ends. In the inaccessible regions of space the test is prediction, but, with regard to the phenomena around us, in addition to this, imitation and control follow understanding and are the signs that we are on safe ground.

Here, again, knowledge may only be beginning, but the success achieved is a justification for the view that mystery in any real sense has been banished from the inanimate universe. In engineering we draw upon the chemical energy of fuel, and by combustion convert it into heat-the chaotic rush of molecules in every direction at once-and from this chaos, by the steam-engine or other prime-mover, we produce the orderly motion of masses of matter which is mechanical energy, and this is used to lighten the heavy labour of the world and perform tasks which before would have been done by draught cattle or slaves.

The terms "vital energy" or "vital force" have disappeared. Energy, like money, has many denominations, but these are honoured at fixed exchange ratios throughout the universe, whether in the living organism or in the non-living world. The power by which we live and move and have our being is none other than that which drives on the stars in their courses and maintains their splendours over the long epochs of cosmical time. Science now takes it where it is to be found, whether in fuel, waterfall or sunshine-it is all one-and uses it to do the labour of men. Science can even transfer energy from its inanimate originals and direct it into living bodies, so that now two may live where before one would have struggled miserably for an existence.

A simple people, who confused power with deity, 
like the ancient Greeks or primitive Vikings, would have seen, in this control of the powers of Nature, the act of a god, and from their point of view it, truly, is the most god-like achievement man has ever accomplished. But it would be an unsophisticated person who to-day would regard physical power as an attribute of the deity. On the view I have expressed the only connection between will and power is through the agency of life, animal or vegetable.

\section{The Body as a Mechanism.}

The principles of energy and matter, with which we are confronted in the inanimate world, govern man no less than mechanism. The physics and chemistry, the mechanism of molecules rather than masses, of a living organism, differ from the physics and chemistry of non-living matter notably in character, but, so far as we can ascertain, not in any fundamental way. That is to say, the physicochemical processes of the living body conform to all the laws which apply when life is absent.

As is well known, many of the peculiar products of life can be artificially or "synthetically" prepared without the aid of the organism. Cane-sugar has been made identical with that produced by the cane or beet, and so with camphor, the familiar flavouring essences derived from plants and fruits - vanilla, pineapple, and so on-dyes, like alizarine and indigo, so that the cultivation of madder-root has ceased, and that of the indigo plant, the woad of our ancestors, is dying out.

It is quite' true that the methods employed are, almost without exception, entirely different from those that take place in the plant, and are of such a character that they would instantly destroy life of any sort. But we do not think, for all that, that 
there is a "vital chemistry" different from ordinary chemistry. Some of the most peculiarly vital chemical processes have lately been found to be precisely similar to those that occur in mineral and inorganic chemistry. Thus fermentation, once thought to depend upon living organisms, is now known to do so only indirectly. Directly, fermentation processes are due to unorganised "enzymes," secreted by the organism, and these enzymes are analogous to the "catalysts" of inorganic chemistry. A suggestive point is that such catalysts-finely divided platinum metal is one of the commonest used-are "poisoned" by the same poisons-arsenic, prussic acid, and so on-as are most deadly to life. This means that the chemical processes occurring in the living body, through the presence of enzymes, are largely of the same character as those that occur with mineral substances in presence of finely divided platinum and similar "catalysts." The poison acts by destroying the peculiar activities of these catalysts, and so stops the processes they bring about.

I do not wish to imply that bio-chemistry, as yet, has been reduced to a special branch of ordinary chemistry, but that all the principles that govern chemical phenomena in inanimate matter are observed in the processes peculiar to life.

\section{The Organism as a Mechanism under Internal} Control.

The achievement of a certain limited, but still very significant, control over the processes of inanimate nature so as to make them proceed to ends different from that which naturally they would take, and, especially, in directions which are useful, or which produce results otherwise only attainable by the complex processes in the living organism, 
enables us to construct, as it were, a model of the living organism. It is a machine, or mechanical microcosm, under continuous and varying control, by means of an internally resident directing intelligence or personality. It may assist in making the abstraction of the personality from the organism more clear if we consider a somewhat parallel case.

For ages Niagara roared over its gorge in accordance with the laws of nature, uncontrolled. To-day, the laws of Nature are obeyed as perfectly as before, but the flow of the water is under human control to a considerable extent. The sun shines and vaporises the waters of the ocean. The solar energy is used in lifting the water to the skies to descend subsequently as rain, which arrives in due course at the Falls. Here the water suddenly drops 160 feet clear, acquiring a velocity of about Ioo feet a second before it mingles with the river in the pool below the fall. At this moment it has mechanical energy, and this is the moment that must be seized if that energy is not to be dissipated and lost for use. A moment later, otherwise, its motion is replaced by commotion, the water eddies and swirls in all directions at once, until its former motion is evenly distributed among its molecules, moving in every possible direction. At this stage the energy has become heat energy, which is due to the perfectly deco-ordinated motion of the individual molecules. If the temperature at the bottom of the fall were taken, it would be found to be about one-ninth of a degree, Centigrade, higher than at the top. Such is a simple natural system, a colossal example of waste and rsthetic indulgence which would have delighted the heart of a Ruskin, but which humanity is scarcely yet so wealthy as to be able to afford.

Now tunnels have been drilled in the rock, 
through which a part of the water falls, no longer to run riot in commotion at the bottom, but smoothly to be checked and deprived of its energy in a turbine, to which is geared a dynamo, from which, again, the transformed energy flows out as electric power capable of lightening the labours of men.

Niagara to-day is a mechanism as before, but it has been linked to an external intelligence, capable of guiding and varying its action at will. It is thus one step nearer to being a living organism than before, and it may serve as a rough and partial model of that which I have conceived the living organism to be.

There is no life-body, mind or soul, so far as this world is concerned-no birth, growth or even existence, without a continuous supply and expenditure of energy. For good or evil, man has geared his own mechanism with the unbounded machinery of inanimate Nature, and so has made possible the elimination of the ugliest features of his existence, under wisdom, or their accentuation to a degree hitherto unimagined, under folly. Not only fertilisers but also high explosives, or some of raw materials from which they are made, such as nitric acid, are now largely produced by the power of hydroelectric installations. A modern definition of the valleys of Switzerland is "glacier at one end and 98 per cent. nitric acid at the other."

Man is thus able to project out of himself the personality, that is in control of his own body, into the mechanism of Nature, so that, without violating any law or principle, a process that goes naturally in a useless direction may be made to go in a direction that is useful. In the control of his own mechanism, similarly, it is the energy of the external inanimate universe which is guided, not coerced, and still less created. The guidance with- 
drawn, the processes of life resume their uncontrolled natural direction. In low organisms the guidance seems to be largely automatic, a response to stimuli which can be artificially imitated. Even in man, the more important routine functions of life are performed, asleep and awake, by a subconscious regulation, or, as some hold, a subconscious personality. But in the higher animals there has developed a consciousness or awareness of its individual existence and of the existence of its environment, which intelligently varies and directs the acts of life at will. The mystery is in none of the phenomena of life upon which, perhaps, the most wonder and poetic fervour have been lavished, and which are hardly more wonderful than those that occur in inanimate materials under human guidance. It is in the combination of the intelligent guidance with what, for present purposes, has to be considered a perfectly understandable machine. Separately the two functions are readily comprehensible. Their combination in a single self-contained organism is the real mystery of life.

\section{An Argument in Favour of Theism.}

It is quite outside my intention or capacity to indulge in any specifically theological argument. But perhaps I may be allowed, in passing, to point out that the argument might be extended in favour of theism. The self-contained organism is not comprehensible, but the combination of an inanimate mechanism and an external will is more intelligible. But there is in man a conscience as well as a consciousness, an ineradicable aspiration towards virtue, which is certainly no less difficult to understand. The combination of the machine and soul is as much a riddle as the combination of machine and 
mind. Theology has striven to separate the two, has abstracted the soul as an independent existence, and regarded it as a projection from and part of a general soul of humanity, existing distinct from and outside of individual men. For the mechanism of Niagara we have the bodily mechanism, and for the personality in control, instead of the humble representative of applied science, the humble individual soul, acting upon orders received from and owing allegiance to an external deity of which it forms a part.

H. G. Wells has defined the main difference between an ordinary, modern, intelligent, welleducated, benevolent and morally right-minded atheist or agnostic and the genuine religious enthusiast, as being in the former's view of his, as I have indicated, very high-minded and unimpeachable personality as a separate isolated existence, independent of all others, and the latter's view that what is benevolent, high-minded and noble in his personality is not a natural consequence of the lifeprocess, but part of a personal God, who responds to and lives in the closest relationship with the individual souls of men.

The engineers in the power-house of Niagara are assuredly not isolated existences actuating their machinery out of their own self-sufficiency. They take their instructions from a superior, and the science and practice embodied in those orders are an accumulation of all that is best in the labours of many men, alive and dead. No single mind could create that knowledge, even if one could be found fully to comprehend it. If you talk to these men at their work, you would find, no doubt, that they were astonishingly self-contained, knowing little of and caring less for the mere theoretical amateurs who, with a few bits of sealing-wax and wire and some 
crude home-made machines, created their livelihood. In much the same way the religious philosopher holds that the benevolent atheist attributes to himself and his own innate self-righteousness a very great deal indeed. He prefers to believe himself the humble subordinate of a superior being that combines, in one personality, the best of all beings that ever lived.

There is common ground in the position, that even though a single mind might be able to comprehend all that has gone to the evolution and survival of the essentially humane type of man, no single personality could, if isolated, arrive at it by himself. There is a continuity that endures in the creative achievements of humanity, whether, as the theist believes, in the form of a personal Deity, or whether as a collective memory, engraved in type or ancient saga, and from which, whether we read or not, we can hardly escape. There seems very little between these views worth argument, and among educated modern peoples, were it not for the priests, religious differences would scarcely trouble the world.

\section{The Rubicon between Mechanism and Life.}

There is, of course, a danger, since knowledge in these days is of necessity patchy, and first-class minds are rarely content with the known, but are the first to push off into the unknown, and so become specialists, that the mystery of life becomes automatically thrust out from those regions each has independently explored for himself into those known only at second-hand and by hearsay or from books. Thus, as a physicist or chemist, I hold that there is no mystery in the proper sense in the inanimate universe, and I put the Rubicon between mechanism and life. A biologist would probably have a very 
great deal to say on this question, and conceivably might totally disagree. But, apart from extreme opinions on such a point, I think there is a growing tendency to distinguish between the mechanism of life and its conscious regulation. I think it would be admitted that a completeness of knowledge, equal to that in the processes of inanimate nature, with regard to the former, and even the artificial generation of life of a simple kind, would not necessarily add anything to the solution of the real mystery.

Once the Rubicon between the most complex non-living mechanism and the simplest living cell is crossed, the doctrine of evolution seems to point clearly to an unbroken road of development up to the higher expressions of life. On this view, the peculiar problems of religion and the human soul are not the most fundamental or incapable of enunciation. In man, it is true, we get hopelessly beyond the range of physical science, but, in comparison with the simplest living organism, it is a difference between magnitudes alike infinite. Mechanism there is as before, and subconscious control for most complicated routine processes, but the mind can hardly be equal to the task of explaining itself to itself. The mechanical and even the animal or vital aspects have been thrust into the background by a developed personality, that consistently acts and tries to act-and therefore, in the language of science, already explained, is-a distinct being, resident in the body as a man may live in a house, and, if real, then by the canons of human thought, immortal. Thought, reasoning power, memory, free-will, the æsthetic perceptions of beauty and harmony, the ethical ideas of virtue, justice, duty, and self-sacrifice, and the spiritual aspirations of holiness and triumph over death, divide him from the simplest form of life. Science, assuredly, has a 
long road to travel from the stars to the kingdom of heaven. But there seems to be but the one chasm that cannot be crossed, and which, though the gulf ever narrows, still remains unbridged. As Tennyson has it-

"Flower in the crannied wall,

I pluck you out of the crannies,

I hold you here, root and all, in my hand,

Little flower-but if I could understand

What you are, root and all, and all in all,

I should know what God and man is."

Some Consequences of Physical Science.

The link in the chain that binds man and his destiny with the external universe is as dangerous to ignore as is the link forged by ethics and philosophy that connects man with his fellow-men and with the realm of spiritual things. Physical science divorces power from will, two very important functions that theology in the past has confused to the unutterable discomfiture of mankind. The will to perform, and, in the special sense that concerns human beings, the goodwill to perform good, is in its nature and origin alone an attribute of life. The power to perform is derived in toto from the inanimate world, however many elaborate metamorphoses it may undergo, and through however many organisms, vegetable and animal, it may pass before it reaches man.

The world that is dead vitally and spiritually is not dead physically. The moon, it is commonly supposed, is a dead world, though since the same sun shines upon it as upon us it cannot be really dead. It is in the present state of physics impossible to conceive of a physically dead world, that is to say, a world without any available source of energy. The discovery of radioactivity has revealed an immense 
store of energy in the atoms of matter, compared with which all that hitherto has been known sinks into insignificance. In certain elements-those that show the property of radioactivity-this energy is being slowly given up. This has made, in certain departments of thought, a complete revulsion of outlook. Instead, for example, of the world gradually cooling by radiation it must be getting steadily hotter in its interior owing to the energy evolved by the radioactive elements it contains, unless there are unknown factors at work to compensate for this. A world without energy, in the present state of knowledge, implies a world without matter and, therefore, no world at all.

Hitherto it has been supposed that we were for ever cut off from the major sources of natural energy, which maintain throughout the ages the profligate expenditure from the sun and stars. The coal and oil from which the modern world derives its new powers represent but a limited legacy from the past, rather than a permanent increase in its income of energy. But the discoveries in radioactivity have shown that, in the smallest atoms of matter all around us, there exists stores of energy a million times greater than any so far harnessed. Limitless physical power awaits humanity so soon as the knowledge that shall lead to its control and application has been obtained. How many unrecorded ages elapsed before the energy of fuel was controlled, and in how short a space of subsequent time has it altered the whole mode of life of the world! Given a clear course and that most rare of national qualities, common sense, physical science can abolish the struggle for existence so far as concerns food and fuel.

But so far the pearls of science have been cast before swine, who have given us in return million- 
aires and slums, armaments and the desolation of war. But let us turn to the other side of the picture. The use, rather than the abuse, of this control of the unlimited resources of Nature brings within the range of practicability the abolition of poverty, destitution and economic slavery of the many, in contrast to the few. Weighty enough influences still prevent any approach to the realisation of Utopia, but-and this should be written on every Church throughout the length and breadth of the land-they are not now physical but moral. The Churches, which should have been the first to welcome the possibility of making such a forward step, have still to be won over to the side of the humane man. They have hitherto in this country proved themselves the most bigoted and powerful opponents of the science, which alone has been able to bring within the realm of practical politics for the masses the Christian principles to which they have rendered such devoted service as academic aspirations and ideals.

One of Huxley's truest and most profound remarks is contained in the Rectorial Address he delivered to theistudents of this university. "Men are beginning, once more, to awake to the fact that matters of belief and speculation are of absolutely infinite practical importance."

It is of the greatest practical sociological importance to ask ourselves whether or not we believe in God. If so, in what sort of a God-absolute, exercising complete dominion over the soul and spirit of man, his mind, intellect and aspiration towards the beautiful, his body, over animals, vegetables, the inanimate universe of space and time, matter, energy, the ether and electricity? A religion that on the most important questions of everyday life has nothing to say, either definite or constructive, 
is a greater danger to the vitality of a nation than downright scepticism and unbelief.

The Need for more Rational Creeds.

Human nature changes very slowly and only by painful experience. The influences that were most progressive and elevating in the one age, have to be fought and beaten out of the path of progress in the next. The idea that physical power is one of the attributes of deity, and the conception of an allpowerful being directing the universe and the physical affairs of men, has left behind it a legacy of nothing but calamity. According to the scientific definition of truth, which earlier I precisely formulated, there is no such being. The external universe behaves as a machine working automatically according to the laws and principles contained in its own mechanism, and, so far as exact knowledge extends, it does not exhibit a vestige of that arbitrary and purposeful variation that would imply a personality in control. Science, through the personality of men, has in part assumed its control, and never yet has it been interfered with or resisted. We hear from well-meaning, but rather unpractical, people that the evils the world suffers from are due to its neglect of God, but surely the worst of them are directly traceable to the enthronement of God in the wrong place. Science has banished the conception of deity for ever from the working of the inanimate world, which behaves in all respects as, and therefore is a simple machine left to go. The task of controlling it is man's, not God's. If through ignorance and incompetence he fails, no personality, vindictive or benevolent, will interfere. The machine will go on in the same way as before, and as, according to geology, it has been going on in a regular uniform manner for æons before man arrived on the scene. 
I do not expect to escape or shirk the question, "Who, then, created all this wonderful and intricate machinery?" Science answers that matter and energy cannot be created or destroyed. The universe is eternal. The very idea of creation and destruction is drawn not from the inanimate universe, but from the phenomenon of life. These ideas cannot be considered apart from life, whereas the inanimate universe can. Just as the man of science is unable to push his mechanical conceptions to explain life and the Deity, so the theist must not push his conception of the Deity and life into the inanimate universe. The Rubicon that cannot be crossed in the one direction obviously must not be crossed in the other.

It is not sufficient privately to make mental reservations about a creed, and publicly to avow it. For these ancient creeds are working an infinitude of harm in the world, and nowhere more than to the cause of religion.

The conceptions of the Deity as the creator of the heavens and earth, the controller of the inanimate universe and the worker of physical miracles, have, with the growth of science, merely a historical connection with the conceptions which to-day would be regarded as specifically Christian and are definitely alien to them. If to science were rendered the things that belong to science, what is left would gain rather than lose in significance. 


\section{'TO THE NEW LAUNCH! ${ }^{1}$}

THE Science Students of the University of Aberdeen are to be congratulated on their initiative and enterprise in starting a magazine to be devoted to their interests. It is badly needed. May it prosper and become a factor making for progress.

Old wine into old bottles and the new wine into new! The danger of bursting the old bottles by new wine is, in an ancient university, not a very imminent one, but that of wasting the new wine is. Assuredly students of classical subjects in ancient universities and students of new subjects in modern universities have much to be thankful for ; but it is not, so I am told, unalloyed bliss to be a classical student in a new university, nor a purely honorary privilege to be a science student in an old one. From a residential experience of six universities, three old and three new, I should judge Aberdeen to be the oldest, from the price paid by the science student.

It changes, I am told, rapidly, but its attitude towards science does not change. Huxley's rectorial address to the students of this university in 1874before I was born-will, I firmly believe, never be out of date. I read it regularly to keep up with the times. True we have a Faculty of Science now, a little different from the one Huxley welcomed in anticipation. The Commissioners in 1893 said, "Let there be a Faculty of Science"-and the Faculty of

${ }^{1}$ Written for the first number of The Crucible, May 1919. 
Science was, not to say had been for many years, for the two youngest component Chairs in it were already thirty-three years old, and the next was just celebrating its tercentenary. What a gift is the creative type of mind of the lawgiver. Huxley's poor imagination could only suppose that "the establishment of a Faculty of Science in every university implies that of a corresponding number of Professorial Chairs, the incumbents of which need not be so burdened with teaching as to deprive them of ample leisure for original work." There is, however, now one Chair in the Faculty of Science which was not in existence half a century ago, but I have still to hear that its occupant is actually bored with his ample leisure.

Another perennial favourite of mine is the address by another of Aberdeen's Lord Rectors, delivered in Edinburgh in 1906. ${ }^{1}$ I was in Scotland then, and remember the hopes it gave rise to.

I can imagine the science students here, whose prospective grandparents are now attending our classes, turning to this address, as it is to be found in Nature, 25th October 1906, for something really fresh and up-to-date.

But Carnegie, alas! was, like Huxley, no lawyer. The magician's wand which could create Faculties of Science ready-made waved again. Cinderella and her elder sisters became hopelessly mixed. Whereas before we had arts, lo! now they were all sciences. Everything that ever has been, is or will be studied can at least be studied scientifically. An even more justifiable use of that blessed word will occur naturally to many of my readers, at least among the sporting fraternity. There is a science of the ring, of billiards, football, and so on. The Union Committee should certainly try to get a grant for ${ }^{1}$ Quoted on p. 224 (Appendix). 
a billiard table. We have the authority of the President of the Royal Society, Sir Joseph Thomson, as to its scientific uses. He tells how he once lured a sporting member of his class quite a long way into the kinetic theory of gases and the primrose paths of mathematical physics by tactful references to and illustrations from that very science.

Joking apart, however, the price paid for putting new wine into old bottles has become ruinous. Before the war had branded into the consciousness of the people what the lack of science brought in its train, in the eternal antagonism of authority to new knowledge, verbal subtleties like the above were a perfect god-send. When, however, we were at grips with a scientific enemy, whose science was of the Huxley type rather than that of the $188 \mathrm{r}$ Commissioners, and with the character of which Carnegie was more familiar than his trustees, verbal subtleties did not save the situation, and youth paid the bill. If science is not to get ordinary decent fair-play in ancient educational establishments, it is the youth of the country who will pay again. It is not good to be young in a country that is governed by worm-eaten prejudices and absurd conjuring-tricks with words.

The teaching of a single main science subject, such as chemistry, which demands full lecture and practical courses almost without number for students drawn from the three Faculties of Arts, Medicine and Science, to-day involves probably more actual work than the teaching given in the whole Faculty of Arts a century ago. Of course it could not be done at all, but for the loyal and devoted staff of lecturers, assistants and demonstrators.

Throughout Scotland since, with the B.Sc., serious training in science began, which, though the numbers formerly attending were relatively 
small, more than doubled the amount of tuition to be undertaken, it is to the juniors very largely indeed that science students owe the, in many cases, really excellent courses, especially in practical work, that have been provided. In my own subject, from a knowledge of two Scottish Universities, I can say that when I was a student there was nothing then to approach it in thoroughness, and it can be compared without hesitation to what is done, so far as systematic training is concerned, anywhere. The juniors have seen the needs and tried to meet them, until sometimes their whole time and energy has been absorbed in carrying on in a single department the work that in former days would have been spread among a whole faculty of professors. Whether you take as the criterion duties and responsibilities, or the national indispensableness of the training, or the contribution of the subject to the highest realms of philosophy and inspiration, a subject such as chemistry, in any university attempting to keep abreast of its work, should be represented not miserably by one professorship, but adequately by three or four. Research, worth the name, is a practical impossibility, and it is idle to pretend that a teacher can teach others to research, if he is not carrying on research himself, or indeed can teach first-class students at all for long very much better than they themselves could learn from books.

Of the income of the million pounds given by Carnegie to the Scottish Universities, with the primary object of promoting scientific study and research, up to I9I5, I4 per cent. has been spent on research of all kinds, including historical, linguistic, and economic subjects. Twice as much has been saved, and the loss on the money saved, occasioned by the depreciation of British investments 
owing to the war, would have maintained several first-class Research Professorships since the Trust was founded. I may seem to exaggerate the importance of research in the scientific departments of the Scottish Universities, but the science students can be assured of this, that unless active and famous centres of original investigation spring up in Scotland, and make themselves known all over the scientific world, the whole body of students turned out will suffer grievously in competition with those trained from institutions where such centres exist.

There has lately been much valuable discussion in the Scientific Society and elsewhere of the needs of science students and their perplexities, animated by the commendable desire that the University should afford a serious life-training rather than a collection of academic distinctions and degrees. The state of war has hitherto prevented anything being actually accomplished in the way of bringing the training afforded in science into line with modern requirements, but now that the war is over these matters have a paramount claim for settlement, and it is to be hoped that the new magazine will serve as the focus through which the wants and difficulties of the science students may be brought into general notice and prominence.

As regards the grave and pressing question of the reform of the Science curriculum, I have heard but two kinds of objections. There is first the objection of vested interests, which I will not deal with here because I want to make myself as pleasant as I can, and no discussions are so unpleasant as those which turn on such points. And there is, secondly, the much more respectable objection, which takes the general form of the reproach that, in thus limiting the curriculum, we are seeking to narrow it. We are told that the scientific man ought to be a person of 
good general education and general information, if his profession is to hold its own among other professions. ... Did I not say that you had to read Huxley's address of 1874 if you wish to be abreast of the times?

It is a somewhat portentous moment, perhaps, to launch a new venture. True, it is peace, and we are soon to have bonfires, but there is peace, as sudden and strange, in the centre of the hurrying typhoon, which but heralds its renewal from another quarter. It was at some such moment that H.M.S. Caliope put to sea from the harbour of Samoa, upon which every other vessel there, riding powerlessly at anchor, was about to be piled, and pitting the science of which she was the embodiment against the forces against her, came through with her flag flying the right way up. Science seeks no treacherous anchorage in the wreck-strewn harbours of make-believe, but a clear course with unthrottled power to drive on. Let us wish then for the new launch a voyage as adventurous and triumphant, and power in its engine-room to tow out a whole regatta! 


\section{THE IDEALS OF A SCIENCE SCHOOL ${ }^{1}$}

I HAVE chosen, for my farewell address to the Scientific Association, the ideals of a science school, because there is no subject in which greater misconceptions exist at the present time. The deluded victims of our curiously archaic system of classical education point to the manifold evils of the world which they have misgoverned and the terrible consequences of science under their misdirection as the proof of the superiority of the ancient culture and ideals. I wish to show that the ideals of science, no less than its achievements, compare favourably with their own, and that they must ultimately prevail and permeate the whole university with their spirit, because, like the age in which they have originated, they are creative, insatiable and prospective, whereas the ideals we owe to the age of the revival of learning and the rediscovery of the civilisation of ancient and extinct races are essentially imitative, self-sufficing and retrospective. I would not waste your or my own time with a theme so trite, and which only in academical circles is still actively and bitterly opposed, if I did not believe the time of change is at hand. The old régime in our universities and schools is so discredited that now it is merely carrying on in the interregnum between war and peace. Science for more than a hundred years has had every vested

1 Farewell Address to the Scientific Association, Aberdeen University, 2oth June I9r. 
interest in the established order of things in league against it, happily, as we now may feel assured, quite in vain. Haphazard as we are as a nation, mere mental inertia and conservatism does not explain the unfortunate position in which we find ourselves to-day as regards the neglect of science in our universities and educational institutions. Without the powerful and active opposition of the representatives of the established and organised religions, clinging to old creeds which have ceased to be credible, the classical element alone would have been powerless. Men of common sense may be trusted not to commit the cause, say, of temperance to brewers, or to hand over key industries to the control of foreign rivals and competitors. So in the new régime, which may not be better but at least can hardly be worse, I trust there may be sufficient men of ordinary common sense not to entrust the direction of science in our universities to the unholy alliance of the pagan classics and the Christian Church which hitherto has been dominant therein.

It is only because of the lessons we, as a nation, have learned in the war that I have thought it worth while raising again such questions while I have been in Aberdeen. I am well aware that for more than fifty years scientific men in this country have given their testimony in vain, regarding the evil consequences of the survival of the classical system of education and the ignorance and misunderstanding of science. The sphere of knowledge in which, by common consent, this age is the greatest that the world has ever seen remains still outside the understanding of those in whose hands our national and educational destinies have been committed. Its rightful place has been taken by the studies of the languages, history and customs of two, or, if we include the ancient Hebrews, three nations, which, 
great as they were in their day, have now given place to greater. It is only fair to say that some of the most severe critics of the social effects of classical education have been drawn from the ranks of scholars and men of letters. I can recommend to your perusal the Essays on a Liberal Education, edited by the Rev. F. W. Farrar, and published by Macmillan and Co. in 1867 . Lord Houghton, the father of a recent Minister of Education, the Marquis of Crewe, in the concluding essay is the author of one of the most notable of these indictments, to which it would be possible to add little even to-day. Discussing the product of this education he says, for example: "To the social phenomenon of all this elaborate study, which cannot be applied to any practical purpose, must be added this other peculiarity of the system, that, when once the ordinary British youth has bidden farewell to school and college, any attempt to prosecute, or even keep up, his classical attainments and interests, would make him an object of curiosity, if not of censure and alarm, to all who might be solicitous for his future welfare." $\mathrm{He}$ touches on the snobbery of the assumed universality of classical culture on the ore hand and the artificial barrier which "makes it seem something incongruous and offensive in any man's assuming to know or care about classic objects or classic letters without having been taught to construe Greek and Latin," though no one needs to have a first-hand acquaintance with Italian to enjoy Dante, or with Oriental languages to appreciate the Arabian Nights or Sanskrit philosophy. And he remarks :-

"There are too many flagrant examples in the history of the human mind of the persistent adherence, not only of public opinion and private judgment, but of the religious conscience and the moral sense, to forms and ceremonies after the belief on which 
they were founded have faded into shadows, to permit the hope that any amount of negative experience will bring about a reformation in the matter we are now considering. It is solely to a growing conviction of the necessity of larger and wiser instruction of our governing classes, if they are to remain our governors, that we must look as the source of any beneficial change."

The instinct of self-preservation, to which Lord Houghton appealed, is one of those primitive instincts which are weakened by security and protection from the struggle for existence. What neither it, nor any amount of negative experience, was able in fifty years to accomplish has been accomplished by the last five years' bitter positive experience, which nearly made of us just one more of those flagrant examples which the history of the human mind affords. Since Lord Houghton's day the further operation for fifty years of the causes which he deplored, has made the necessity, or even the desirability of preserving our governing classes, if they are to remain our governors, a question of relatively small importance. But the necessity of preserving the nation if it is to remain a nation has become obvious to the remotest inhabitant of our wide-flung Empire. There is therefore every hope that the unholy combination against science in our universities has done its worst, and that once more, as at the Renaissance, the love of truth for its own sake and the enlargement of the boundaries of knowledge, the present ideals of science in other words, will again dominate our universities and schools, and through them all classes and conditions of the people.

It has become a question, no longer of the issue at stake, but merely of the means by which the necessary changes are to be effected. There is a widespread feeling that within a few years we shall 
have a Labour Party in power in this country, and, whether or no this does occur, much that is taking place can be traced at all events to the possibility that it may occur. It is well that the universities, especially, should re-examine their ideals, for the Labour Party, unlike the parties of which we have had experience, profess very high ideals-indeed, judged by the canons of a literary and classical education, altogether utopian ideals. From the standpoint of science the ideals they profess are not utopian, whatever may be the case from the moral and human standpoint. On the score of physical practicability they are no longer visionary, for science within the past century has multiplied the resources of this planet to support a higher standard of living among all workers to an extent that even the criminally wasteful and ignorant methods of the existing competitive and individualistic system has not been able altogether to conceal.

The President of the Board of Education, the Rt. Hon. H. A. L. Fisher, at the recent Anniversary Dinner of the Chemical Society, after a reference to the issue of the recent conflict as one of the greatest victories which chemistry had ever won in the history of mankind, and, incidentally and humorously, to himself as a melancholy product of the dark ages of compulsory Greek, went on to say: "Nevertheless, if we turn over the pages of Huxley's Addresses on the place of science in national education-and there are few finer specimens of virile English prose-I think we shall feel that if the great master were among us here, he would acknowledge that the cause to which he dedicated his life has been practically won. We want more money for science-we want a great deal more money for science-we want more teachers, we want more learners, but in the main the battle is won. If there are any sceptics to-day they 
must surely have been converted by the achievements of science in the war."

Unfortunately, science has been so outrageously used as the stalking-horse for less popular crusades, for the support of systems of education which have had their day but not yet ceased to be, that one is bound to add that what we want even more is that science should get the money when it is given. I trust in my successor's time an end will be put to the scandal of the Chemistry Department here being practically self-supporting in a university which derives the greater part of its revenue from grants from the Carnegie Trust and the State already, and that some of this promised support may go to the doubling or trebling of the staff so that everyone in the department may have some uninterrupted time to pursue investigations as well as teach.

I had intended to deal in some detail with the backward condition of our B.Sc. regulations and the absurdity, in these days, of making a man who wished to train himself properly as a chemist take two other subjects on an equal standard for the B.Sc. degree. But that also has been rendered unnecessary by the recent action of the Privy Council in arranging a conference of the four universities in respect of the new science ordinances which have been framed, or are in preparation in all four universities. This conference, which was held last Saturday, I am glad to say resulted in complete agreement being reached as regards the main principles. By the session I920-2I the other three universities certainly will have in operation a science degree providing for pass and honours candidates, which will mark a great advance. The battle, as Mr Fisher said, is won, and all that is necessary is to see that Aberdeen does not suffer by virtue of its geographical remoteness from other centres of intel- 
lectual activity, and that nothing is permitted to prevent the university from being in a position by the session 1920-2I to compete on equal terms with the other three.

It will still be necessary to see that the teaching provided for the new degree is strengthened. As regards chemistry, the greatest need is that students should be able to get within the university training in experimental physics and mathematics more suited to their requirements than the courses in natural philosophy and mathematics provided for the honours M.A., as it is recognised that it is not essential to follow the traditional order of classical mathematics to give the student a practical working knowledge for the purposes of engineering and chemistry. For those who wish to become experimental rather than mathematical scientists, in which mathematics is a tool rather than a branch of philosophy, an entirely different and more practical curriculum is essential and desirable.

The Universities of Oxford and Cambridge have agreed, at $\mathrm{Mr}$ Fisher's suggestion, to co-operate with the Government in setting up Commissions of Enquiry into their affairs; and in Scotland, though there is no comparison, the feeling everywhere is gaining ground that a thorough reconstruction of the universities is the essential first step towards progress.

Science has been subjected to so much misrepresentation and depreciation by the champions of ancient studies, no doubt much of it on perfectly honest, if mistaken, grounds by the victims of those studies, that, in criticising them, I must not give you the impression that I am dominated with the same feelings of animosity and distrust to them as they have shown for the last century towards science. At various periods of the world's history great move- 
ments have arisen which have permanently enlarged the common heritage of the race, and which have been followed by an aftermath of Pharisaism, when the high priests of learning holding the keys of knowledge can neither enter in themselves nor allow others to do so. Youth has so far preserved science from that fate, but there is another powerfully contributive factor in the usefulness of much of scientific knowledge. Great and striking discoveries to-day are to-morrow the starting-points of whole industries and professions, and the pioneer is compelled to keep marching on. If a contemporary of James Watt were to return and attempt to lecture to us on the design and construction of the steam-engine, tens of thousands of quite humble people would in turn instruct him. No doubt he would feel much the same as a classical scholar being corrected by some cad who had got his classics from a crib, but he would have to recognise that his first-hand acquaintance with James Watt made of him no high-priest of the steam-engine. So a pioneer in what but yesterday was an abstruse field of inquiry, purchasing instruments for its pursuit, may receive a lucid exposition of the principle of his subject from the instrument maker, and any wireless operator on board ship would probably be equal to expounding to one Hertz, were he alive to profit by the information, the ether waves by which messages were sent. To be a scientific pioneer to-day, in any of the useful branches of science, at any rate, it is necessary to keep moving on.

It is just because we, to-day, are not such great sculptors or poets as the Greeks, so great lawgivers as the Romans, or so great architects as the cathedral builders of the Middle Ages, and because the desire to study these past ages of pre-eminence has not resulted in any overmastering 
ability to emulate and surpass them, that they are revered and cherished. At their own valuation their present-day exponents are feeble and pale imitations of the original masters, who uphold an example which they genuinely believe it is impossible to improve upon, and to them of all people are entrusted the shaping of the youth of an age, in science the greatest that has ever been, and in which the achievements are not objects of veneration impossible to be imitated, but stepping-stones to greater. Science would accord to the ancient studies the fullest and most generous appreciation were the original ideals which dominated the creative ages of the past, rather than the overgrown ruins of those creations themselves, still in active and effective existence.

But the overwhelming love of truth for its own sake, and the passion for enlarging the boundaries and deepening the foundations of knowledge, which are the ideals of science and therefore of any scientific school worthy of the name, need not lead us into the error of supposing that these ideals alone are sufficient to satisfy the human mind, though we may believe that, apart from the aspiration for truth, and, moreover, apart from the belief that truth is humanly attainable, other aspirations are likely to prove evanescent.

If we may cut ourselves adrift completely from the past and, in imagination, attempt to state, in this twentieth century, the objects for which a university should live, we shall find them expressed fairly comprehensively in a favourite phrase of Professor J. Arthur Thomson, "the true, the beautiful, the good." But we shall not mean precisely by those terms what they would have connoted in any earlier epoch of human thought, for we are living in the twentieth century, and quotations from 
other ages must be interpreted with regard to the state of learning at the time. Thus, to take the well-known quotation from Keats :-

\author{
"Beauty is truth, truth beauty, - that is all \\ Ye know on earth, and all ye need to know,"
}

and to make of it the motto of a university to-day would be absurd. Even as an answer to the famous question of Pontius Pilate, "What is truth?" in the spirit of the pagan classics he worshipped, it was out of date. For had not Plato written over the garden gates of the place destined to give the name Academy to a school of learning, "Let no one enter who is destitute of geometry?" Now nothing is truer than geometry, nor so far removed from the æsthetic emotions. It has been contended ${ }^{1}$ that this inscription secures for Plato the priority for the discovery that real truth is ascertainable by mortal men, and that his famous Dialogives were satirical commentaries on the systems of education in vogue among the Athenian youth of his day, in which that important discovery had not been grasped. If so, would he were alive still, for what a first-rate champion of science he would be, and what a wealth of illustration for his argument he would find in sciences other than geometry.

Of another of these great masters, Aristotle, it is of interest to note that Huxley put forward the theory that the text of his works, which blindly dominated intellectual Europe to the time of Galileo, is in reality nothing more than a collection of the notes of his lectures taken down by one of his students. It is impossible otherwise to account for such an amazing juxtaposition of marvellously

1 William Whewell, "Science and Education," p. 23. W. Heinemann, 1917. (Lectures delivered at the Royal Institution of Great Britain, edited by Sir E. Ray Lankester.) 
accurate observation and absolute rubbish, as, from the standpoint of present knowledge, they are found to contain. Think of some new Dark Age oversweeping the earth again-another war such as the last may bring it yet-and, a thousand years hence, all that survives of our present knowledge of the internal structure of atoms being some notes, taken down by one of you, of the lectures I have been giving this term. It might well take another thousand years of patient study to unravel them, during which epoch my reputed lectures would constitute part of the classics. Punch tells a story of how, to amuse a patient laid aside on a bed of illness, a friend sent her a jig-saw puzzle of "The finding of Moses," with a handful of "The Map of Europe" thrown in to make it interesting. So, beware of relying too implicitly upon what has come down to us by ancient records.

To return to our theme, it is idle to pretend that what is true must necessarily be either beautiful or good. To adopt such a position is to assume different kinds of truth: one for spiritual matters, elevating and inspiring, another for the things of the flesh, sordid and base, and yet a third for the inanimate world, of utilitarian but of no possible human significance. The scientific man regards truth, not as an aspiration, but as an achievement, and he holds that the truth he has been permitted to achieve is but part of an ascertainable whole, to which poets, seers and prophets have aspired.

Science can claim to have kept the ideal of truth burning very brightly in our universities. How have the older studies covered their part of the field and cherished the ideals of beauty and virtue? As regards the first, I am quite certain that a Labour Government would not find the present faculties of arts in our universities to be sufficiently 
catholic. The cult of beauty there is confined almost to the beauty of words. Poetry and literature, however beautiful in form, if divorced from the spirit and knowledge of the age and finding therein only what is ugly, sordid and low, degenerate into one of the most artificial and insidious forms of the æsthetic function. There surely would be a renaissance of classical studies, more in keeping with their original models, to the interpretation and portrayal of the world in its present greatness. The beauty of form-sculpture in marble and bronzethe beauty of colour--painting and the arts of decoration-the beauty of harmony-music-finds no official recognition in most of our modern faculties of arts, and the same may be said of the chief values for which the ancient world stood. The drama, the building, of cities and the general ordering of the civic and national life received attention in the early world, but now are neglected, not because of the growth of science or of what is termed in contempt "materialism," but because of the decay of the creative spirit of the past and its usurpal by a craven imitative habit of mind, which deems the present inferior and tries to make it so.

You may wonder that I should really look for a revival of the lost glories of the ancient world to Labour. First, I would answer, because Labour is young, virile and strong, and, secondly, because upon it has pressed without mitigation the sordidness and squalor of our modern industrial and commercial life. The love of beauty, like the love of truth, is innate and inextinguishable, and from the horrors of the nineteenth century and the mismanagement of the blessings of science under systems that had atrophied even before its advent, men are now earnestly looking everywhere for a way of escape.

The following extract from the Report on Recon- 
struction, published by the Labour Party, shows the proposals they make for dealing with the surplus of wealth, which science has created and which is at present absorbed by individual proprietors. Whether one agrees with the methods proposed or not, their aims express a high ideal totally new in practical politics.

"From the same source must come the greatly increased public provision that the Labour Party will insist on being made for scientific investigation and original research, in every branch of knowledge, not to say also for the promotion of music, literature and fine arts, which have been under Capitalism so greatly neglected, and upon which, so the Labour Party holds, any real development of civilisation fundamentally depends. Society, like the individual, does not live by bread alone, does not exist for perpetual wealth production."

Lastly, with regard to our third ideal of virtue, concerned with the ethical and religious perceptions, the study of the laws of God and man, rather than with the laws of Nature, is it not even worse served at present in the universities than either of the other two? What, in these times of transition and doubt, does the university contribute to the innate aspirations of men after virtue and justice? The existing codes and creeds into which human and divine laws have been formulated and crystallised still purport to be their authoritative expressions. But these, with the growth of science and the upheaval it has brought into social relationships and the whole mode of living and outlook of men, whether in peace or war, have become no more than the empty forms from which the living spirit has departed. They are in profound and irremediable disrepute. But the reality we have had exemplified in the modern spirit of duty and self-sacrifice, which the war has revealed to be 
alight and alive amongst us more intensely than ever. Nor is it the monopoly of a class, profession or religion. Duty, like Truth and Beauty, is one of the universal values without which a university cannot live, but, of all, even less than Truth owes to any Faculty of Science, or Beauty to the Faculty of Arts, does Duty, as a living, burning flame in our midst, owe to the Faculties of Law and Divinity.

We have had no academical lesson of the stern reality of duty. As a memorial let us install in our universities, not only a pure Faculty of Art, charged with and carrying on the creative work which, rather than their languages, made our ancestors great, but also a pure Faculty of Duty, pursuing the tasks which, in these days, have fallen from flaccid hands. The duties which I am advocating should be the concern of a pure university Faculty of Duty, to be studied like a natural science solely in the interests of the advancement of knowledge and the'love of truth; are the duties of the twentieth century, as distinct from mythological, ancient or feudal man, rather than the codes and creeds, the survival of which brings into contempt our whole ethical system. In earlier times, more corrupt or more openly corrupt than our own, the profession of the law was magnified, rather than the research aspect into the application of its principles and spirit to modern life, which is now the most pressing need. The status, emoluments and pensions, for example, of judges were fixed on a scale such as to make them superior to the temptation of bribery. To-day the power of money and its concentration into the hands of wealthy corporations makes, on the one hand, such a device absurd, and, on the other, we have a more generally developed sense of public honour, which makes it seem nothing remarkable that duties calling for equal integrity and incorruptibility should be honestly done without such 
inducements, and by officials frequently among the humblest and least well-paid in the State. To ensure a higher respect for law rather than for the legal profession, it should not be so apt to shut up like a steel trap to the humble wayfarer, and open of its own accord to the gilded coach-and-four.

In feudal times, again, vast powers and privileges were acquired by territorial magnates in return for the distinct duty of maintaining on their estates, in times of peace, the people from whom, in times of war, armies could be raised for the defence of the realm and the king's external adventures. These rights survive, but we do not now raise armies in this manner. On the very lowest ground of expediency, and apart from ethical considerations altogether, a State that calls on fit men to serve in time of war must, in time of peace, provide conditions of existence capable of producing an $\mathrm{A}_{\mathrm{I}}$ instead of a $\mathrm{C}_{3}$ army.

It is impossible to reconcile the cold, unrestricted operation of soulless economic law, the beggarmy-neighbour, devil-take-the-hindmost competitive individualism associated with nineteenth-century industrialism and commerce, with the supreme socialism and self-sacrifice for the common weal which is asked of a section of the population in time of war. It seems impossible that we should say to these men, "Good fellows! upon you has fallen the nobler and better portion of sacrificing, for the national good, that individualism which we prize so highly as essential to efficiency, enterprise and progress. At home we will carry on as usual and expect to make fortunes, as individuals, out of the nation's necessities. It is for you to display the communal virtues of loyalty and devotion to the common weal, which we personally loathe, abominate and fear"; at least, it is impossible to say so more than once. 
The question of a citizen's duty and place in a complex State to-day would surely be a better basis for his education than Latin and Greek or introspective philosophy. Parliament and the country are being daily confronted and settle by votes similar questions of practical twentieth-century ethics, which it should be as much the function of a university to explore, in a scientific spirit, and reduce to a reasoned and complete form, as it is its recognised duty to enlarge the boundaries of natural knowledge. Applied professional Faculties of Law, Divinity, Medicine, Education and so on, without the pure Faculties to carry out constructive and creative work in the subjects with which they deal, are just one example of our artificially engendered retrospective habit of mind. Professional Faculties merely carry on, but whose business is it at present to say what it is shall be carried on when what is being carried on becomes anti-social and out of date? We pride ourselves on being the greatest nation on earth, with an empire on which the sun never sets, and all that sort of thing, and we leave to haphazard, popular vote and professional interests, the settlement of the problems arising out of the very growth and development upon which greatness alone depends.

There is only one principle, and that an undeniable one, which needs to be logically accepted and carried out in practice to make this nation exorcise the evil spirit which has brought us so near to the brink of ruin and made of us the object of real concern and despair to every one of our daughter dominions beyond the seas. We must act as we have been forced to act during the war, as though we were great because of ourselves, our environment, our powers of making original discoveries and of applying them without fear to the peculiar problems of our day, not merely in science but universally. Act upon 
the principle which has dominated the past century in our education and government but a little longer and the time for reform will be past. The principle in question cannot be better illustrated than by quoting the opening words of Charles Stuart Parker's "Essay on the History of Classical Education," in the volume to which I have already alluded. Referring to the Greeks and Romans, as well as the Jews, as our spiritual ancestors, he says: "They left treasures of recorded thought, word and deed, by the timely and judicious use of which their heirs have become the leaders of mankind. But they left them in their native tongues." If one comes out of a fog or mist among the mountains, natural colours of grass, flowers and sky take on an unreal vividness in contrast to the blank pall of a moment before. I can imagine that after the Dark Ages, when the world once more emerged from the fog of barbarism, the treasures of the recorded thoughts of the ancients must, by contrast, have appeared similarly vivid and satisfying, and I can imagine how the tradition arose that to these treasures the renaissance of Italy, France, Germany, and, though assuredly least of all, Britain, as great nations, was to be traced. I am not concerned with its historical truth or otherwise. But if we ask ourselves to-day, fifty years after the words I have quoted were written, whether the great nations of the earth-the United States, France, Germany, Italy, Austria, Britain, Japan, to name them in haphazard order-do actually lead the world, or can ever hope to do so again, either the world of thought, the world of action, or even the world of art, because of the recorded treasures of Greeks, Romans and Jews, the question appears too ridiculous to be answered. They will lead or fail, primarily, because of the timely and judicious use or the suicidal neglect of those treasures-also written 
in their own peculiar jargon as unintelligible to the scholar as Greek to the multitude-which they, to a greater or less extent, have themselves discovered, the treasures of modern science. So utterly have these changed the whole mode of living of the world that, not only in science, but in the other great divisions of learning as well, the past has proved rather a millstone round the neck of the future than a source of inspiration and wisdom. One knows from experience in scientific research how easy it is to immerse oneself in a subject that was fascinating to a past generation, and waste time in the minutia of still ungleaned detail, until one finds oneself in a backwater which the main tide of discovery has left long since, and wherein one can waste a lifetime, which, if spent among the real outposts of knowledge, would have resulted in substantial and permanent progress being made.

Although science, in the sense it is understood to-day, owes but little to the past, it has already, in its conception of research, contributed to the ideals of a university immensely more than has ever been contributed by preceding ages, and the contribution it has made in its own sphere, if logically applied to the older branches of study, would be productive of the most valuable and far-reaching social consequences. The association of scientific research with the universities is mainly due to the exigencies under which it, as distinct from other creative work, can alone be pursued. One may read Parker's "Essay on the History of Classical Education" from end to end in vain to find the remotest parallel to the ideal which science holds up as the most important and the highest function of a university to-day, little as it has yet been realised even in science by actual British universities. From it there follows at once the idea I have here developed of pure Faculties of Art and 
Duty to carry on research and constructive work in the rsthetic and ethical questions of to-day, to inspire the applied professional faculties, the imperial and local legislature, and the primary and secondary schools, and to do, without bias or political and sectarian passion, just that for lack of which the nation perishes, the deliberate reconstruction of the social order to meet the entirely altered conditions that prevail in consequence of the growth of science. Never yet in the history of the world have such faculties found a place in the universities. In early days the university was simply a divinity faculty, and its glory was that it provided the ladder, of which we hear so much to-day, whereby children of the humblest origin could rise through the Church to the highest positions of the State, though that was not its raison d'être. Then, all business requiring education was transacted by ecclesiastics, and the spirit of research in the sense of finding out the new, not that which is old but has been lost, had not arisen. It would indeed have been very dangerous for any one to act on the view that the pagan classics and Christian writings did not between them contain all there was to know. The revival of learning was literally the re-learning of what had been known, but now was inaccessible save to those possessing the Greek, Latin and Hebrew languages. Discovery connoted rediscovery of lost territories rather than being the first entrant into some new and hitherto undreamt - of world. There is, unfortunately, a tendency to confuse this sort of original investigation and research with that understood by scientific men. In those days the extraordinary idea that there was a peculiar virtue in the teaching of Latin and Greek and ancient philosophy as the foundation of a liberal education was natural and justifiable enough. Latin was the universal written language of the learned 
world. It was in no sense the dead language that it is to-day, but the key to learned literature, not only of the past, but also of the present. When it became necessary for a gentleman to know how to write, it was Latin that he wrote, not his mother tongue. The Faculty of Arts has never yet, though the necessity has long since ceased to exist, dissociated itself from its original preoccupation with the teaching of dead languages, as a, then, necessary preliminary to any kind of learning and culture. Original creative work in painting, sculpture, architecture, the drama, music and so on have hitherto been pursued outside the university, and this applies also to by far the greater and most valuable part of poetry, and literature generally.

Even theology has been more progressive. After science had shown the value of the patient, unbiassed examination of data, pursued solely with the desire to elicit the truth, the traditional records, upon which theology is based, became the subject of critical examination, especially in Germany. Parker, writing in 1867 , says: "Much of our embarrassment in Biblical Criticism is due to our ignorance of Hebrew and German. For Latin, as a common language, has died out, and German has now for a long time been the tongue in which all questions relating to antiquity are discussed with the most research and learning." But the popular attitude to such inquiries apparently is still similar to that which unbiassed inquiries in science evoked in the Middle Ages, and many times during the war have I read letters in the press tracing the decline of the moral forces in Germany to her eminence in theological studies, with never a protest from our own learned theologians against such bigotry.

But if to the old Faculties of Arts and Theology the ideals of science are not without application, the 
case is even more striking when we consider the professional Faculties of Medicine and Law. Here there is the most clearly marked distinction between the interests of the country as a whole and of those who follow these professions. The worse the condition of the country the more must both these professions thrive, and, the more free from disease and litigation it is, the worse, financially, for these professions.

Until the most recent years there was nobody in this country primarily concerned with the scientific study and prevention of disease. The best and most energetic of the young doctors might, and often did, spend a few years in purely voluntary research into the scientific aspects of medicine, but so soon as their success in their profession grew, and their consultingrooms commenced to fill up, such investigations became more and more competitors with actual lucrative and bread-winning service. With the passing of the Health Insurance Act, the State, for the first time, became interested in the health of the people. At first its interest was purely a financial one, and was concerned with the solvency of the Insurance scheme, but, during the war, with the state of health revealed by recruiting statistics, its interest assumed also a military character. In consequence, just those aspects of medicine which are not of interest, financially, to the medical profession, the research aspect and the preventive aspect, are now receiving more consideration. It is clear that, from the national standpoint, it is more important to study, scientifically, the causes and character of disease with a view to its prevention and elimination than even to provide that disease, after it has been contracted and begun its work, should be properly treated. The prevention of disease is the creation of health, and modern uni- 
versities ought to be no mere professional schools of medicine, but primarily concerned with the research and creative aspect of their subject.

But is not the case of the Faculty of Law and its relation to the legal profession an even more forcible one? The study of the cause and character of social maladies with a view to their prevention, the elimination of the causes of dispute and litigation, the simplification and modernisation of our inherited codes with continual and timely regard to everchanging conditions, the tasks which, in an ideal university, I have assigned to the hypothetical research Faculty of Duty, to be pursued for its own sake, by students of the foundation of human law, is surely more in keeping with the real character of a university than even the training and qualification of professional lawyers. That is the true preventive medicine of social injustice and its attendant contempt for the law and tendency toward anarchy and Bolshevism. It is sad to ponder on the history of the great conflicts with which the advance in knowledge has inundated society, in which every change has been forced, as it were, at the point of the bayonet, against the existing law, and hardly a single one has been intelligently anticipated and forestalled by suitable legislation. No anomaly however glaring, no injustice however scandalous, is rectified without a wearing and demoralising political agitation. The principles of equity and justice and esteem for the higher value of life in general are, to-day, whatever was the case in the ancient world, indigenous to society and come into conflict rather with its rulers than with the masses.

Of modern times research in science has more and more been confined to universities, and the number of scientific amateurs, who once did so much good work, grows yearly less. For if it is not 
pursued in the universities it can hardly be pursued anywhere. A mathematician, even a purely mathematical physicist, is under no such restriction, for he does not need a laboratory, and even in books his requirements are relatively modest. $\mathrm{He}$ is no more necessarily attached to a university than a poet, painter, preacher or musical composer. But an experimental physicist, chemist or biologist can hardly carry on research outside a university, for a laboratory is essential. It thus has come about, largely through the exigencies of the work, that experimental science, practically alone of the great creative activities, is necessarily almost wholly bound up with universities, and has thereby enlarged their whole raison d'être. There are many advocates for retaining and strengthening the connection, even at great sacrifice to the interests of research itself, because only can the teaching in science be living and up-to-date if research is being pursued.

But in Scotland and England alike the bond is weakening. Unintelligent "pseudo-democratic" administration, increasing numbers of students and the never-ending expansion and multiplication of curricula and examinations, and the lack of any clear financial distinction between the dual functions of the university have brought serious research, in many institutions, practically to the point of extinction. On the other hand there is an evergrowing technical demand for research workers of the highest quality. Some of the finest research in pure physical science that is being produced in America to-day emanates from the General Electric Company's Research Laboratories at Schenectady, New York. In this country the Government scheme of scientific and industrial research has resulted in the formation of numerous research associations, each in connection with a 
group of trades or industries, totally outside the universities, and taking from them some of their best brains. The Carnegie Trust is in real danger of being absorbed into this great central scheme. Badly as the governing bodies of our universities have exploited the passion for research and the necessities of those who wish to be able to prosecute it, in Germany under State control matters have probably been much worse. So there is every reason to fear that in future the exploitation of research workers will be taken in hand directly and unblushingly by the State.

It is not too much to claim that the universities owe entirely to modern science the conception that they are something more than professional and technical training schools, and the permanent homes of the learning and culture which has survived in the world-the conception that their highest function is creative rather than imitative or didactic. It is the conception of all best worthy of preservation as the basis upon which to build, and I have merely followed here its necessary logical development in attempting to extend it beyond science to the innate aspirations of mankind after beauty and virtue. But little is it yet valued. A motley horde of interests, like the money-changers of old, invade the temple of learning, and each year seems to make the creative element therein more of an intruder, and the seeker after knowledge for its own sake out of place. The creative element in science will never lack a home. Industry and commerce will house it in a noble and spacious prison with bars of solid gold, even if the universities reject it.

But there could be no finer memorial to the great dead than to accept frankly and without reservation the fact, of which they themselves are the most con- 
vincing witnesses, that the years $1914-1918$ form the climax in the annals of the human race, and the implications that follow therefrom in our outlook on the world. We shall look for greatness not in the past but in the present, and for the sources of greatness not to our ancestors but to the creative element and the spirit of science in ourselves. The scientific spirit of honest and unprejudiced inquiry for the pure love of truth is not to be confined to concrete things. It is as essential to the proper understanding of the laws of God and man as it is to those of Nature, for they also are the continuously growing and developing expressions of the conceptions which are practically summed up, so far as they are living, by the word Duty. But when we leave the past behind, as children leave their youth, and press forward to the discovery and apprehension of the new, we create and join forces with the other great creative agency of Art. After a chequered career of successive patronage by kings and courts, priests and patricians, municipalities and millionaires, creative Art still wanders in the world, a vagabond without a home. Its rightful place is in the university alongside of science. And for the inscription of our ideal university, upon which the actual universities of the future will be founded, we might do worse than to alter, if it is permissible, the words of Keats in accord with the spirit of modern science and modern heroism-

\section{"Beauty and Truth and Duty-that is all}

Ye know on earth, and all ye need to know."

In taking leave of the Scientific Association I have now inflicted upon you, I suppose for the last time, what I notice have come to be referred to in the press as my well-known views, and it only remains for me to bid you farewell. I hope and 
expect that you will continue to grow in numbers and usefulness. I have tried to show that as a Scientific Association you stand for the ideals upon which the universities of the future will be built, and which need not fear comparison with the noblest that have been paramount in the great periods of onrush of human thought. They are safe in your hands. For the love of truth and the passion for its advancement are the ideals of youth and hope, and so long as the tide of youth annually rejuvenates our universities there at least they cannot wholly die.

It is the birth-right of youth to start anew. Once to burst out from the coffin of the past and survey the world with clear and open eyes. The vision may fade. The cloud-capped towers and gorgeous palaces may dissolve and leave not a rack behind. But not for you!

You come here, ostensibly to "get on"-how I loathe the words-to win for yourself position, power and importance in the world that calls itself great, to train for this or that profession or calling, to enable you to hew your way and distance your competitors in the race of life. But what have these tawdry ideals of bygone far-off unhappy days to do with your Alma Mater or with you? Leave them, at least, until you are out in the world that calls itself great, and, while you are here, live in the world that is great, in the realm of expanding ideas and the rapidly widening horizons of truth!

Were all the powers of darkness in dominion over her, yet is the university a holy place, where year by year congregate pilgrims in the greatness and generosity of youth, "to learn what none may teach, to seek what none may reach," to perpetuate the vision of youth after youth itself is sped. When this ceases to be true, then and then only will the ancient universities have grown old. 


\section{APPENDIX A}

A CRITICISM OF THE FINANCIAL OPERATIONS OF THE CARNEGIE TRUST FOR THE UNIVERSITIES OF SCOTLAND. ${ }^{1}$

MR ANDREW CARNEGIE, on 7 th July I9CI, signed a trust deed bequeathing $£ 2,000,000$ to the Scottish Universities, which was recorded in the Books of Council of Session on 9th July 1901. The Trust Deed opens as follows:-

"I, Andrew Carnegie, of New York, and of Skibo, in the County of Sutherland, having retired from active business, and deeming it to be my duty and one of my highest privileges to administer the wealth which has come to me as a trustee on behalf of others, and entertaining the confident belief that one of the best means of my discharging that trust is by providing funds for improving and extending the opportunities for scientific study and research in the Universities of Scotland, my native land, and by rendering attendance at these Universities and the enjoyment of their advantages more available to the deserving and qualified youth of that country to whom the payment of fees might act as a barrier to the enjoyment of these advantages; and having full confidence in the Noblemen and Gentlemen afternamed, ..."

A list of Trustees follows, to whom the donor undertakes to entrust "Bonds of the United States Steel Corporation of the aggregate value of Ten Million Dollars, bearing interest at 5 per cent. per annum, and having a currency of fifty years."

It is only with the first of these objects, the improve-

1 Published in Science Progress, January 1917. 
ment and extension of the opportunities for scientific study and research, that this criticism is concerned.

In a document signed by $\mathrm{Mr}$ Carnegie, entitled "Constitution of the Trust referred to in the foregoing Trust Deed," the two objects of the Trust are referred to under Clauses A and B respectively, and a third clause, $\mathrm{C}$, provided for any surplus income.

Clause A opens :-

"One-half of the net annual income shall be applied towards the improvement and expansion of the Universities of Scotland, in the Faculties of Science and Medicine; also for improving and extending the opportunities for scientific study and research, and for increasing the facilities for acquiring a knowledge of History, Economics, English Literature, and Modern Languages, and such other subjects cognate to a technical and commercial education as can be brought within the scope of the University curriculum, by the erection and maintenance of buildings, laboratories, class-rooms, museums, or libraries, the providing of efficient apparatus, books and equipment, the institution and endowment of Professorships and Lectureships, including post-graduate Lectureships and Scholarships, more especially Scholarships for the purpose of encouraging research, or in such other manner as the Committee may from time to time decide. . . ."

The two passages cited from the official copy, issued by the Carnegie Trust, of the Trust Deed and the Constitution of the Trust referred to in the foregoing Trust Deed, respectively, contain all that is germane to the present criticism.

But a reasonable interpretation, and the one initially followed in the two larger of the Scottish Universities, Edinburgh and Glasgow, would seem to be that the money was given for the primary purpose of encouraging scientific study and research, including, of course, medicine, and that history and other subjects cognate to a modern education were legitimate ancillary beneficiaries under the Trust, and, lastly, that the older subjects of a classical education were entirely excluded from participating. 
Thus over the first period of ten years and nine months, up to 3oth September I9I3, covered by the first two quinquennial and interim distributions, in Edinburgh 62 per cent. and 15 per cent., and in Glasgow 67 per cent. and 19 per cent. of the total sums received were allocated by the Trustees to what have been termed the primary and ancillary objects respectively. The remaining 23 per cent. and 14 per cent. in the two institutions have gone mainly to the maintenance of the libraries and other purposes in which the two sides share more or less indefinitely. In neither institution was any money given definitely to benefit what have been termed the classical group of studies.

If this had been the interpretation adopted generally, and subsequently to 1913, by the Carnegie Trustees, certainly no one would have been disposed to criticise them, or submit the legality of their operations to the test of the powers responsible for the observance of the Trust Laws of Scotland. Neither would there have been any disposition to examine with a microscope the exact apportioning of the moneys between the two sides. If they had secured a broad common-sense distribution among the primary and ancillary objects, the gift was handsome enough in amount not to necessitate the making of fine distinctions. But this interpretation has not been followed, either universally, or subsequently to I9r3. In the University of Aberdeen for the whole period up to 30th September 1918, covering the first three quinquennial and interim distributions, only 23 per cent. has been allocated to the primary object, while 46 per cent. has gone to the ancillary object. The maintenance of the Library has taken 12 per cent., and there remains 19 per cent. This has been allocated for the erection of new buildings and examination hall for Arts subjects and an extension of the Library, objects which, in so far as they are not illegitimate, are ancillary. So also, since I9I3, it is in Glasgow and Edinburgh. The former is given 90 per cent. of its total allocation for five years to 
"Buildings for Faculty of Arts and Department of Zoology," and Edinburgh 65 per cent. to "Chemical Department and Arts accommodation." As regards St Andrews and Dundee, the position in the main is between that of Aberdeen on the one hand, and Edinburgh and Glasgow on the other. But the practice of slumping legitimate and questionable expenditure under one head, illustrated above in the case of Glasgow and Edinburgh, and the payment of debts previously incurred, make a detailed analysis difficult to the outsider.

In addition to payments to the four universities, and relatively small grants to technical colleges and other institutions, the Carnegie Trustees administer themselves a scheme for the endowment of research. Of a total in round figures of some $£ 621,400$ spent under Clause $A$ to 3oth September 1915, $£ 86,000$ or some I4 per cent. have been spent on the research scheme, that is, $£ 27,000$ on Fellowships, $£ 30,000$ on Scholarships, $£ 21,000$ on Grants in Aid, and some $£ 8000$ on a Research Laboratory of the Royal College of Physicians of Edinburgh. One might fairly have expected that something more than 14 per cent. would have been spent on the research scheme. The answer may be that initially Scotland was ill-equipped with scientific laboratories, and these had first to be provided. But now that these laboratories have been provided, the money is going to provide buildings for Arts subjects to a very questionable extent, instead of to promoting scientific study and research.

But even what has been done has not been done for research so much as for the teaching of research, a highly important and worthy object enough, but only to be confounded with scientific research by those who have never done any or even been taught the methods. Research Scholarships and Fellowships are excellent in themselves, and will be even more so if, as a result of the war, something less like starvation awaits the holders at the end of their research training. Grants in aid of research are again excellent, and would be more so if 
they were given when they were wanted; whereas, to suit the conditions laid down by the Trustees, the money has to be applied for before a definite date in the year before it is wanted. But of the three indispensable requirements for getting research done, these two, the training of the apprentice and the provision of money for instruments, are preliminary. The third indispensable, letting the trained man with the instruments do the research, is the one this country has not yet thought much about.

At the bottom of the ladder, the Research Scholar or Fellow at the end of his training has had to abandon the work for which he was training and seek a livelihood. If he is lucky he will get a teaching position, and if, again, he is lucky he may find odd moments to continue his researches. If he is not so lucky he has to begin late in life the study of the art of earning a living. The Professor at the top, nowhere more than in Scotland, finds that he must now be content to do his research by deputy, and the most he can hope for is to train clever apprentices. Some subjects, naturally, lend themselves to this requirement very much better than others, and what is possible in them is not possible in general. The real business for which the Professor is paid, again nowhere more than in the land to which $\mathrm{Mr}$ Carnegie gave his millions, is to teach. Instead of being treated as a life-business, requiring years of devoted training and study for the preparation, and equally devoted and uninterrupted application for its pursuit, research is treated as a hobby to be followed by busy teachers in the intervals of their regular duties. This is not the way to foster perhaps the most important and repaying of all the State's numerous activities. The Carnegie Trustees have not even attempted to meet this difficulty.

The Annual Reports issued by the Carnegie Trust do not contain the names of the Trustees. The original list in the Trust Deed consists of fourteen nominated members, two of them, Lord Kelvin and Sir Henry Roscoe, having 
in the past contributed to the advancement of natural knowledge, four ex-officio members (the Secretary of State for Scotland, and the Lord Provosts of Edinburgh, Glasgow, and Dunfermline for the time being), and four members elected by the universities. The vacancies in the nominated members are filled up by the Trustees remaining.

The nominated Trustees apparently hold office for life, and consist almost entirely of eminent public men, more or less universally known, many of them distinguished in History, Literature, Philosophy, and the Law, that is, in the ancillary or illegitimate rather than the primary group of studies. Moreover, the branches of the ancillary subjects in which they are distinguished are not those cognate to a technical or commercial education. The two original scientific members are dead, as also is Sir Arthur Rucker, who replaced one of them. In the case of all three, their career of active scientific investigation had practically closed before they were appointed. In no case, so far as the writer is aware, has an active scientific investigator been a Trustee. At the present time there does not appear to be a single scientific man on the Trust. ${ }^{1}$ Of the four Trustees elected by the universities, two are distinguished members of the medical profession; a third, Sir William Turner, having lately died. The legal profession, past and present Cabinet Ministers, and public administrators supply the whole of the present nominated members. Sir Henry Roscoe's death removed the only scientific member. The others are: Earl of Elgin and Kincardine, Earl of Rosebery, Lord Balfour of Burleigh, Lord Kinnear of Spurness (ex-Senator of the College of Justice), Lord Reay of Reay, Rt. Hon. A. J. Balfour, Viscounts Bryce and Morley, Lord Shaw, Rt. Hon. H. H. Asquith, and W. J. Dundas (Crown Agent for Scotland). It is mere hypocrisy to expect from a body so constituted,

1 Between the time of writing and publication Sir Alfred Ewing became a member of the Trust, as the representative of the Edinburgh University Court. 
to the majority of whom the words science and scientific research mean little more than the letters out of which the words are composed, an equitable balance between science and the other subjects cognate to a technical or commercial education. Either they should be totally neutral as regards the two competing beneficiaries, or they should be reconstituted to give a representation to each side in accordance with the intentions of the founder of the Trust.

In the general awakening to the national importance of giving fair play to science, and especially to scientific investigation in the universities, it is to be hoped that the composition of the Carnegie Trust and its record of work under Clause A will not escape unchallenged.

It would indeed be strange if out of between one-half and three-quarters of a million pounds interest available for the promotion of scientific study and research, science had not benefited at all. That of course is not alleged. But the almost total lack of representation of living science on the Trust, and the over-representation of the humanistic element, has made for fatal timidity and lack of imagination and originality in the application of the moneys, so far as the primary object of the benefaction is concerned. There is no automatic retiral of members annually, or provision making them ineligible for re-election till after an interval, which has been found to be necessary, from experience, for good and effective management. Of a body so constituted, probably the best and worst that could be said is that they were given a unique opportunity to promote scientific study and investigation, and even if they had had the best will towards science in the world, they could not have grasped it, because that is a branch of human endeavour which the overwhelming majority had not explored for themselves. In these circumstances a secretary who had some acquaintance with scientific study and investigation might have been of service to them.

No doubt their difficulties were enormous in conrection 
with the peculiar relations to the universities in which they were thrown, but the difficulties have proved the master. The nation should look for something more real in the promotion of scientific study and research in the future from the million pounds which $\mathrm{Mr}$ Carnegie gave for the purpose.

It would not be fair to saddle the Carnegie Trustees with the responsibility, at least before it has been pointed out to them; but their attention and that of the public may be directed to a very important cognate question. How much of the grants from the Carnegie Trust nominally given to science is diverted from that object? Special information, not contained in every case in the financial statements of the universities presented to Parliament, is needed in this inquiry, and this must excuse the writer's inability to consider any but his own university, and indeed little more than his own department, of which naturally he has the fullest information.

The one scientific post in Aberdeen endowed by the Carnegie Trust is the Lectureship in Geology. The endowment, $£ 12,632$, and an annual grant of $£ 1000$ towards equipment of the laboratories, practically exhaust the Trust's scientific allocations in this university. In the early years a total sum not exceeding $£ 2500$ in addition went in small increases of from $£ 75$ to $£ 50$ in the salaries of some half-dozen science lecturers and assistants. In the published accounts, the interest of the Geology endowment to the extent of $£ 400$ is stated to have gone to the payment of the Lecturer's salary, and the part payment of that of an assistant. But, taking 1913-14, the year before the war, the students' class fees, $£ 505-$ mainly derived from the second Carnegie million, administered under Clause $\mathrm{B}$-alone, without counting an equivalent proportion of examination and degree fees, more than paid the total salaries of the Geology staff, $£ 475$. If the examination and degree fees are included and the external examiner's salary deducted, there remains a balance of $£ I 73$, which is more than enough to wipe out 
the item of $£ \mathrm{I} 28$ which the department is credited with receiving from the Carnegie Trust out of the annual grant of $£ 1000$ for equipment. Thus so far as the main provision for science by the Carnegie Trust in Aberdeen is concerned, the money is diverted to other purposes.

The Chemistry Department, when the writer was appointed to the Professorship, was credited in the I9I3-I4 accounts with the receipt of $£ 534$ of public money-that is, $£ 149$ from the Carnegie Trust out of the annual $£ 1000$ grant for equipment, 'and $£ 385$ from the Exchequer. Nevertheless, counting in an old endowment which brought in $£ \mathrm{I} 94$, it was entirely supported by the class and examination fees paid by the students taught, without this $£ 534$, which was diverted to other purposes.

By the Act of 1889 all financial control and responsibility was taken out of the hands of the Professors and vested in the University Court, who were enjoined by Ordinance 26 , Clause V, to keep a separate account of the fees, distinguishing those drawn from each class, and by Clause XI, in providing for the educational needs of the several Faculties, to have due regard, inter alia, to the contributions made by the Faculties respectively to the funds of the University.

Latterly the accounts have ceased even to attempt to conform with the first of these obligations, and for lack of this information it is impossible to say where the moneys nominally given to Chemistry and Geology really go. It is not suggested that they go to Arts or Law, or any particular Faculty, specially. The Court alone can give the necessary information.

A questionable system seems to be in vogue, euphemistically known as "saving the General Fund," whereby grants of public money are given not directly only to such departments as are spending more than they earn, but even to those like Chemistry, which are earning what they spend. The Court is under obligation to report to the Government and the Carnegie Trust annually the manner in which the grants have been expended, and the 
nominal purpose reported is not in all cases the real one. It is not a question of principle, whether a flourishing department ought to support one that is not, but of straightforward bookkeeping. Moneys are given to a department $A$, the effect of which is to transfer the equivalent amount of fees to another department B. A is credited in the annual statements with the receipt of the money, but $\mathrm{B}$ gets it. Why is not $\mathrm{B}$ given the money directly instead of $\mathrm{A}$, and the transaction recorded in the accounts? The answer is that though $A$, by the terms of the gift, is necessarily a proper recipient, B may or may not be.

Whatever may have been the abuses of the régime before the Act of 1889, the fact that such a subject as Chemistry at least would have been better off, if it had been left as it was, in spite of all the wealth from the Government and the Carnegie Trust, which has since come to the coffers of the University, is a sufficient indictment of the present system.

Enough has, perhaps, been said to show that some inquiry not only into the Carnegie Trust, but also into the manner the financial system of the Scottish Universities is operating, is called for. It is not mainly a question of money. Money is merely the measure. Here is a department, original investigation in which, it has been shown, is vital to the future prosperity of the country. It supports itself by hard teaching. It is stated in the published accounts to receive sums which it in fact does not receive, and which if it did receive would enable the teaching staff to be increased and some time allowed for research. It is idle for any public or private benefactor to give money for a specific object, such as the improvement and extension of the opportunities of scientific research, until the system is overhauled which makes it possible for moneys so given to be diverted.

The University fees go almost wholly into the one "General Fund" created by the Act of 1889 . The departmental expenses are borne by grants from this fund, from 
the public money provided by the Exchequer, and by the Carnegie Trust. Hitherto the giving of a grant to a department has often meant merely the diminution of its grant from the General Fund. If the departments are all stereotyped as regards the amount of tuition performed, it is obvious that the simultaneous gift of public money and the withdrawal of the same amount of fees would not benefit the department in the slightest, nor lessen its burden of tuition. But if, as is the case with a subject like Chemistry, the fees earned and burden of tuition, of which they are to some extent the measure, are rapidly growing relatively to the rest of the University, each year must increase its burden and lessen its power of original production, its increased earnings all the time going to make up corresponding losses of fees in other departments. This has got to the point with the Chemistry Department of Aberdeen that it has actually become self-supporting, though nominally receiving large grants of public money. It would be better off if it had been left as it was before 1889 in possession of its own earnings, and without the sort of assistance it receives from the Carnegie Trust and the Government. Until this matter is looked into, it is useless for the Chancellor of the Exchequer or the Carnegie Trust to grant further moneys to the universities if their object is to foster those departments which are becoming of increasing national importance, and for which there is growing up an increasing demand. 


\section{APPENDIX B}

REPORT OF A COMMITTEE OF THE BRITISH SCIENCE GUILD UPON THE CARNEGIE TRUST AND SCIENTIFIC RESEARCH. ${ }^{1}$

THE Carnegie Trust for the Universities of Scotland was founded by $\mathrm{Mr}$ Andrew Carnegie in I90I, with a gift of two million pounds. One-half of the annual income from this fund has to be devoted to the payment of students' fees in Scottish Universities, and the other half is to be applied "towards the improvement and expansion of the Universities of Scotland, in the Faculties of Science and Medicine; also for improving and extending the opportunities for scientific study and research, and for increasing the facilities for acquiring a knowledge of History, Economics, English Literature, and Modern Languages, and such other subjects cognate to a technical and commercial education as can be brought within the scope of the University curriculum."

The annual income of the Trust has amounted in the past to rather more than $£ 100,000$; and after defraying the expenses of administration there has been left about $£ 99,000$ as the net revenue available for distribution under the two main heads of the scheme, or $£ 49,500$ for the part of it referred to above. In the future a very appreciable increase of revenue is to be anticipated.

In the article contributed to Science Progress for January 19I7, Prof. F. Soddy, Professor of Chemistry in the University of Aberdeen, analysed the operations of

1 Published in the Journal of the British Science Guild, December - 1917. 
the Trust, particularly as regards the promotion of scientific study and research. Prof. Soddy pointed out that, by a reasonable interpretation of the Trust Deed, the primary purpose of the income from one-half of Mr Carnegie's gift was the encouragement of scientific study and research, including medicine, and that history and other subjects cognate to a commercial and technical education were to be regarded as ancillary beneficiaries; while the other subjects of a classical education were entirely excluded from participating in the fund. He showed, however, that in the case of the University of Aberdeen only 23 per cent. of the grants made had been allocated to the primary object, while 46 per cent. had been devoted to the ancillary object, and I9 per cent. to the objects which, in so far as they are not illegitimate, are ancillary. Up to September 1913, the Universities of Edinburgh and Glasgow had each received more than 60 per cent. of the total sums for the primary purpose of the fund, but the quinquennial distribution since then had been allocated to buildings chiefly for Arts accommodation, as well as for departments of science. As regards St Andrews and Dundee, the position of the allocation of funds in the main has been between that of Dundee on the one hand and Edinburgh on the other. Of the total amount spent by the Trustees up to the end of September I9I 5, about 14 per cent. has been expended on a research scheme independently of the grants made to the Universities. This has been spent mainly in providing Research Scholarships and Fellowships, and grants for research instruments-objects excellent in themselves, but more or less preliminary to the fostering of research.

The main point put forward by Professor Soddy is that the funds of the Trust are not in general being applied to the specific purposes for which they were intended, and are used for general University needs, and to provide buildings and endowments for Arts subjects, instead of the promotion of scientific study and research. In support of this contention, definite facts were stated which seemed 
to demand an equally definite answer if they are contested. The Guild therefore sent Professor Soddy's article to the principals and representative professors of scientific subjects in the Scottish Universities, and asked for an expression of opinion on the matter. Nine replies were received, but no attempt was made by any of the correspondents to refute the particulars given by Professor Soddy as regards the allocation of the amounts received from the Fund. The general opinion expressed was of a laisses-faire kind, with the addition of the following individual views :-(I) That the Board of Trustees should consist much more largely of men who are professionally and actively engaged in scientific work and have had experience of research; (2) that commercial education on a large scale should be taken in hand by the Trustees; (3) that a case had been made out for careful investigation, and that the matter should be considered by the British Science Guild to see what action, if any, is justifiable and practicable.

As the chief object of the British Science Guild is to safeguard the interests of science and promote the application of scientific knowledge to national welfare generally, the matter is one to which the Guild is bound to give attention. After careful consideration of the material placed before it, the Guild has come to the conclusion that Professor Soddy's serious charges should not be left unanswered, and that the diversion of the funds from their main purpose, as defined by Clause $\mathrm{A}$ of the Trust Constitution, and their use to strengthen the general finances of the Scottish Universities, deserve the attention of those to whom has been entrusted the future of science in national reconstruction.

The Guild is glad to note that three well-known men of science-Sir J. J. Thomson, O.M., President of the Royal Society; Sir David Prain, F.R.S., Director of the Royal Botanic Gardens, Kew; and Sir George Beilby, F.R.S.-were appointed at the last Annual Meeting of the Trust to fill the vacancies on the Board of Trustees, 
thus increasing the number of scientific representatives from none to three. ${ }^{1}$ Some adjustments in favour of scientific study and research may therefore be expected; but the Guild is of the opinion that the Trustees should consist chiefly of representatives of the scientific and other interests involved in proper proportions to ensure that the original intentions of the founder of the Trust are carried out justly.

With regard to the commercial interests, it seems probable that their representatives have been thoroughly awakened by the war to the necessity for better education. It is desirable, however, that these interests should not be satisfied at the expense of, but in addition to, those of science; and for this reason the British Science Guild, believing that $\mathrm{Mr}$ Carnegie's intentions admit of no dispute, desires to support Professor Soddy's claims that future allocation of the Trust Funds should be made more liberally, specifically, and inalienably for purposes of scientific study and research than has been the practice hitherto.

1 See footnote, p. 2 I2. 


\section{APPENDIX C}

CARNEGIE TRUST FOR THE UNIVERSITIES OF SCOTLAND. ${ }^{1}$

IN the December I9I7 number of the Journal was printed a Report of a Special Committee of the Guild on an article by Prof. F. Soddy, F.R.S., dealing with the Carnegie Trust and Scientific Research.

This report was forwarded to the Board of Trustees, and the following excerpt from the Minutes of a meeting of the Board, 7 th January I9I8, was communicated to the Guild in reply:-

"A letter from the Executive Committee of the British Science Guild, dated 6th November 1917, as also the 'Report of the Special Committee of the Guild appointed to consider the whole matter of the Financial Operations of the Carnegie Trust as set forth by Prof. Soddy, F.R.S., in his article published in Science Progress for January I9I 7 ;' were fully considered.

"In the letter and Report criticisms of the application made by the Trustees of the half of the Trust Income under Head A. are put forward. These criticisms may be divided under two heads, and it was resolved to reply for the information of the Guild as follows :-

"(I) As to the first, the Executive Committee altogether decline to admit the contention that the purposes to which one-half of the Income of the Trust falls to be applied can

${ }^{1}$ Twelfth Annual Report of the Executive Committee of the British Science Guild, July 1918. 
be assorted into 'primary' and 'ancillary.' The direction in the Trust Deed as to the application of the half of the Income under Head A. is quoted in the Report of the Special Committee of the Guild; and it only requires to be read with care to show that the idea of any distribution between subjects to be favoured and subjects to be subordinated is wholly without warrant. The Executive Committee regret that the Special Committee of the Guild commit themselves to the statement that there has been a 'diversion of the funds from their main purpose.' The Executive Committee can see no justification for this statement.

"(2) The other criticism is to the effect that the Trustees are not men who are professionally and actively engaged in scientific work, or have had experience of research. The Guild may be reminded that the members of the Trust were chosen by Mr Carnegie himself; and it is therefore obvious that they are men whom he considered capable of interpreting his wishes. In so far as vacancies in the Trust have occurred, consequent on deaths among the Trustees, it is the fact that these have been for the most part supplied by the appointment of men eminent in various branches of Science."

On the 28th February 19I8, in reply to this, the following Resolution was sent to the Board of Trustees by the Guild :-

"The Executive Committee of the British Science Guild notes with regret that the Excerpt from the Minutes of the Executive Committee of the Carnegie Trust on the 7 th January 1918, shews some misapprehension, which need not be pursued at the present time, of the position of the Guild in putting before Mr Carnegie's Trust the communication from Prof. F. Soddy. The Guild, however, cannot accept the views of the Carnegie Trustees indicated in the Minute which seem to involve self-imposed restrictions on the exercise of their powers and discretion, with respect to the promotion of scientific education."

The following is a further communication from Prof. F. 
Soddy, regarding the "Excerpt" from the Minutes of the Board of Trustees :-

Remarks by Professor Soddy on the Minute of the Executive Committee of Carnegie Trust for the Universities of Scotland, 7th January 1918, communicated to the British Science Guild.

I merely suggested as a reasonable interpretation of the Trust Deed of $\mathrm{Mr}$ Carnegie that the subjects included could be divided into primary and legitimate ancillary, those not included being for the purpose termed illegitimate. The interpretation may or may not be capable of strict defence. By concentrating on this single point the Executive Committee of the Trust seek to evade the real criticism, fairly summed up and endorsed by the British Science Guild.

Substantial and undenied examples were brought forward of just the same neglect of, contempt for, and unfair discrimination against, science, which, operating during the past century mainly through educational channels, have now brought about the position of national insecurity and peril, manifest to all, and which the founder of the Trust himself stigmatised in the heartiest manner in I906.

In an address entitled "Modern Needs in Universities," delivered at the opening of the new Carnegie buildings of the Natural Philosophy and Engineering Departments of the University of Edinburgh (Nature, I906, 74, 648), $\mathrm{Mr}$ Carnegie, after referring to the millions being devoted to science and practical studies and the progressivelinfluences at work in the universities of America and Canada and of the five principal English cities, continued :-

"Scotland has to keep marching on. The progress of scientific departments in British Universities, considerable as it has recently been, of which the schools we are about to open here to-day are gratifying evidence, yet has not kept pace with the startling progress of science itself and 
the wonderful discoveries that threaten to revolutionise human conceptions."

"The older branches of learning in our Universities may well welcome the newer branch, cap in hand, not only as the foundation of material progress, but also as one of the very highest agencies in the imaginative domain."

"This mighty force of our day-science-has hitherto been the Cinderella of the sisterhood of knowledge, but the Prince has appeared at last and taken her by the hand. It is now the turn of the elder sisters to greet the once neglected princess. She will more than justify the millions that are being showered upon her in most progressive lands. Thus has the University developed to the present all-embracing type through the successive reigns of scholasticism, theology, and ancient classics, always behind the age, conservative in the highest degree. Science has arisen and established her claim to equality. We have long had the Republic of Letters; we now hail the Republic of Knowledge."

These quotations do not appear to admit of much doubt as to what the founder's own view of the purpose of his benefaction was. They are refreshingly clear and frank, with a point capable even of penetrating the admitnothing, dispute-everything defence which the advocate unable to face facts invariably puts up. It is an especially curious commentary on the cry that it is now the turn of Arts, heard at the last quinquennial distribution, and which, in the University of Aberdeen, has been the interpretation of the gift from the beginning, that what Mr Carnegie actually said was : "It is now the turn of the elder sisters to greet the once neglected princess."

If the legal instrument, which $\mathrm{Mr}$ Carnegie signed to give effect to his intentions, were being administered by a body of men of like mind to himself, in a broad and sympathetic spirit, without any desire to strain it beyond its natural interpretation and twist it to serve ends not intended, legal questions as to its exact meaning could scarcely arise.

But if, unfortunately, at any time that should not be 
the case, and it should become necessary to consider the deed as an instrument to ensure that the purposes of the founder, whatever they were, shall be permanently respected without regard to the outlook and sympathies of those administering it, it will be found to be curiously impotent. Although, among the intentions of the founder as set forth in the preamble of the Trust Deed, only two objects are referred to, the encouragement of scientific study and research and the payment of students' fees, in the operative part, which embraces the Trust Constitution, a new and totally distinct purpose, technical and commercial education, not mentioned in the preamble, is added on to share with scientific study and research, without any specific instruction of the apportionment of the funds for each, this being left to the discretion of the Trustees, the share of the payment of fees purpose alone being strictly defined. So that by concentrating entirely on the new purpose, scientific study and research could be effectively excluded and the first of the two intentions of the founder frustrated. Whether, however, the Trustees could justify doing this on a narrow construction of the deed or not, no reasonable beings could claim that they were thereby carrying out the declared intentions of the founder, as set forth in the Trust Deed. Apart, therefore, from a second Mr Carnegie, willing to take the deed into Court to get it interpreted, the question of the relative share of the different objects set forth must remain more or less open.

Admitting this, and allowing to the Trustees the most absolute power of discretion, it is still extremely difficult to see how the current uses to which the moneys are being put can be defended. The clause to which the Executive Committee refer does not exactingly or convincingly convey the particular construction which they put upon it, and therefore had better be re-quoted :-

"One-half of the net annual income shall be applied towards the improvement and expansion of the Universities of Scotland, in the Faculties of Science and 
Medicine; also for improving and extending the opportunities for scientific study and research, and for increasing the facilities for acquiring a knowledge of History, Economics, English Literature, and Modern Languages, and such other subjects cognate to a technical or commercial education as can be brought within the scope of the University curriculum. . . ."

The word "other" shows that the specified Arts subjects are included as cognate to a technical or commercial education, but the Faculties of Science and Medicine, and scientific study and research, participate on their own merits independently, and not as subserving or ministering to a technical or commercial education. It is recognised by the clause that technical or commercial education can only to a limited extent be brought within the scope of the present university curriculum. That it is technical and commercial education rather than the subjects of the present university curriculum that are to be benefited is further shown by the concluding paragraph of Clause B, which deals primarily with the payment of students' fees :-

"In the case of Schools or Institutions in Scotland established to provide Technical or Commercial Education, the Committee may recognise classes which, though outside the present range of the university curriculum, can be accepted as doing work of a University level, and may allow them and the students thereof to participate under both $\mathrm{A}$ and $\mathrm{B}$ to such an extent as the Committee may from time to time determine."

It is thus natural to inquire in the cases to which I directed attention in which scientific and medical studies had not received a due share of the moneys, whether technical or commercial education has received it. It is only necessary to reiterate a specific instance. In the University of Aberdeen the scientific and medical subjects -Chemistry, Inorganic, Organic, Physical, Agricultural, Physiological, and Technological; Physics, Mathematical and Experimental; Mathematics; Astronomy; Engineer- 
ing, Civil, Mechanical, Electrical, and Marine; Geology; Botany; Physiology ; Pathology ; Bacteriology ; Anatomy ; Embryology; and the subjects of Medicine and Surgery in their numerous sub-divisions-received one endowment for a lectureship in Geology. Whereas in Arts subjects endowments were given for History and Archæology, Political Economy, French, German, Education and Constitutional Law and History, without regard to whether or not these subjects were taught with reference to the requirements of technical or commercial education.

If this had been done genuinely in the interests of technical or commercial education, and Aberdeen in comparison with the other university centres had in this respect a specially urgent and pressing need, it would be only the discretion of the Trustees that was in dispute; but it was not. It is true that since the war the commercial community have realised the need of higher commercial education on a university level. These endowments were allocated long before the war, and the best proof that the needs of commercial education were not the consideration at the time of the allocation is that they are now being considered, and a Faculty of Commerce is in process of being brought into existence.

The powers of the Trustees in law may be so great as to enable them to over-ride the claims of both science and technical or commercial education, in order to elevate Arts subjects that can in any way be regarded as cognate to the latter. But, if so, it would be sanguine to expect that anyone again will provide funds for the improvement and extension of the opportunities for scientific study and research in the universities of Scotland or in the efficacy of the law to accomplish the object when the funds are provided.

The question being whether the Trust as constituted has in point of fact fulfilled the wishes and intentions of the founder, the second head of the Executive Committee's reply hardly calls for comment, except in so far as it raises a point of interest. At the date of the minute- 
7 th January 1918 -there were eight original nominated Trustees, and five subsequently appointed. The Rt. Hon. H. H. Asquith was appointed in 1909, W. J. Dundas, Esq., in I9I4, the only three scientific members among the nominated Trustees having been appointed in 1917. There is still one vacancy, caused by the death of Lord Kinnear at the end of 1917 , and when this has been filled up, it is hoped that the statement made-to the effect that the vacancies have for the most part been filled by the appointment of men eminent in various branches of science-may continue to be true.

FREDERICK SODDY.

9th February 1918.

\section{POSTSCRIPT ADDED BY PROFESSOR SODDY, 2 IST FEBRUARY I9I8.}

"The papers announce that at the Annual Meeting of the Carnegie Trust held on 20th February 1918, the vacancy above referred to was filled by the appointment of Lord Sands, so that the British Science Guild will draw its own conclusion as to this misleading statement."

F. S. 
PRINTID BY

OLIVER AND BOYD

EDIMBURGH, BCOTLAND 


\section{BY FREDERICK SODDY, M.A.}

\section{THE INTERPRETATION OF RADIUM}

Fourth Edition, Revised and Enlarged. With Illustrations.

THIs work gives in popular language an account of radium, and describes how its unique properties have been interpreted on the new theory of the disintegration of its atoms, which invades so many departments of thought.

Spectator.- " A most admirably conceived exposition which does not seek merely to attract us by turning marvels, at once outstripping our imagination and humbling our conception, into cheap popular gazingstocks, but rather supports its unfailing charm by the legitimate interests-pointed here into a fascination that may arrest even an habitually desultory reader-of science at once genuinely and delightfully taught."

British Medical Journal.- "We have endeavoured to give a general idea of Mr Soddy's book in the hope that it may induce many to read it, because it affords by an orderly progression from the simple to the complex, and with as little mathematics as possible, a clear idea of the nature of the activity of radium, and the relation of that astonishing element to others which precede and succeed it in the process of disintegration or evolution." 


\section{Standard Works on SCIENCE}

Issued by Mr. Murray

\section{PRACTICAL ZOOLOGY : A Junior Gourse of}

By the late Professor A. MILNES MARSHALL, M.D., D.Sc., F.R.S., and the late C. HERBERT HURST, M.D. 8th Edition. Revised by Professor F. W. GAMBLE, D.Sc., F.R.S., University of Birmingham. I2s. net.

"A most successful and important book.... It is provided with an exceedingly good index, and presented in a form demanding our sincere thanks." Nature.

\section{HEREDITY}

By J. ARTHUR THOMSON, M.A., Ll.D., Regius Professor of Natural History in the University of Aberdeen. With Coloured and other Illustrations. 3rd Edition. I5s. net.

"This is certainly the best modern book on heredity to recommend to the student and the intelligently curious." Science Progress.

\section{THE STUDY OF ANIMAL LIFE}

By J. ARTHUR THOMSON, M.A., LL.D., Regius Professor of Natural History in the University of Aberdeen. With many Illustrations. 4th Edition. $6 \mathrm{~s}$. net.

An authoritative and thoroughly comprehensive exposition by an author who is recognised as one of the leading authorities on the study of Zoology and Natural History. The present edition has been expanded and largely rewritten. 


\section{ANIMAL LIFE}

By F. W. GAMBLE, D.Sc., F.R.S., University of Birmingham. With many Illustrations.

6 s. net.

This work is written in the first instance for those who wish to learn or teach such a survey of the animal pageant as can ally itself with observation and experiment; and in the second place for those who wish to organise their knowledge of animal life.

\section{VARIATION, HEREDITY \& EVOLUTION}

Recent Progress in the Study of

By R. H. LOCK, M.A., Sc.D., sometime Fellow of Gonville and Caius College, Cambridge. With a Biographical Note by BELLA SIDNEY WOOLF. (Mrs. R. H. LOCK). 4th Edition. Revised by LEONARD DONCASTER, Sc.D., F.R.S. With portraits and diagrams. 7s. 6d. net.

The object of this book is to describe the connection between the new science of Genetics and those ideas which have long been summed up under the expression Darwinism, as well as to point out the practical importance and theoretical interest of these subjects. "It is an admirable summary of the subject, well and lucidly written." British Medical Journal.

\section{MECHANISM, LIFE AND PERSONALITY}

An Examination of the Mechanistic Theory of Life and Mind. By J. S. HALDANE, M.D., LL.D., F.R.S., Fellow of New College and Reader in Physiology, University of Oxford. 2s. 6 d. net.

"Dr. Haldane has succeeded in packing an immense amount of knowledge and thought into the compass of a small volume. The complexity of his themes has never for a moment betrayed him into ambiguity either of thought or expression." Sunday Times.

\section{THE TIDES}

and kindred phenomena in the Solar System

By Sir GEORGE HOWARD DARWIN, K.C.B., Plumian Professor in the University of Cambridge. With many Illustrations. Third Edition. 7s. 6d. net. 


\section{MICROSCOPY}

The Construction, Theory, and Use of the Microscope. By EDMUND J. SPITTA, F.R.A.S., F.R.M.S., etc. With numerous Diagrams and Illustrations. Third Edition. Revised and Enlarged.

" Let us hasten to urge every student of the microscope who wishes to gain a thorough understanding of its principles and possibilities and its defects, and every user of the instrument who desires a work of reference to which he may turn for an explanation of some unexplained optical phenomenon, or for particulars of up-to-date apparatus, to procure a copy of Mr. Spitta's book without delay." Nature.

\section{THE RECENT}

\section{DEVELOPMENT OF PHYSICAL SGIENGE}

By W. C. D. WHETHAM, M.A., F.R.S., Fellow of Trinity College, Cambridge. With Illustrations. 4th Ed. 6s. net.

The author has sought to express the results of recent physical investigations in a form which "might prove useful to students of science in general " and "also appeal to those who, with little definite scientific training, are interested in the more important conclusions of scientific thought." The continuous demand for his book, now in its fourth edition, is evidence that he has successfully accomplished his task.

\section{FORM AND FUNGTION}

A Contribution to the History of Animal Morphology. By E. S. RUSSELL, M.A., B.Sc., F.Z.S. With Illustrations. I2s. net.

This book deals with the principles of comparative anatomy, under the form of an historical account of the development of the science from Aristotle to W. Roux, and it is shown that the history of morphology, hitherto somewhat neglected in this country, throws considerable light upon its present problems.

"A scholarly and thoughtful book. It is based on many years of first-hand study of the documents and is illumined by insight." Nature. 


\section{SIR JOSEPH DALTON HOOKER}

O.M., G.C.S.I. The Life and Letters of. By LEONARD HUXLEY. Based on material collected and arranged by LADY HOOKER. With Illustrations. In Two Volumes. and Edition. 36s. net.

The long life of Sir Joseph Hooker covers the whole of the scientific renaissance. Pre-eminent in botany, as Traveller and Explorer he was hardly less eminent. The history of his scientific career is also the history of many iriendships, revealed in his unceasing correspondence, most of all with Charles Darwin, for he was Darwin's confidant, helper and critic for fifteen years before the "Origin" appeared.

\section{CHAPTERS IN MODERN BOTANY}

By PATRICK GEDDES, Professor of Botany, University Coll ge, Dundee. With Illustrations. (Murray's University Manuals).

3s. 6 d. net.

"A most charmingly written account of some of the more striking phenomena of plant life." Daily Chronicle.

\section{DAVID GILL : Man and Astronomer}

Memories of Sir DAVID GILL, K.C.B., H.M. Astronomer (1879-1907) at the Cape of Good Hope. Collected and arranged by GEORGE FORBES, F.R.S. With Portraits and Illustrations. I2s. net.

"It is the aim of the memoir to present to the world David Gill the man, and the results of his life work only so far as they illustrate his character. His irascibility, his charity, his hatred of shams of all kinds, but particularly of sham science, his genius for friendship, his love of music and out-of-door sport, and his devotion to his work, each has some story to demonstrate it." Pall Mall Gazette.

\section{A HISTORY OF ASTRONOMY}

By ARTHUR BERRY, M.A., Fellow of King's College, Cambridge. With many Illustrations. (Murray's University Manuals.) 6s. net. 


\section{THE REALM OF NATURE}

An Outline of Physiography. By H. R. MILL, D.Sc., LL.D., Director of the British Rainfall Organisation. Second Edition. Revised and entirely reset. With I9 Coloured Maps and 73 Illustrations in the Text. 6s. net. "Dr. Mill is to be congratulated on having now brought his information, so far as space permitted, well up-to-date. . . It would, indeed, be difficult to point to any other English work on physiography giving so much trustworthy matter in equally condensed form, yet so readable."

A thenaeum.

By T. G. Chamberlin and R. D. Salisbury Heads of the Department of Geography and Geology, University of Chicago.

\section{GEOLOGY : Advanced Course}

In three Volumes. With many Illustrations. 24s. net each

Volume I. PROGESSES AND THEIR RESULTS

Volume II. EARTH HISTORY-GENESIS, PALEOZOIC

Volume III. EARTH HISTORY-MESOZOIC, CENOZOIC

"The student . . may at once be assured that it is a sound, vigorously written work, abounding in original information and suggestions, and abreast of the everexpanding knowledge to which American geologists have so largely contributed." Nature.

\section{GEOLOGY : Shorter Course}

With 21 Coloured Plates and 608 Illustrations. 24s. net.

Guided by their experience as teachers, the authors have in this book treated their subject, the history of the earth, as a unit, and little emphasis has been laid on the commonly recognised sub-divisions of the science, but prominence is given to the historical element. The central purpose has been to present the subject so that the student will be introduced to the methods and spirit of the science. 
THE LIBRARY

UNIVERSITY OF CALIFORNIA

Santa Barbara

Goleta, California

THIS BOOK IS DUE ON THE LAST DATE STAMPED BELOW.
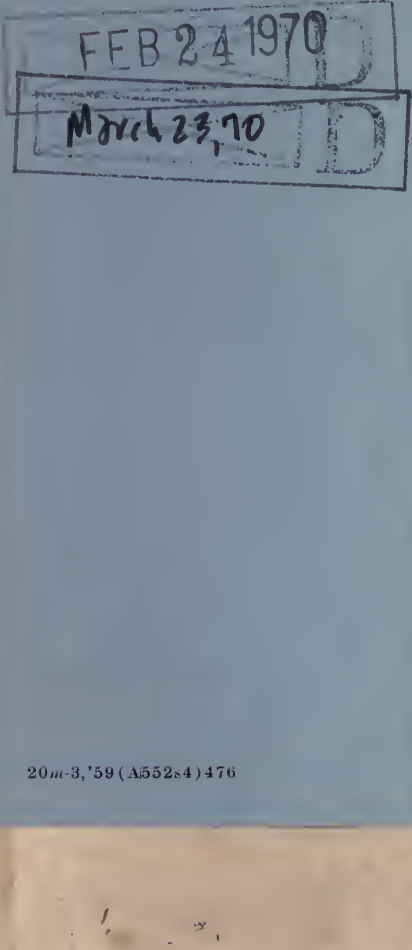
This label must not be removed from this book, nor the figures thereon altered.

For use when

issued its

an exira.
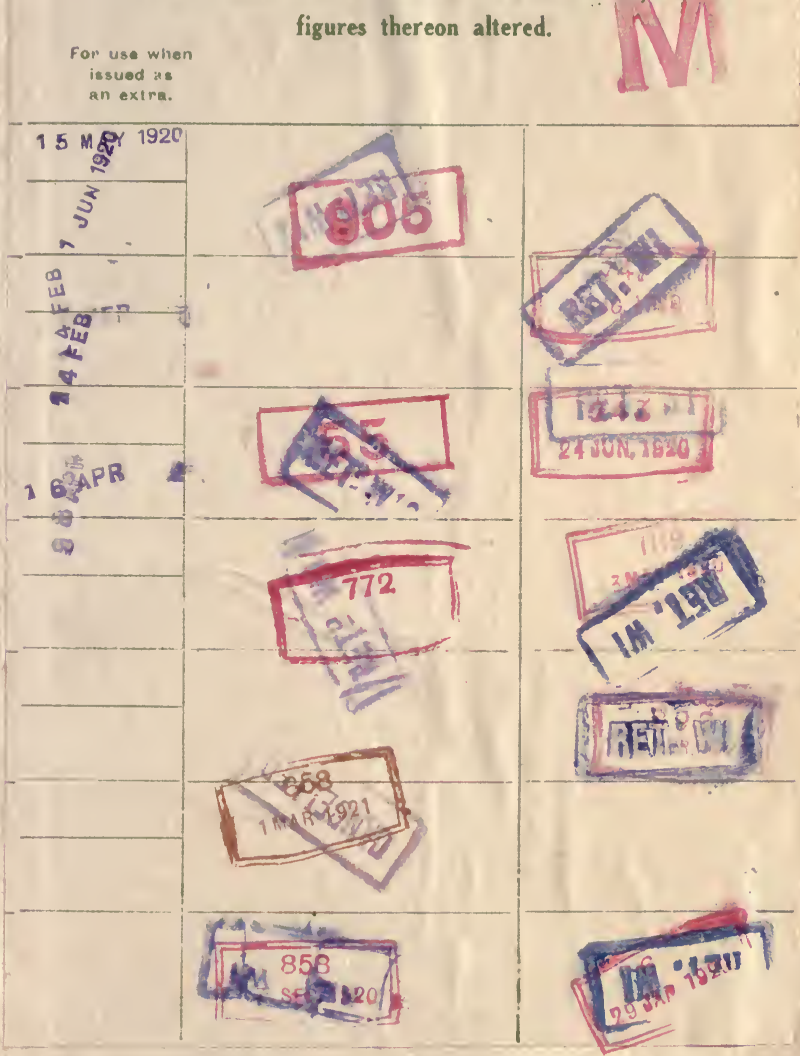
